\title{
Fuzzy Logic Based Module-Level Power Electronics for Mitigation of Rapid Cloud Shading in Photovoltaic Systems
}

\author{
by \\ Rachel Beverly Belcher \\ Thesis submitted to the University of Ottawa in partial fulfillment \\ of the requirements for the Masters of Applied Science in \\ Electrical and Computer Engineering
}

School of Electrical Engineering and Computer Science

Faculty of Engineering

University of Ottawa

(C) Rachel Beverly Belcher, Ottawa, Canada, 2020 


\section{Abstract}

A module-level DC optimization proof of concept architecture is proposed to increase the efficiency of photovoltaic (PV) strings by minimizing the negative effects of shading caused by intermittent cloud cover while reducing cloud induced fast frequency fluctuations. The decentralized inverter approach combines the benefits of string and micro-inverter technology. This device can be affixed to pre-existing or new systems and operates in compliance with IEEE 1547 and California rule 21 standards by operating in maximum power point tracking (MPPT) or curtailment mode whenever necessary. The modular level device encapsulates three individual processes: an optimization engine to determine minimum power requirements, a fuzzy logic controller (FLC) to eliminate the effect of passing cloud cover, and a voltage regulation stage to monitor and appropriately adjust the output voltage of the device. Ramp rate reduction was accomplished using adaptive fuzzy logic control with a heuristic rule base inference engine. The modular design can be affixed to grid connected or islanded systems allowing for operation in regulated and variable load conditions. Matlab/Simulink 2019a was used to design and simulate the proof of concept model to verify the resiliency to partial shading, reduction of ramp rates during passing cloud coverage, and optimal output voltage for each panel while maintaining a constant DC link voltage of $120 \mathrm{~V}$. This proof of concept has been successfully validated therefore further testing will be performed for various irradiance conditions. 


\section{Dedication}

First of all, I would like to thank my supervisors Dr. Karin Hinzer and Dr. Henry Schriemer for providing me with the opportunity to learn and grow in such a supportive environment. I am amazed by the incredible work they do - both in the forefront and behind the scenes - to provide exciting opportunities for their students, thank you for all that you do.

I am thankful for the continuous support provided by Dr. Javad Fattahi, his valuable input and guidance was a key factor in completing this work. I am very proud to have been a member of the SUNLAB, my experiences were enhanced by simply interacting with and learning from all the professors, senior members, and my fellow students. Thank you for making my graduate studies memorable and entertaining.

I am immensely grateful for my parents, it is impossible to put into words how their constant patience, support, and love impacts me every day. You are my strength and inspiration and I would not be where I am today without you. 


\section{Contents}

1 Introduction 1

1.1 Overview of Inverter Technologies . . . . . . . . . . . . . . . . . 3

1.2 Thesis Overview . . . . . . . . . . . . . . . . . . . . . 7

2 Background $\quad 9$

2.1 The Solar Resource . . . . . . . . . . . . . . . . . . . . . . . . . 9

2.2 Producing Power using Solar Modules . . . . . . . . . . . . . . . . . . 11

2.3 Maximum Power Point Tracking . . . . . . . . . . . . . . . . . . . . . 13

2.3.1 Perturb and Observe . . . . . . . . . . . . . . 14

2.3.2 Incremental Conductance . . . . . . . . . . . . . . . 15

2.3.3 Limitations of Conventional Techniques . . . . . . . . . . . 16

2.3.4 Improved MPPT Algorithms . . . . . . . . . . . . . 17

2.4 Active Power Curtailment . . . . . . . . . . . . . . . . . . . . . 19

2.5 Ramp Rate Reduction . . . . . . . . . . . . . . . . . . . 21

2.6 The Impact of Load Variations on Islanded Systems . . . . . . . . . . 23

2.7 The Benefit of Power Optimization Techniques . . . . . . . . . . . . 23

2.8 Managing Rapid Shading . . . . . . . . . . . . . . . . . . . . . . 24

3 Design and Modelling $\quad 26$

3.1 Modelling the Solar Array . . . . . . . . . . . . . . . . . . . . . 28

3.2 Improved Maximum Power Point Tracking . . . . . . . . . . . . . . 30

3.3 Mode Selection and System Optimization . . . . . . . . . . . . . . . 32

3.4 Designing the Fuzzy Logic Controller . . . . . . . . . . . . . . . . 33 
3.5 Designing the DC Regulation Stage . . . . . . . . . . . . . 35

4 Simulation Results and Discussion 38

4.1 Panel Optimization . . . . . . . . . . . . . . . . . . . 39

4.2 Mode Selection and System Optimization . . . . . . . . . . . . . . 41

4.3 Ramp Rate Reduction with Fuzzy Logic Control . . . . . . . . . . . . 43

4.4 DC Regulation Stage . . . . . . . . . . . . . . . . . . . . 45

4.5 Output Power Comparisons . . . . . . . . . . . . . . . . . 46

4.6 Output Voltage Comparisons _ . . . . . . . . . . . . . . . . 48

5 Conclusions $\quad 50$

$\begin{array}{ll}\text { Appendix A - Improved MPPT } & 54\end{array}$

Appendix B - System Optimization $\quad 56$

Appendix C - Fuzzy Logic Control (FLC1) 58

$\begin{array}{ll}\text { Appendix D - DC Regulation } & 109\end{array}$

$\begin{array}{lr}\text { Appendix E - Simulation Diagrams } & 112\end{array}$

$\begin{array}{ll}\text { Bibliography } & 118\end{array}$ 


\section{List of Figures}

1.12010 - 2050 U.S. predictions for (a) energy market and (b) energy mix trends presented in $[1] . \ldots \ldots \ldots . \ldots \ldots 2$

1.2 Diagram of a basic photovoltaic system design. . . . . . . . . . . . . . 3

1.3 String inverter technology operating in (a) unshaded and (b) partially shaded conditions. . . . . . . . . . . . . . . . . 4

1.4 Micro-inverter system under partial shading conditions. . . . . . . . . 5

1.5 Power optimizer and string inverter system design under partial shading conditions. . . . . . . . . . . . . . . . . . . 6

2.1 Geographical characteristics affecting PV production, adapted from [5]. 10

2.2 (a) Low-level cumulus clouds and (b) global horizontal irradiance on a high cloud variability day in Ottawa Ontario. . . . . . . . . . . 11

2.3 PV curves describing (a) current-voltage and (b) power-voltage characteristics. . . . . . . . . . . . . . . . . 13

2.4 Perturb and observe function description. . . . . . . . . . . . . . . 15

2.5 Incremental conductance (a) system level design adapted, from [2], and (b) function description, adapted from [3] . . . . . . . . . 16

2.6 The effects of non-uniform irradiance conditions on PV power pro-

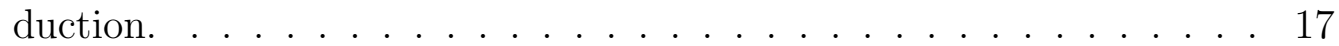

3.1 Proposed system-level block diagram. . . . . . . . . . . . . . . . . . . 27

3.2 The module-level improved power optimizer design. . . . . . . . . . . 28 
3.3 The effects of shifting the string power generation data by (a) two minutes, (b) five minutes, (c) ten minutes, and (d) fifteen minutes. . . 29

3.4 Test environment for simulation model. . . . . . . . . . . . . . . . 30

3.5 Maximum power points in (a) unshaded and (b) partially shaded conditions. . . . . . . . . . . . . . . . . . 31

3.6 Block diagram of the system level optimizer. . . . . . . . . . . . . . 32

3.7 Block diagram of the proposed fuzzy logic controller. . . . . . . . . . 34

3.8 Feedback loop control system featuring controller and plant model. . 35

3.9 DC regulation stage block diagram with second fuzzy logic controller for islanded systems. . . . . . . . . . . . . . . . . . . . 37

4.1 System level design with the four main operations: a) improved MPPT, b) system optimization, c) FLC ramp reduction, d) DC regulation. . . . . . . . . . . . . . . . . . . . 39

4.2 Improved MPPT operation in clear sky conditions. . . . . . . . . . . 40

4.3 Improved MPPT operation in variable cloud conditions. . . . . . . . . 40

4.4 The power characteristics under MPP operation for (a) each module in the string and (b) the total string. . . . . . . . . . . . . . . . 41

4.5 Current voltage characteristic curves while operating in (a) MPPT and (b) curtailment modes.

4.6 Power characteristics of the (a) individual modules and (b) entire string while when curtailment mode is enabled. . . . . . . . . . . 43

4.7 Ramp rate of reference voltage with and without the FLC1 stage enabled. . . . . . . . . . . . . . . . . . . . . 44

4.8 The effects of introducing a step response grid variability on a reference voltage with and without a self-tuning gain controller. . . . . . . 45

4.9 Oscillation experienced in output voltage under steady state operation. 46

4.10 Output power comparisons of traditional MPPT and proof of concept architecture. . . . . . . . . . . . . . . . 48 
4.11 Output string voltage (DC link voltage) fluctuations during variable irradiance conditions. . . . . . . . . . . . . . . . . . . 49

A.1 Variable step MPPT algorithm [4] . . . . . . . . . . . . . . . 54

A.2 The dffect of variable irradiance on step size. . . . . . . . . . . . . 55

B.1 Simulation results for the central optimization stage of a three PV string. . . . . . . . . . . . . . . . . . . . 58

C.1 Membership functions for designed for FLC1 for (a) the power and voltage linguistic variables and (b) the rates of change. . . . . . . . 60

C.2 Representation of the quantity of rules necessary to determine the response of the output based upon input conditions. . . . . . . . . . . 61

C.3 (a) The input power change and (b) output response of FLC1 designs featuring different number of linguistic variables. . . . . . . . . . . 62

C.4 Example of input quantities for FLC1. . . . . . . . . . . . . . 63

C.5 Fuzzy logic rules for determining (a) the impact of the rate of change on power quantities and (b) the ratio $\left(\frac{P_{n}}{P_{s t r}}\right)^{\prime}$ required to calculate the reference voltage. . . . . . . . . . . . . . . . . . . 64

D.1 Conventional design for buck-boost converter. . . . . . . . . . . . . 110

D.2 Four-switch buck boost DC converter design. . . . . . . . . . . 111

D.3 Fuzzy logic rules for determining the necessary change in (a) $K_{p}$ and

(b) $K_{i}$ to account for dynamic load changes in islanded systems. . . . 112

E.1 Simulink diagram of one module-level power optimizer. . . . . . . . . 113

E.2 Three PV string simulation diagram depicting the improved MPPT, mode selection, ramp rate reduction, and DC regulation stages. . . . 114

E.3 Optimization engine schematic diagram presented in Simulink. . . . . 114

E.4 Fuzzy logic controller (FLC1) in Simulink environment. . . . . . . . . 115

E.5 Fuzzy logic toolbox depicting four inputs and one output for FLC1. . 116

E.6 An example of the membership function for the input power quantity $P_{n}$ for FLC1. . . . . . . . . . . . . . . . . . . 116

E.7 A sample of the rule base used for the inference engine of FLC1. . . . 117 
E.8 Simulated four switch buck boost system. . . . . . . . . . . . . . . 118

E.9 The Simulink diagram of FLC2 to determine the necessary change in

PI controller gains for islanded systems. . . . . . . . . . . . . . . 118 


\section{List of Acronyms}

DC Direct current

AC Alternating current

MLPE Module level power electronic

MPPT Maximum power point tracking

MPP Maximum power point

MPC Model predictive control

APC Active power curtailment

SLMC Sliding mode controller

FLC Fuzzy logic controller

MLPO Module level power optimizer

GMPP Global maximum power point

LMPP Local maximum power point

BB Buck boost converter

NERC North American Electric Reliability Corporation

BJT Bipolar junction transistor

MOSFET Metal-oxide semiconductor field effect transistors 


\section{Chapter 1}

\section{Introduction}

Renewable energy is the fastest growing energy production source in the North American energy mix and is predicted to continue this trend through to 2050 [1]. Natural Resources Canada reported an 18\% increase in renewable based generation between the years 2010 to 2017, with the majority of this growth attributed to solar and wind technologies [5]. The fast growth rate of solar and wind systems is motivated by declining capital costs and higher state-level sustainability targets [1]. While the global need for electricity increases, it is predicted that these demands will be largely met by renewable energy sources and less by conventional generation methods, as shown in Figure 1.1(a). With continued innovation and improvement, solar energy is expected to dominate the energy mix, resulting in $46 \%$ of electrical generation and use by 2050, as shown in Figure 1.1(b). 

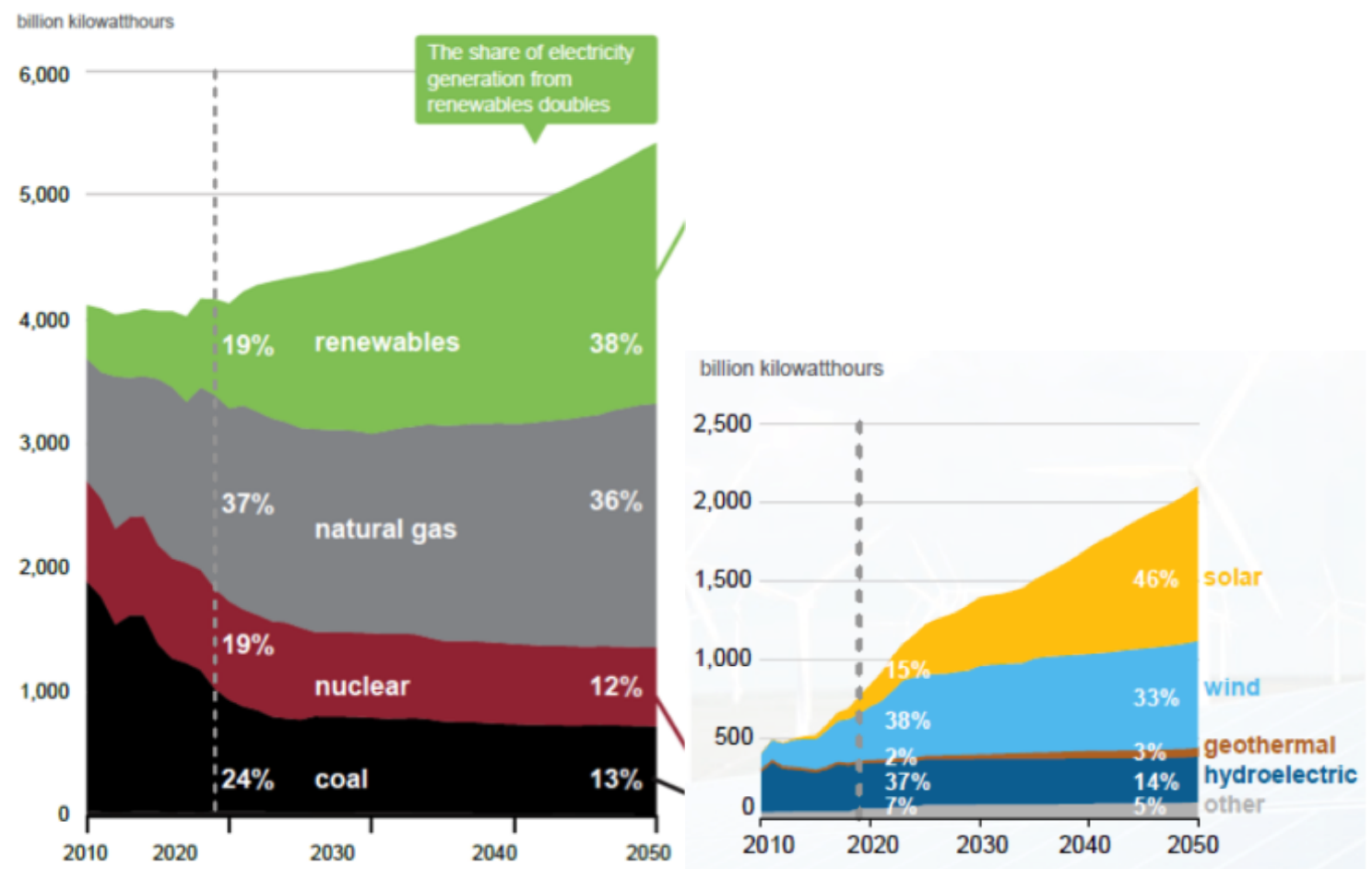

Figure 1.1: 2010 - 2050 U.S. predictions for (a) energy market and (b) energy mix trends presented in [1].

The main contributor to the continued increase in solar production is related to the advancement of solar cell efficiency and design. Various types of cells are available such as multi-junction solar cells, which have a record efficiency of $47.1 \%$ which are often used for concentrated photovoltaics, and silicon solar cells which have peak efficiencies of $27.6 \%$ and are commonly used for non-concentration PV systems [6]. Solar cells are strung together to form a PV module or panel to meet a certain voltage and current rating; similarly, various topologies of modules are connected to form a solar array. Solar cells produce current and voltage characteristics which are direct current (DC) in nature. Inverter technology is required to convert those DC quantities to a grid-accepted alternating current (AC). The overall efficiency of a PV system is relatively low, approximately $17 \%$, due to a variety of factors including the natural intermittency of the resource; without storage, electricity will not be available at night or during periods of significant cloud cover. Similarly, the production of electricity from solar is extremely variable and sensitive to small variations in irradiance caused by partial shading of nearby building or overhead 
clouds. To aid in the mitigation of partial shading and mismatch losses caused by environmental factors, power optimizers are often implemented to condition the voltage produced on the DC side of the inverter. A brief overview of the PV system is shown in Figure 1.2.

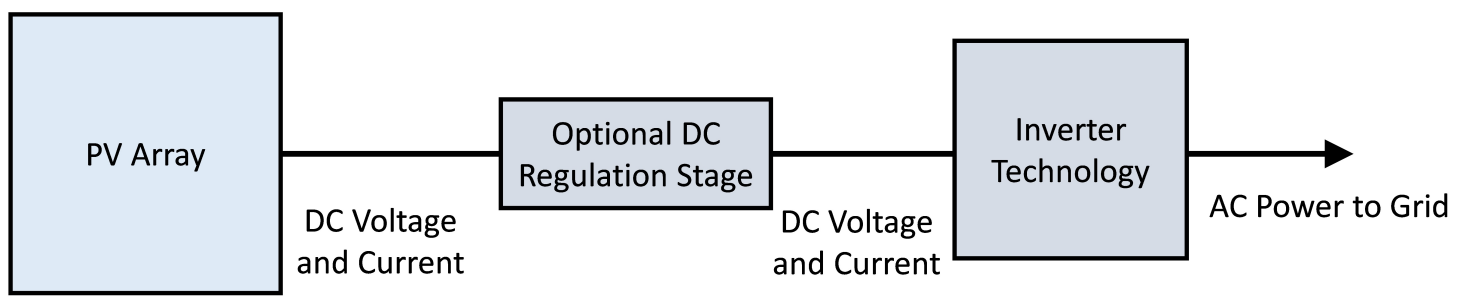

Figure 1.2: Diagram of a basic photovoltaic system design.

\subsection{Overview of Inverter Technologies}

Module-level power electronics (MLPE), such as power optimizers and microinverters, are an increasingly popular form of regulating the DC power produced by the individual panels in an array. String inverters, power optimizers with string inverters, and micro-inverters are the three main classifications of conversion technologies currently on the market. String inverters are the simplest and perhaps most stable inverter technology. While they often report higher efficiencies when converting $\mathrm{DC}$ to $\mathrm{AC}$ under optimal conditions, they often hinder the overall efficiency of the system under non-ideal conditions. These inverters convert the total DC string power to AC, where the string power is the summation of the power produced by each series-connected module on the string, as shown in Figure 1.3(a). Systems that use a centralized inverter are negatively impacted by partial shading of one or more panels in the string due to the nature of series connection, as shown in Figure 1.3(b). The modules in the string produce power to meet that of the lowest producing module, thus partial shading of one or more panels affects all panels in the string. 


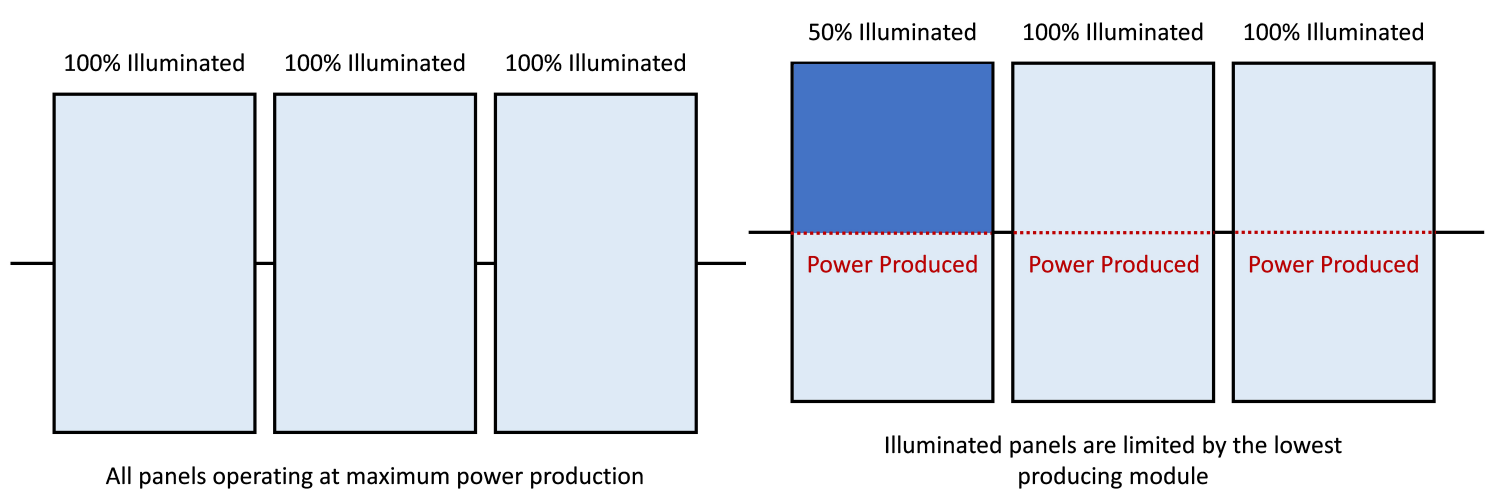

Figure 1.3: String inverter technology operating in (a) unshaded and (b) partially shaded conditions.

Micro-inverters offer a solution to partial shading losses by performing direct DC to $\mathrm{AC}$ conversion on a per module basis. Affixed to each module in the array is a micro-inverter which converts the power produced at the module then transmits the power through AC cables, as shown in Figure 1.4. The advantage of using microinverters is that the production of one panel does not affect the production of any other. They also enable better monitoring so it is easier to determine faults within the system. Micro-inverters are currently more expensive than string inverter-based systems and require significantly more electronics to regulate and convert directly on the module; due to economic constraints micro-inverters are usually limited to smaller systems. It is important to note that the cost associated with micro-inverters is decreasing and in future may be similar to that of power optimizers with string inverter systems. 


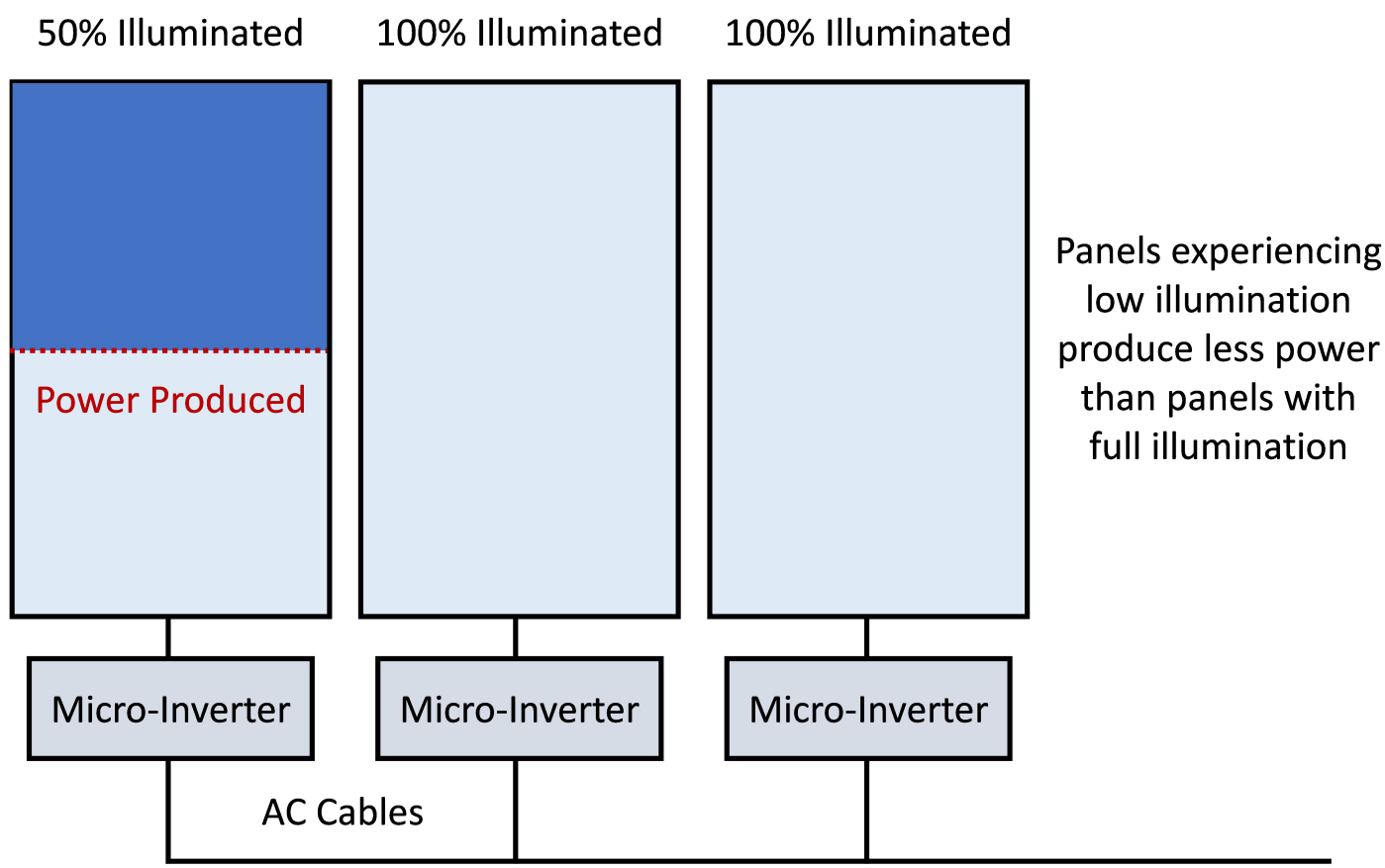

Figure 1.4: Micro-inverter system under partial shading conditions.

A power optimizer is essentially a compromise between the string and microinverter technologies. They offer the same resiliency to shading while limiting the number of inversion stages within the system. Power optimizers and micro-inverters are two types of MLPE devices that attach directly to the panel; the main difference is that power optimizers do not perform DC to AC conversion, this process is still performed by the string inverter. A power optimizer consists of a DC operation stage prior to the central DC-AC inverter. Power optimizers are less expensive than micro-inverters but they perform similarly by optimizing the power produced by each panel and eliminating the negative effects caused by non-uniform irradiance. Power optimizers benefit from the ability to condition the DC power of the module before conversion to AC by a high efficiency string inverter. Power optimizers are a modular design that can easily be scaled for arrays of any size and are less expensive than micro-inverters, as shown in Figure 1.5. 


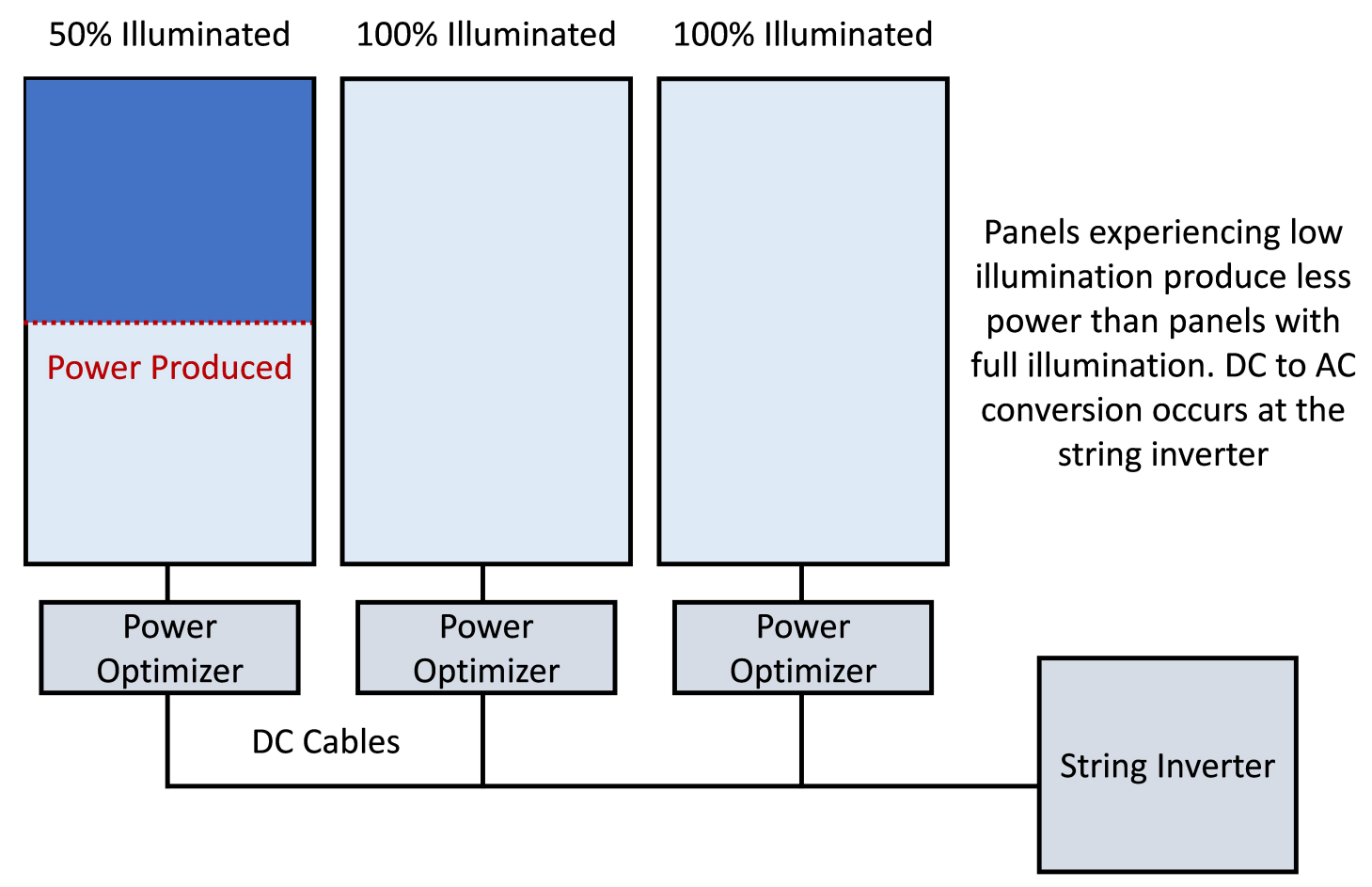

Figure 1.5: Power optimizer and string inverter system design under partial shading conditions.

The world is moving toward a significant solar energy mix; although exciting, significant limitations and challenges must be addressed. Companies such as Solar Edge, Tigo, and EnergySage are some of the key manufacturers leading the power optimizer market. The solar resource is often intermittent and cells are highly sensitive to rapid changes in irradiance, including those caused by rapid shading which impacts the control of energy production. These control challenges can be resolved with improved energy storage devices to manage under production and curtailment to eliminate over production and over-voltage concerns which occur when operation extends beyond the allowable limits. Curtailment is a key concept in the legislation of evolving standards, such as IEEE 1547 and California rule 21, that require the system to have the ability to curtail active power when necessary. Current power optimizer functionality operates at the maximum power point, and as the electrical grid experiences higher penetration of $\mathrm{PV}$, constant maximum production is not always desirable.

Module level power optimizer (MLPO) designs offer a compromise between string 
inverter and micro-inverter technologies. Power optimizers benefit from the stable operation of a centralized inverter while introducing a similar resiliency to partial shading offered by micro-inverter systems. The intermittent nature of ground level solar irradiance introduces significant variability in PV production leading to inefficient MPPT and high voltage ramp rates. The proof of concept design outlined in Chapter 3 and 4 discuss a method to reduce the negative effects of rapid cloud shading to increase stability and control in grid-connected and islanded systems.

\subsection{Thesis Overview}

Chapter 1 introduces the current environment of photovoltaic renewable power generation as well as the predicted energy mix, which depends largely on the advancements of renewable technologies. As PV cells produce DC electricity, an inversion stage is required to convert to grid-compliant $\mathrm{AC}$ using a string inverter, power optimizer with string inverter, or micro-inverter technology. The overview outlines the merits and disadvantages of each method and introduces the need for a standard compliant power optimizing device.

Chapter 2 describes the background information for solar power production and the necessity of power conversion and optimization for highly efficient PV systems. This section discusses the benefit of power optimizers in various systems and the standards motivating the advancements in this field. This chapter introduces some of the key themes and methodology used to develop the model described in Chapter 3.

Chapter 3 describes the improved power optimizer design using four subsections: improved MPPT, mode selection and active power curtailment, ramp rate reduction using fuzzy logic control, and a self-tuning gain controller for the DC regulation stage. The design of the MPPT algorithm is adapted from [4], the standard buck boost converter presented by Matlab/Simulink was customized for this model, and the work presented by [7] was adapted for use within this application; however, the remaining subsystems are designed by the author. The variable step MPPT 
model is chosen to manage high variability input conditions to accurately determine the maximum operating point in both clear and cloudy sky conditions. The linear programming tool fmincon uses interior point optimization to control the optimal power set point for each module to meet the output load request. A combination of five and seven linguistic variables is selected for the FLC1 membership functions resulting in a 1024 rule inference model. A four-switch buck boost converter regulates the DC output voltage in grid isolated systems using a feedback loop with a selftuning PI controller. The operation of each section within the optimizer is described prior to obtaining the results from simulations performed in Matlab/Simulink 2019a; these results are discussed in Chapter 4.

Chapter 4 introduces the test cases used to obtain the results found in this chapter. The simulation results for each of the subsystems and the total functionality of the device will be discussed. It will be proven that the model effectively increases the stability and reliability by operating within maximum power point (MPP) and curtailment modes whenever necessary. Fast frequency ramp rates caused by rapid cloud cover are reduced using a fuzzy logic controller and the DC string power is regulated to maintain a constant DC link voltage of 120 VDC.

Chapter 5 concludes the thesis by discussing the system design and operation in each design stage including the variable step maximum power point tracking, mode selection, ramp rate reduction, and DC regulation processes. The design described within this thesis meets current IEEE standards while reducing the adverse effects caused by rapid cloud shading. 


\section{Chapter 2}

\section{Background}

\subsection{The Solar Resource}

The use of the solar resource to produce non-greenhouse gas emitting electricity has globally increased in the past decades with certain countries leading the charge. Germany and China produce large scale solar energy partially due to the geographical properties which are ideal for solar generation. Large and small scale PV plants are subject to similar design considerations: the location and orientation of the array should be chosen such that any shading effects are minimized to produce maximum energy yield. The energy yield can be approximated using a clear sky model developed by Christian Gueymard [8] which is dependent on a variety of solar parameters such as the location, date, time, elevation angle, azimuth angle, and zenith angle.

Seasonality is a strong factor associated with the PV production at any location. Depending on the time of year, the position of the array will change with respect to the sun thereby altering the amount of irradiance incident upon the modules. As shown in Figure 2.1, three key parameters are used in PV system design: elevation angle of the sun, $\theta^{\text {elevation }}$, azimuth angle, $\theta^{\text {azimuth }}$, and the zenith angle of the sun, $\psi^{z e n i t h}$. The azimuth angle represents the distance in degrees from true north, the elevation angle describes the distance in degrees above the horizon while the zenith angle is represented as $\phi^{z e n i t h}=90^{\circ}-\theta^{\text {elevation }}$. 


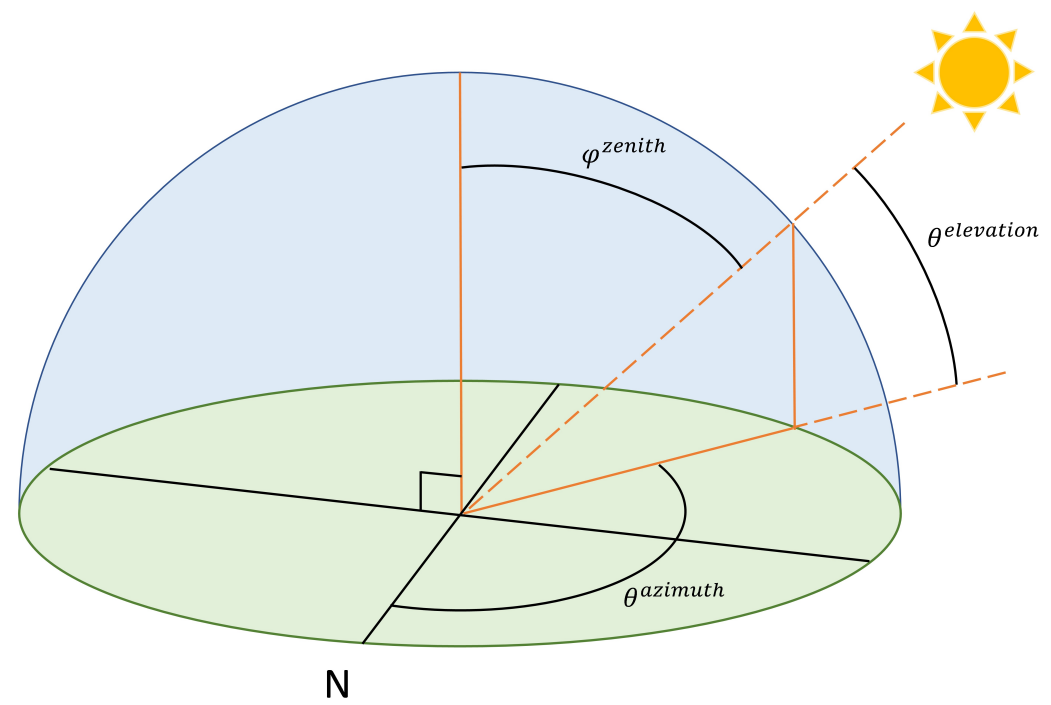

Figure 2.1: Geographical characteristics affecting PV production, adapted from [5].

While PV plants can be designed to limit predictable shading sources affecting the array, variable sources such as aerosols and cloud coverage are difficult to predict. Certain atmospheric conditions such as aerosol optical depth, ozone, and precipitable water content affect the amount of ground-level irradiance thereby impacting the production of the array. Similarly, cloud cover is highly location specific and can impose non-uniform rapid shading conditions on the string or array. Engineers are attempting to create methods to predict uncontrollable shading caused by environmental conditions using a variety of prediction and learning techniques, [9] [10] [11] [12].

Cloud prediction and modelling is a significant cross-disciplinary research topic of great importance in current and future PV production studies. Presently, the research surrounding cloud shading prediction is largely dependent on nowcasting to forecast the ground-level irradiance using very small horizons such as $15-60$ seconds [11] [13]. The main challenge of this method is related to the lack of reliable atmospheric data available at the specific location of the array. Ground level irradiance is impacted by geographical and environmental conditions such as cloud 
shading; therefore, forecasting models depend on high resolution location-specific data.

Rapid cloud shading is most prevalent in environments with low-level cumulus clouds, shown in Figure 2.2(a), which produce highly variable irradiance conditions through rapid sun blocking [14] [15] and irradiance enhancement [16] [17] at the cloud edge. The fast changes in irradiance, shown in Figure 2.2(b), lead to PV characteristics - in current, voltage, and power - with increased ramp rates, which introduce additional system instabilities.
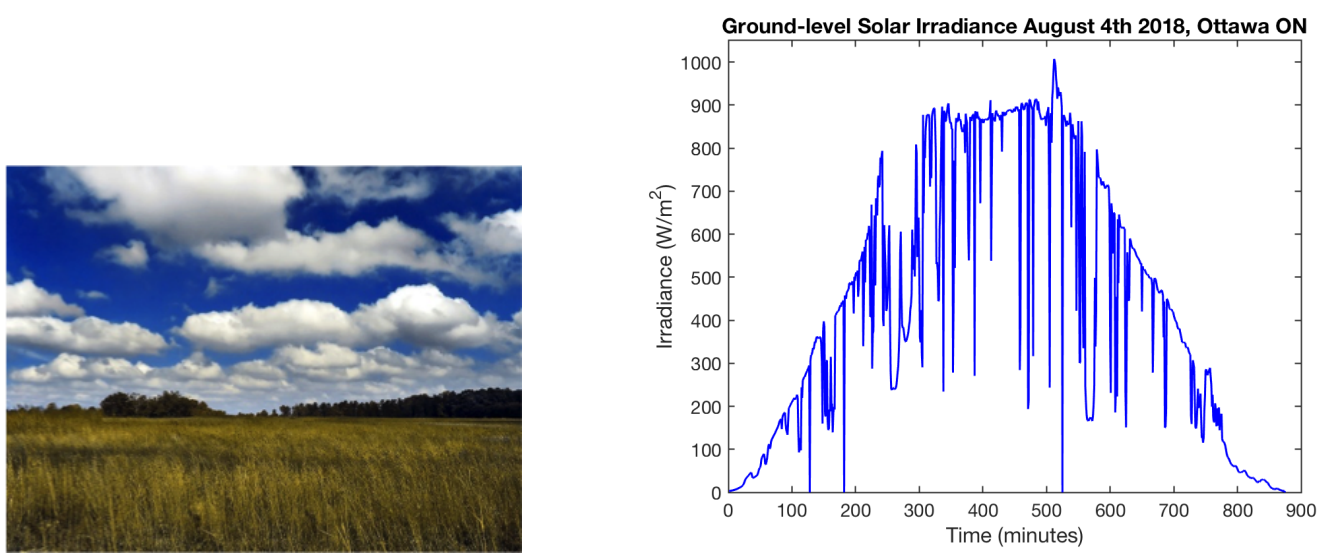

Figure 2.2: (a) Low-level cumulus clouds and (b) global horizontal irradiance on a high cloud variability day in Ottawa Ontario.

\subsection{Producing Power using Solar Modules}

A solar module, or panel, is typically formed by wiring individual solar cells in series; the panels are connected in series and parallel combinations to create an array which produces the appropriate current and voltage based on the design criteria. The photoelectric effect describes how certain materials, like those used in semiconductor devices, absorb photons of light and release electrons. Solar cells use doped semiconductor wafers to form an electric field with a positive and negative terminal. An electron-hole pair is created when an external energy source is supplied to a semiconductor, the valence electrons are energized to the conduction band thereby producing a hole in the valence band. The hole attracts electrons 
from nearby covalent bonds resulting in a flow of electrons which generates electric current; contacts complete the electric circuit by carrying the current out of the cell for external use. The solar module can be a variety of sizes depending on the requirements of the system, typically a full-size panel will consist of 64 or 72 solar cells. The power produced by a solar panel is characterized by the open circuit voltage, $V_{o c}$, and the short circuit current, $I_{s c}$, which are the maximum voltage and current, respectively. These characteristics are affected by the design of the solar cell and by environmental conditions such as temperature and irradiance.

As previously mentioned, the output of the solar panel is DC thereby requiring a form of inverting technology to convert the DC output into a grid compliant AC output. Often installations use an additional voltage regulation or conditioning stage, such as a MLPO to maximize the electricity produced. Typical power optimizers aid in the maximum power point tracking to find the voltage and current to yield the maximum power. A DC converter is typically used to maintain the output voltage to ensure operation at the maximum power producing voltage. Conventional power optimizer designs aid in regulating and monitoring the DC voltage before the inverting stage however they lack the intelligence which can increase control of an otherwise uncontrolled and intermittent resource. Power optimizers can accommodate variability in the $\mathrm{DC}$ voltage of a module by converting to the desired DC output voltage.

New standards and regulations are targeting high penetration PV generation which requires active power curtailment options to maintain stability during periods of increased production. Power optimizers typically do not allow for external communication and system optimization; therefore, the panel is optimized based on the conditions impacting a single panel in the string. Additionally, power optimizers do very little to reduce instabilities caused by high ramp rates from fast frequency fluctuations in power production. By introducing additional intelligence to the system, power optimizers can more efficiently manage maximum power point tracking, active power curtailment, and ramp rate reductions caused by rapid cloud 
cover. The improved power optimizer discussed in this thesis effectively overcomes the limitations of conventional designs by addressing these problems.

\subsection{Maximum Power Point Tracking}

Throughout the day, a solar module will produce power that depends on the time of day and atmospheric conditions. On a clear sky day, the power produced will increase, reaching a daily maximum around midday, before decreasing until nightfall. Due to strong variability in the solar resource, the power produced by a PV module or plant shows significant non-linearity which is managed by maximum power point tracking (MPPT) algorithms. PV characteristic curves are shown in Figure 2.3. The current-voltage curve, Figure 2.3(a), shows the relationship between the voltage applied across the device and the current flowing through it; while the power-voltage curve, Figure 2.3(b), graphically depicts the power produced at various voltages.
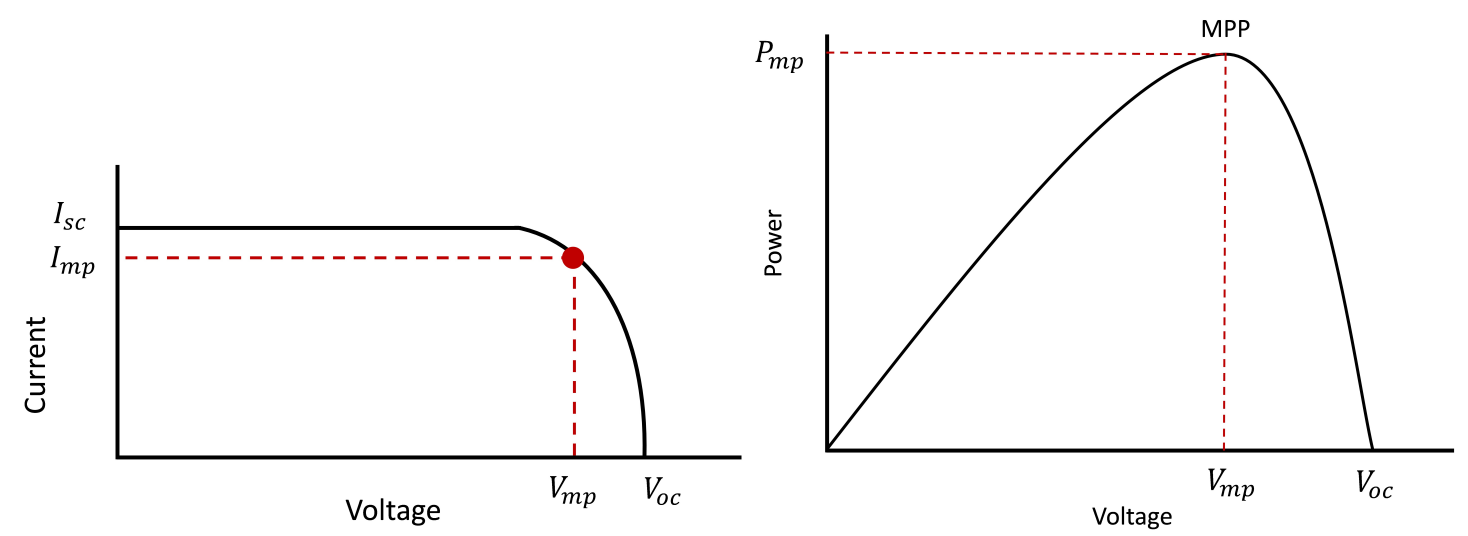

Figure 2.3: PV curves describing (a) current-voltage and (b) power-voltage characteristics.

Panel voltage can be regulated using a variety of MPPT models to consistently yield maximum power under ideal operation. Some of the most common methods of MPPT are perturb and observe [18], [19], [20] and incremental conductance [21], [22], [23]. Each method has advantages and disadvantages which uniquely affect the system specifications; the designer must first determine the algorithm best suited for the device. Perturb and observe and incremental conductance algorithms are described as hill-climbing methods; they are often implemented due to their simple 
design. These traditional MPPT models perform well in clear sky or ideal conditions however operation deteriorates under non-uniform conditions such as shading. The following sections introduce these conventional MPPT methods as well as summarize the recent work to mitigate efficiency losses caused by non-uniform shading conditions.

\subsubsection{Perturb and Observe}

Hill climbing methods are categorized by the process of increasing or decreasing the operating voltage of the panel or array in order to observe the impact on the output power [20]. A perturb and observe algorithm consists of a simple feedback structure which periodically perturbs (whether that be increasing or decreasing) the system to compare the output power with that of the previous monitoring interval. Figure 2.4 graphically describes the operation of the perturb and observe algorithm. The derivative of the measured power is determined during each perturbation cycle; this value shows the perturbation's direction of movement - if positive the perturbation will shift to the right and if negative to the left. This is evident in Figure 2.4 where a starting position on the left of the MPP results in a shift to the right, and vice-versa, leading to oscillation around the MPP. 


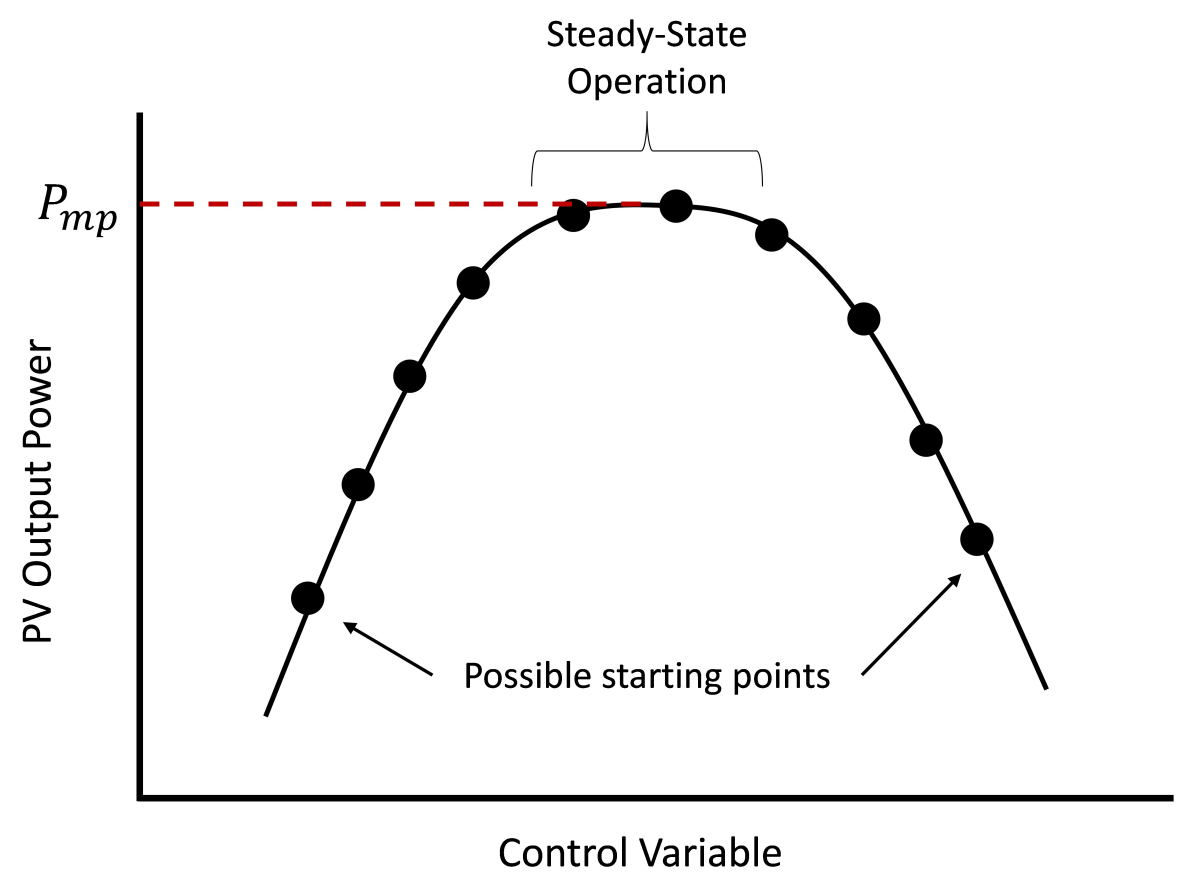

Figure 2.4: Perturb and observe function description.

\subsubsection{Incremental Conductance}

Incremental conductance is often preferred over perturb and observe as it is better suited for fast changes in the atmospheric conditions. Like perturb and observe, it is a hill-climbing technique and requires the measurement of current and voltage but it does not suffer from similar oscillation concerns. Based on the fact that the slope of the P-V curve is zero at the MPP, this method determines the maximum power point by comparing the incremental conductance, $\frac{d I}{d V}$, with the negative of the instantaneous conductance, $\frac{-I}{V}[21]$. The control voltage is increased if the instantaneous conductance is greater than the incremental conductance, and vice-versa, as shown in Figure 2.5. 


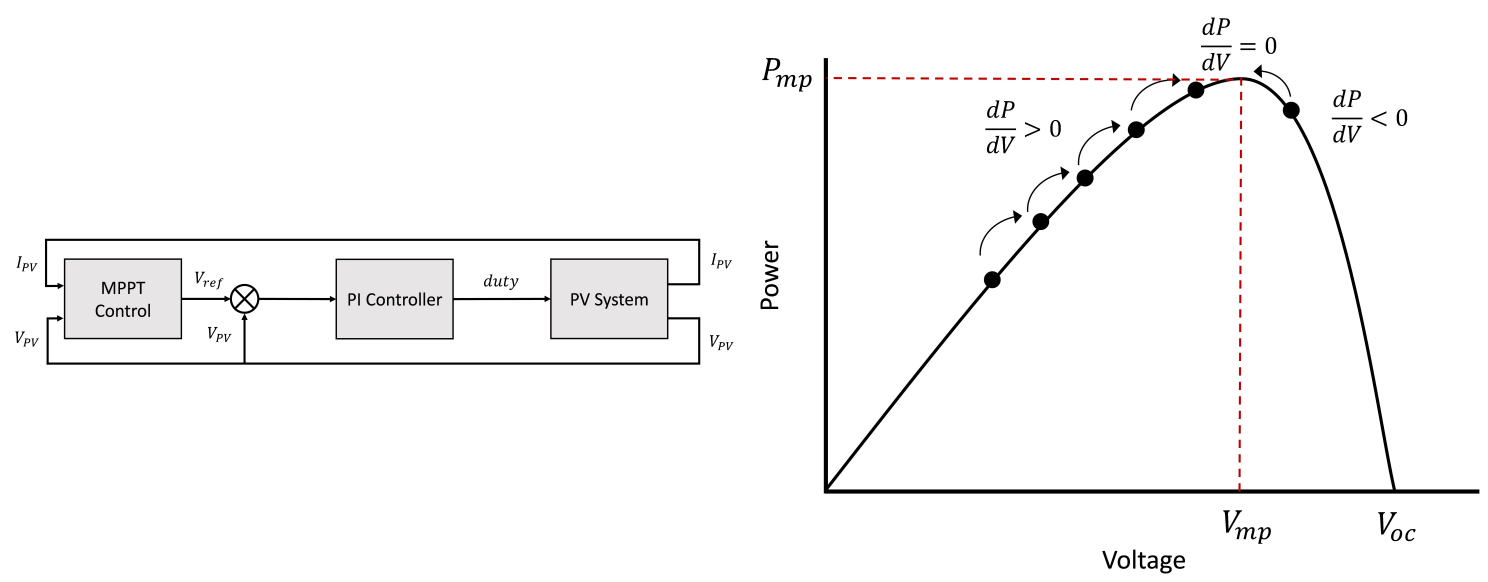

Figure 2.5: Incremental conductance (a) system level design adapted, from [2], and (b) function description, adapted from [3].

\subsubsection{Limitations of Conventional Techniques}

Hill-climbing methods such as perturb and observe and incremental conductance are subject to challenges such as slow tracking speed and inefficiencies due to partial shading conditions. The amount of irradiance incident on the panel affects the short circuit current on the I-V characteristic curve. Shading impacts the shape of the I-V curve causing it to deviate from the typical shape and instead introduces a non-uniform curve with multiple local maxima, as illustrated in Figure 2.6. The multiple-maxima-curve presents tracking difficulties as the hill-climbing models cannot differentiate the local maxima from the desired global maxima. These algorithms also suffer from a fixed step size, where the choice of small step size causes the system to perform slower (as more iterations are required to obtain the MPP) but the faster large step size is less accurate and can result in a large tracking error around MPP [24]. 


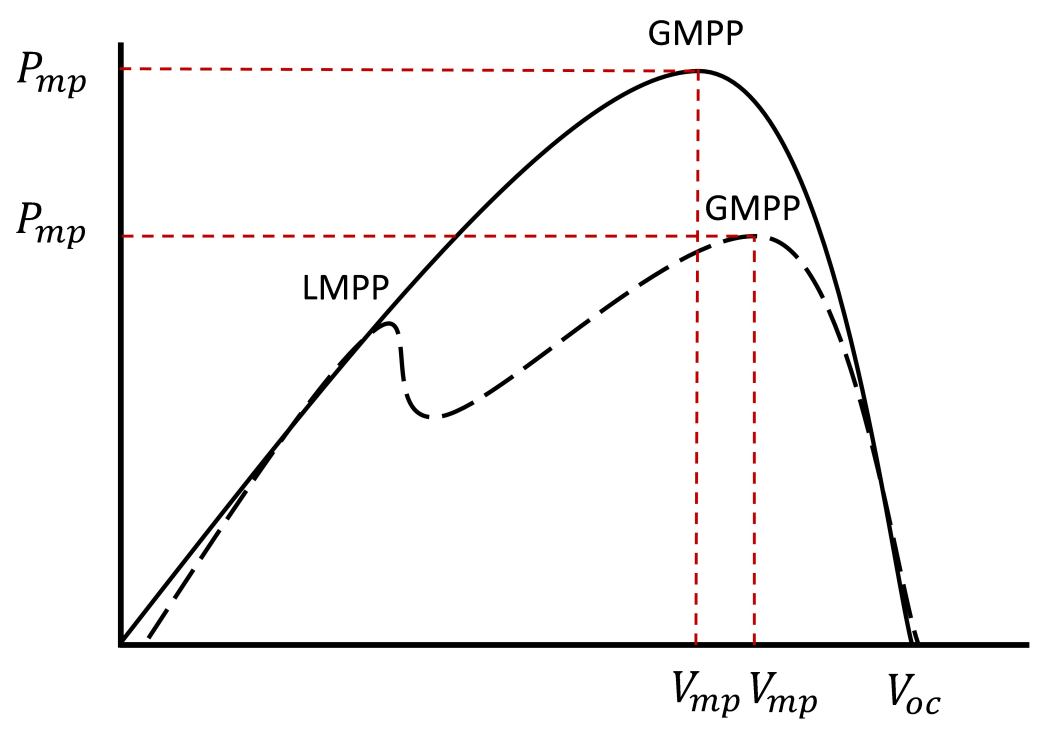

Figure 2.6: The effects of non-uniform irradiance conditions on PV power production.

For perturb and observe, steady-state operation is maintained when the power range around the MPP exists within an acceptable tracking error. This operating zone is present because the algorithm imposes a perturbation at every time step, resulting in an oscillation around the maximum point.

The incremental conductance model is usually limited due to cost constraints, as it requires multiple sensors to measure the present current and voltage as well as storing information from the previous iteration for comparison. Additionally, the incremental current and voltage must be calculated for each time step, as well as the instantaneous and incremental conductance, introducing computational cost. The incremental conductance method is however typically faster than perturb and observe and allows for increased responsivity during periods of rapid irradiance changes.

\subsubsection{Improved MPPT Algorithms}

To account for the limitations of traditional MPPT techniques, a variety of improved and intelligent models have been introduced. Power optimizers and microinverters integrate MPPT and DC converting capabilities directly at the module level. The purpose of these devices is to determine the maximum power point and 
obtain the desired output voltage using the duty cycle as the control variable.

A common method for increasing tracking speed to manage the local and global MPPs is to use a variable step size tracking value. Some authors used a dynamic self-optimizing technique using power and duty cycle measurements to determine the appropriate step size threshold [25]. This study found that the tracking accuracy improved, resulting in reduced power losses, but found difficulties in calculating appropriate threshold limits. Another approach is to increase MPPT sampling periods by introducing additional measurements outside of the perturbation cycles [26]. They found that this technique isolated the rate of change in the power to only consider the impacts of external conditions rather than changes internally imposed by algorithm deficiencies. This method yields higher dynamic efficiencies but the additional measurements introduce greater computational costs which are unnecessary in a system without rapid changes. Another incremental MPPT technique was introduced which resulted in fewer oscillations around the MPP during non-uniform input conditions [27]. They used a variable step size to determine the optimal duty cycle value using the slope and I-V characteristics.

Others have used model predictive control (MPC) to predict the behaviour of the control variables defined in the system [28]. These predicted values are used to obtain the optimal switching state by minimizing the cost function to be applied to a high gain, multi-level DC-DC converter. This model shows increased tracking speed by predicting the error at the next sampling time. However, it requires a more complex design with increased computational cost.

A method to improve tracking using adaptive scaling factors was presented in [29]. This paper describes the development of a MPC based MPPT algorithm to determine the predicted control variables for the next iteration. The inputs to the prediction algorithm are the current and voltage produced by the solar panel while the outputs are the desired current entering the multilevel boost converter and PV voltage of the next time interval. The predicted values are evaluated using a cost function to determine the optimal switching state of the converter using a 
set of discrete time equations derived in the paper. It was found that their model exhibits improvements in speed and efficiency when compared to the incremental conductance method.

An additional complex technique aimed to predict the locations of the local and global maxima used a combination of assumptions and approximations to improve MPPT. The method proposed by [30] which made the assumption that the global maxima occurs approximately at $80 \%$ of the $V_{o c}$ value scaled by the number of unshaded modules in the string. They used this quantity as a starting value to determine the local MPPs and combined the module voltage measurements with perturb and observe and MPP comparisons to find the global maximum value. Their model introduces complexities which increase with string size, a problem which could be better managed using module level power electronics.

\subsection{Active Power Curtailment}

Managing solar PV in the context of variable and imperfectly anticipated demand is challenging. Two types of solar implementation will be considered in this thesis: grid connected and islanded mode operation. For grid connected systems, balancing authorities ensure that supply meets demand while operating under reliability standards. This is realized by transmission and distribution operators within their service areas. As the grid structure evolves and decentralized control architectures are adopted, islanded systems may become increasingly popular. Islanded systems operate independently of the regulated grid structure therefore end-use variability is a prominent concern. In both cases, when PV generation is high and consumption is low, active power curtailment (APC) is necessary to maintain stability within the PV system. The principal concerns that must be addressed are over-voltage and increased ramp rates.

Over-voltage in PV dependent systems is a growing concern as more residential, commercial, and industrial communities implement solar power generation. When grid voltage rises beyond an allowable level, solar generators - including rooftop 
solar - have typically been required to shut down entirely [31]. While fossil fuel burning generators have the ability to increase or decrease production to meet the needs of the systems when required, solar generators are not fully capable of this level of control as the amount of electricity produced depends on the environmental conditions at the time of generation.

Various APC approaches have been advanced to address voltage regulation requirements. A discussion of over-voltage protection for low voltage feeders is presented in [32], where the authors use a droop-based active power curtailment model. They found that the basic APC and the improved design were comparable with the only difference occurring at midday where the increase in active power production was insignificant. Other work aims to maintain voltage regulation through power curtailment using inverters and generation forecasts [33]. They use short term PV power forecasts to curtail active power while approximating the reactive power requirements using a droop-based control method. This model works to maintain voltage regulation through adaptive active and reactive power injection however the work is prone to spontaneous forecasting errors and requires high-resolution historical power production data. The method proposed in [34] proves that APC can be incorporated into an energy management approach where the inclusion of storage allows for a more comprehensive solution to PV power management through optimizing the dispatch of the hybrid system.

The method proposed in this thesis uses proportional voltage reduction from the panel MPP within an APC scheme. To ensure that the power of each panel is properly curtailed, while maintaining the appropriate power and voltage production of the string or array, a system optimization and communication scheme is required. There are many optimization techniques, of varying complexity, that may be used for this. The method proposed in this thesis uses a simple linear programming model to minimize the power production of each module while meeting the power demands of the system. Using bi-directional power line communication between the centralized system optimizer and the individual module power optimizers, a simple 
optimization technique may be used to curtail active power thereby eliminating overproduction concerns without requiring additional energy storage devices or reactive power injection.

\subsection{Ramp Rate Reduction}

Environmental factors such as rapid cloud shading cause the power produced by PV arrays to fluctuate. For distribution grids with high PV penetration, the passing clouds can result in large and fast power fluctuations, that is, in high ramp rates. The current electrical grid was not designed for distributed generation, so intermittency can drive operation outside safety limits, causing blackouts or equipment damage. Ramp rate control is needed to smooth the power fluctuations caused by rapid cloud shading in PV systems. Several extant approaches are described below to illustrate the problem, these focus on mitigation through energy storage management. Ideally, an energy storage device would be incorporated to the system design to manage ramp rate reductions.

Energy reserves are often used to manage short-term variability in order to maintain power quality and network reliability. The authors of [35] describe how to calculate the maximum power and the minimum energy storage requirements for any PV plant size and maximum allowable ramp rate. They observed PV power over one year and found that PV systems experience fewer power fluctuations when operating within an appropriate voltage range based upon the production capacity of the plant. When the ramp rate is reduced, the time exceeding the limits of operation decreases significantly.

State of charge devices are also proposed to control dynamic ramp rates caused by rapid cloud cover. The method proposed in [26] aims to smooth out the fluctuation effects using an energy storage system which is only enabled when a fluctuation occurs. They found that the use of strategy parameters can be further tuned to reduce the capacity requirements using only state of charge parameter modifications.

The model described in [36] also used a control mechanism to reduce power 
ramping with a battery storage system. The battery storage system is used to compensate any large ramp rates by releasing stored energy to maintain appropriate ramp rates. Additionally, by studying the results obtained year-round, they found that the size of the battery storage system is sensitive to the season causing additional optimization and storage requirements to be considered.

PV ramp rates are typically managed using one of the following categories: moving average, filter based, and ramp rate control algorithm based methods [37]. Moving average and exponential smoothing produces reduced ramp rates with limited computational effort; however, an additional energy storage device such as a battery is required. Furthermore, this method requires users to define the quantity of data points to be considered for smoothing. The number of chosen data points impacts the degree of smoothing imposed on the output PV power, any data which exists outside the defined limit will be lost thereby reducing the efficiency of the smoothing technique.

Filter based methods such as the application of low pass, high pass and least square estimator filters have also been used to mitigate the negative impacts of solar variability. Similar to previously mentioned approaches, these have been designed to function in tandem with an energy storage device and state of charge controllers to reduce ramp rates. A further extension of this research surrounds the pairing of natural gas generators, hybrid electric vehicles, and diesel generators to reduce degradation to extend battery lifetimes.

Finally, ramp rate control strategies have shown promise in reducing PV output power ramp rates. Algorithms have been designed specifically to regulate the battery's state of charge thereby allowing for reduced energy storage requirements. Such systems result in higher efficiencies which cost less to implement and experience reduced degradation. This methodology requires a significant degree of knowledge and effort by the designer, a strong understanding of the PV system and the impact of variable shading is vital for system design. 


\subsection{The Impact of Load Variations on Islanded Systems}

Voltage regulating DC converters, a necessary component of power optimizers, are designed using fixed parameters independent of any user-side variability. A traditional DC converter is designed for a certain operation using finely tuned and rigid gain parameters specific to the regulated system. In a system which must manage unregulated output voltage, rigid gain parameters actually hinder the converter operation thereby reducing efficiency by not adapting to the dynamic load changes. The main idea of resolving rigidity constraints is to increase the adaptability of the gain parameters, researchers in [38] compare three types of DC converters to determine the impact of changing load conditions. Proportional-integral (PI) controllers offer a traditional method of performing voltage regulation under external input and output influences. As PI controllers are based upon a linear model they tend to experience a poor response to large signal disturbances due to the finely tuned gain parameters. In contrast, sliding mode controllers (SLMC) and fuzzy logic controllers (FLC) handle nonlinearities well by dynamically modifying the parameters when required. The study [38] found that FLC designs are a promising and viable option for power electronic systems as they manage the non-linearities better than traditional systems. However, the hybrid model proposed in [39], which used fuzzy logic control and multi-objective functions to limit ramp rates, did not function significantly better than simple fuzzy proportional-integral-derivative (PID) controllers, and was found to be more cost and computationally expensive.

\subsection{The Benefit of Power Optimization Techniques}

Power optimizers combine the positive elements of string and micro-inverter topologies to improve the functionality of PV generation systems. Power optimizers condition the DC voltage produced by the individual PV within the larger array to maximize power production and efficiency. As they operate by regulating the 
output voltage of the individual module, the performance of a low producing panel will not negatively affect the production capability of the other panels in the string, a limitation of string inverter topologies. Each power optimizer works to maintain the constant string voltage producing safe and efficient strings of varying lengths. Power optimizers also offer monitoring of each panel allowing for preliminary mismatch detection and resolution. Power optimizer and string inverter systems are a less expensive and more flexible solution offering partial shading mitigation of microinverters and stability and efficiency of string inverters. The method proposed in this thesis aims to solve some of the concerns surrounding the intermittency and resiliency of renewable power generation. The challenges associated with maximum power point tracking, active power curtailment, ramp rate reduction, and load side variability are all studied and methods of improving these areas are explored.

\subsection{Managing Rapid Shading}

Rapid cloud shading is mitigated using a variety of state-of-the-art techniques such as forecasting models, module level devices, and sub-module optimization. Recent advancements surround the understanding and prediction of shading patterns caused by cloud cover.

Forecasting models optimize the inputs and network parameters using popular models such as genetic algorithms, particle swarm optimization and many others. Some works take into consideration the spatio-temporal horizons however the accuracy of the power forecast depends on the type of model used. Creating these forecasts requires significant historical data, knowledge of weather conditions, and location-specific physical modeling. Optimization models can use exponential smoothing or moving average models to reduce the naturally occurring effects of variable irradiance.

Module level devices, such as micro-inverters and power optimizers have successfully been used to manage input side variabilities. Micro-inverters perform maximum power point tracking as well as $\mathrm{DC}$ to $\mathrm{AC}$ conversion on a per module basis. 
The use of filters and algorithms have been introduced to reduce input fluctuations. Historically, incorporating advanced intelligence in power optimizer design has been limited; they typically perform MPPT and some degree of output smoothing on a per module basis thereby not considering string level optimization and control.

For sub-module optimization, partial shading management is further researched and modelled within each panel of the string. Rather than bypass diodes, submodule optimization is performed to reduce mismatch losses and improve overall performance of the module. Applying this method involves a complete redesign of commercially available modules thereby limiting this use to new topologies rather than pre-exisiting arrays. 


\section{Chapter 3}

\section{Design and Modelling}

As introduced in Chapter 1, module level power electronic devices are designed to regulate the DC power of each module in a string. Conventional power optimizers operate at constant MPP and are highly sensitive to rapid changes in irradiance. The control of energy production in the string is negatively impacted by variable cloud shading; the challenges associated with the intermittency of the solar resource can be resolved with improved MLPE design. Chapter 2 discussed mitigating the effects of rapid cloud shading using methods such as variable step size MPPT, active power curtailment, voltage ramp rate reduction, and self-tuning gain controllers to manage changing loads in grid isolated systems. The MLPO proof of concept design is presented in this chapter; further information regarding the individual subsystems can be found in the appropriate appendices. The designs described in this chapter are simulated and discussed in Chapter 4.

This MLPE device is designed to be affixed to each module in a string while communicating with a system optimization engine, as shown in Figure 3.1. This engine, or centralized optimizer, may be located with the inverter or at an external communication hub; the scalability of the device is limited by the optimization engine and communication abilities of the system. Each module level power optimizer determines the appropriate voltage to be produced by its panel in four stages: MPPT, system optimization, ramp rate reduction, and DC regulation. All stages, excluding the centralized optimization engine, are performed locally at each module and 
are not impacted by the number of modules per string. The inputs to the module optimizers are the voltage and current produced by the module and the maximum power point is determined by a variable step MPPT algorithm. The MPP values are communicated to the system optimization engine through bi-directional physical or wireless communication. The simulation is limited by the DC regulation stage which uses a step size of $1.0 \mu s$.

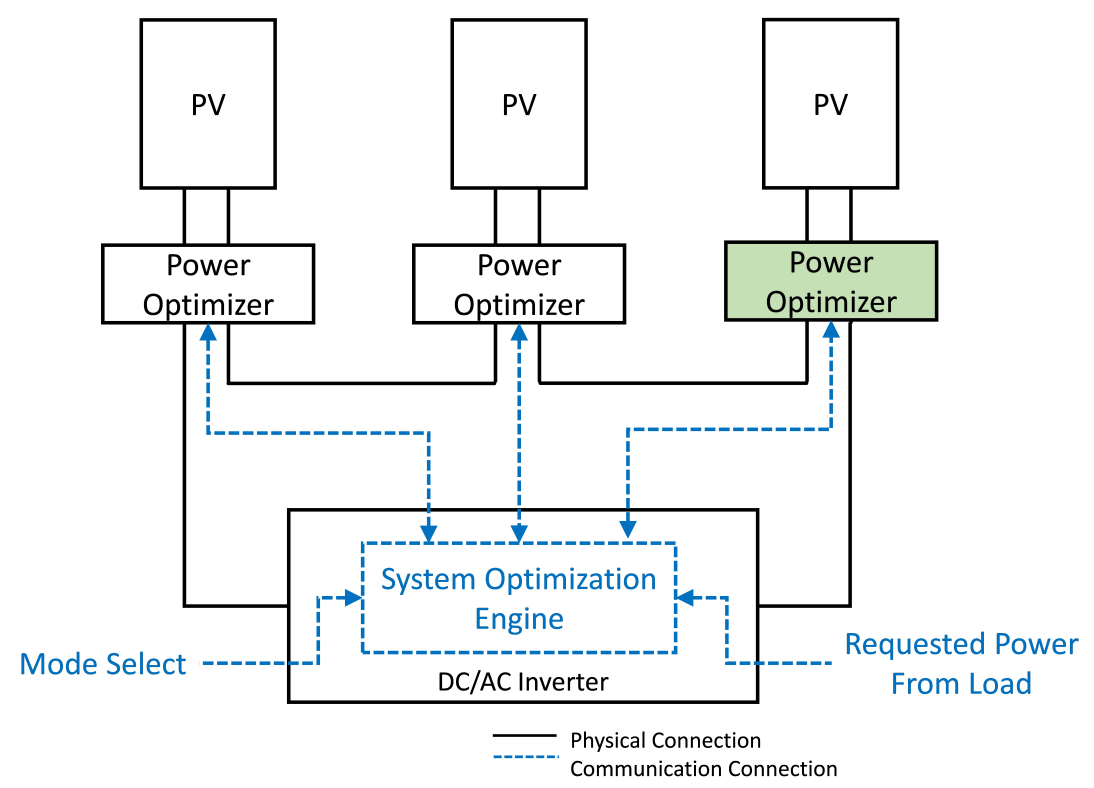

Figure 3.1: Proposed system-level block diagram.

Figure 3.2 shows the four stages of the power optimizer in greater detail, including communication links with the centralized optimizer. This receives the MPP value from each module in the string and returns an optimized value. Within the MLPO, the total string power produced using the MPPT setting is compared to the requested power from the load. If the power generated by the string exceeds the requested load, the power curtailment operation will be enabled; if curtailment is not required, the optimized module power remains at the MPP value. During curtailment mode, the system optimizer will scale the generation of each module using a linear programming method to meet load demands. No matter if curtailment operation has occurred, the power quantities determined by the system optimizer are returned to the appropriate module device via bi-directional communication. 


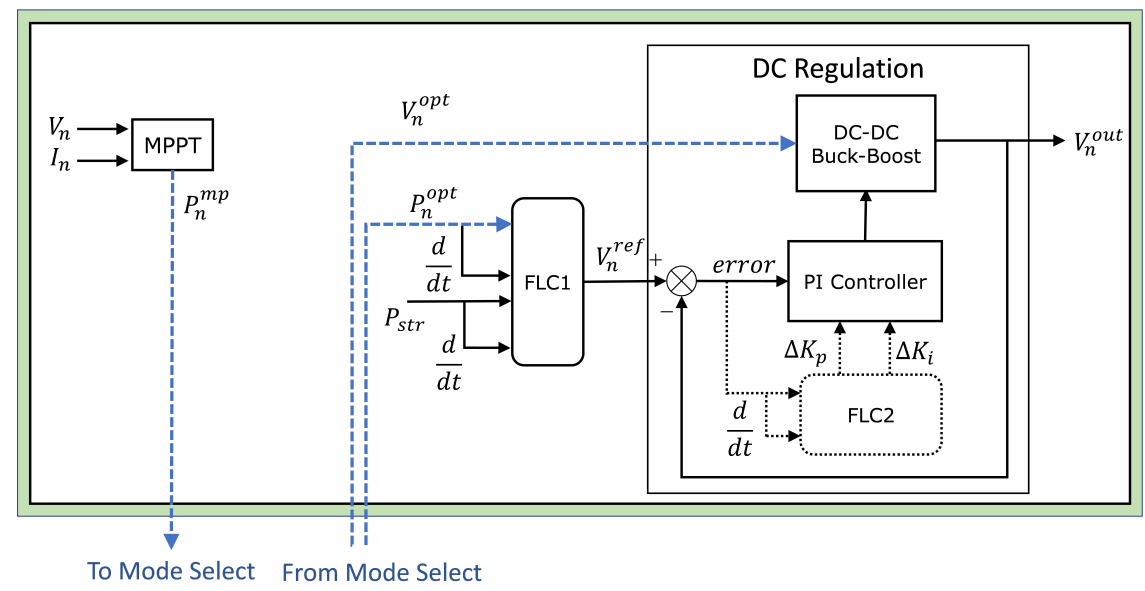

Figure 3.2: The module-level improved power optimizer design.

The multiple input single output fuzzy logic controller (FLC1) receives the optimized module power value, the monitored string power, and their rates of variation. Its purpose is to construct a dynamic reference voltage for the DC regulation stage that performs ramp rate reduction using fuzzy logic control. The output of the fuzzy logic controller is a reference voltage which is used as an input to the DC voltage regulation stage. The voltage regulation stage consists of a four-switch buck boost controller in a feedback loop to minimize the error between the reference and output voltage. As islanded systems are more sensitive to variable load conditions, a second fuzzy logic controller is used to tune the controller gain parameters to adapt to the variable output. Modelling the solar array is a key component of testing the validity of this design, the solar array in grid-connected and islanded system was simulated using Simulink 2019a.

\subsection{Modelling the Solar Array}

All simulations described in this thesis were implemented in Matlab/Simulink 2019a with Simscape Power and Simscape Electrical libraries and the Optimization and Fuzzy Logic toolboxes. The input spectral irradiance and temperature data used to simulate the power production of an array in Ottawa Ontario was provided by Spectrafy Incorporated. The input data was simulated using an array of 230 
W PV modules. The irradiance and temperature data were used as inputs to each panel on the string, a ten minute time shift was used to represent a spatial distance between each panel in the string.

The spatial distance between modules can be approximated with a temporal shift and the average wind speed; thus, the temporal shift is proportional to the distance between the modules. Figure 3.3 compares the maximum power of a string of three modules with two, five, ten, and fifteen minute temporal shifts imposed on the data. The power produced by a string with a small shift has high correlation between the module output therefore showing smoother characteristic curves as the modules are experiencing approximately the same irradiance conditions at any given time. As the temporal shift increases, representing greater distance between modules, stronger variability is observed. A temporal shift of ten minutes was chosen to represent dynamic irradiance changes to test an aggressive proof of concept scenario.
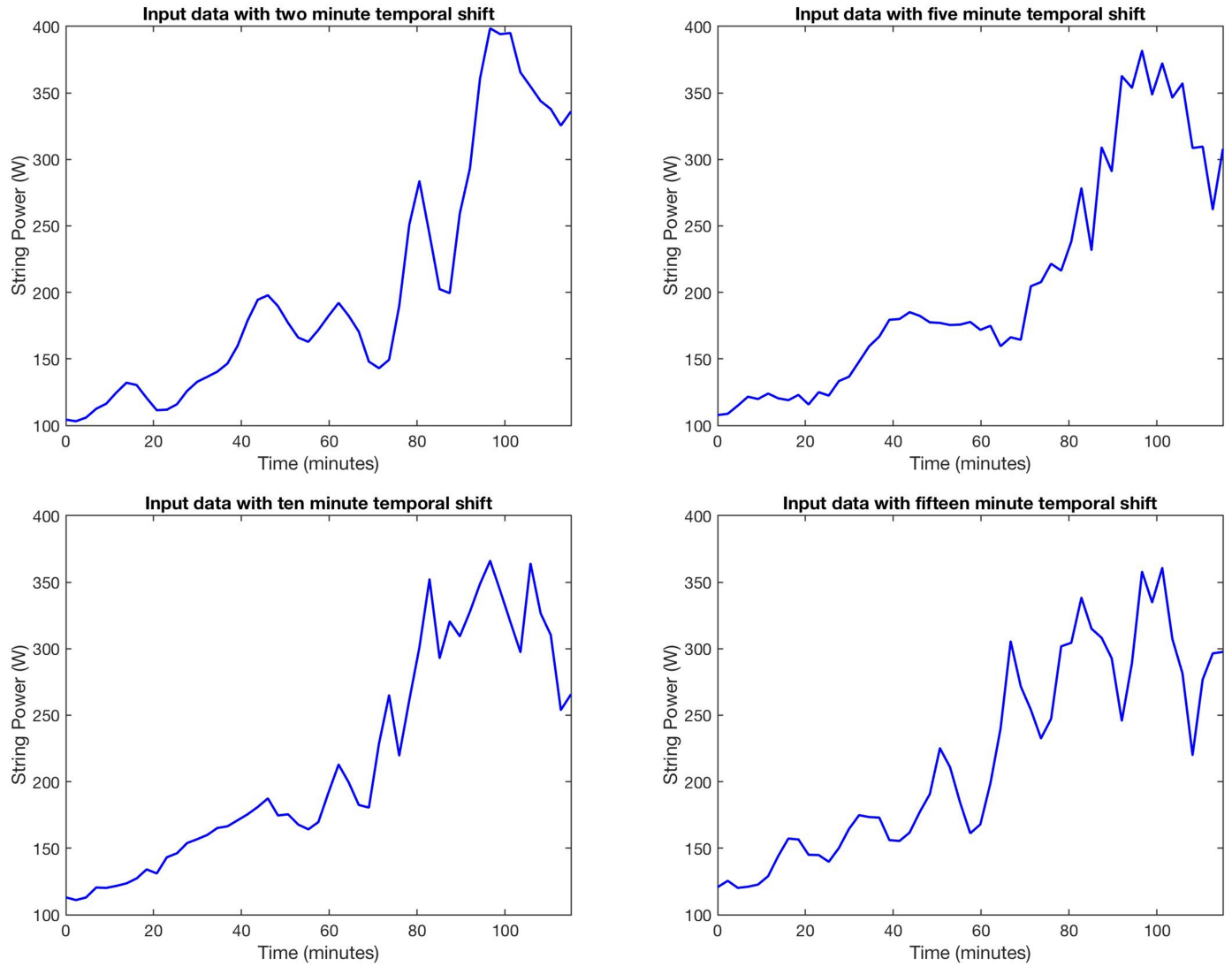

Figure 3.3: The effects of shifting the string power generation data by (a) two minutes, (b) five minutes, (c) ten minutes, and (d) fifteen minutes. 
Rapid cloud shading can occur within seconds however the resolution of the measured data used for simulations is one minute. An extended time delay of ten minutes was imposed on the array to best observe the functionality of the device when operating in highly variable environmental conditions. Using the average windspeed in Ottawa, $1.4 \mathrm{~m} / \mathrm{s}$, the approximate distance between the panels under consideration is 840 meters representing an extreme test case, Figure 3.4.

Now that the simulated environment has been developed, the individual subsystems can be designed and implemented. The focus of the next section is on the maximum power point tracking algorithm required to determine the maximal operating point of the modules in various sky conditions.

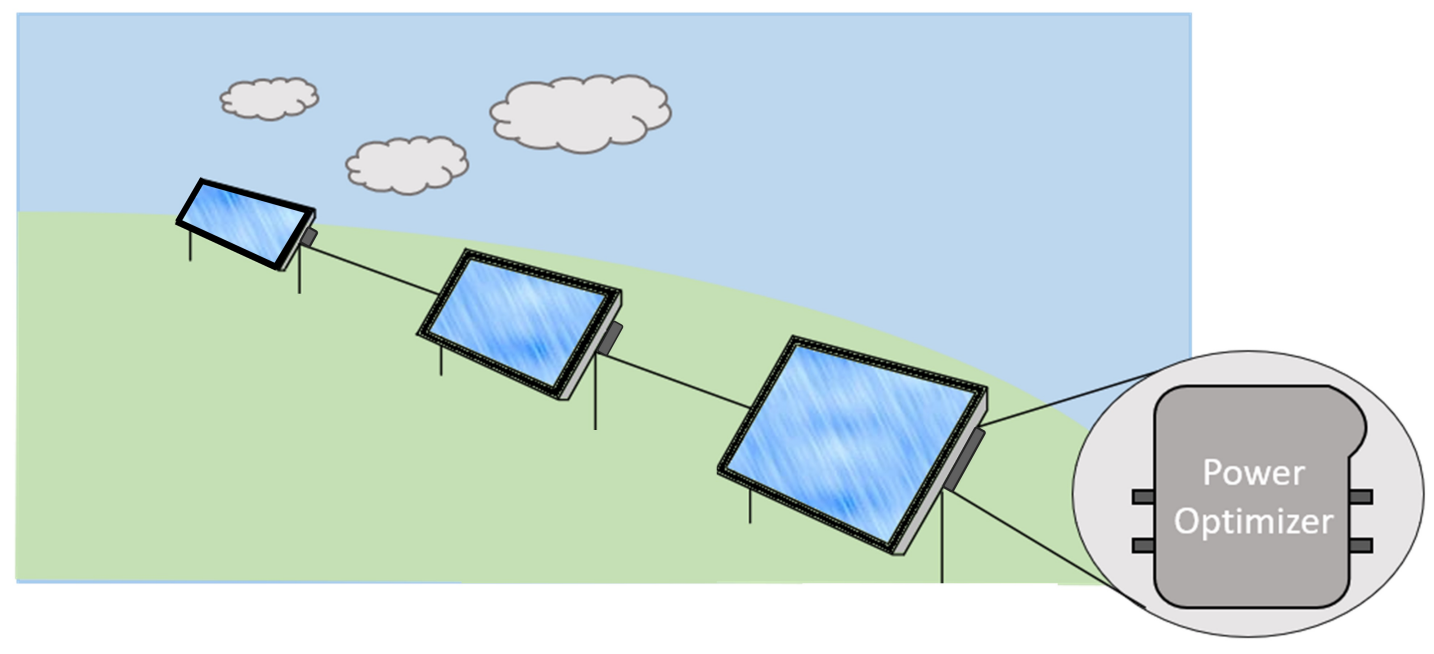

Figure 3.4: Test environment for simulation model.

\subsection{Improved Maximum Power Point Tracking}

Variable step or dynamic MPPT determines the global maximum power point (GMPP) faster than with a fixed step technique. During clear sky conditions the maximum power point is simple to deduce as only one maximum - the GMPP exists, as is shown in Figure 3.5(a). Dynamic step sizes are also beneficial during periods of partial shading as the system is less likely to be caught in a local maximum power point (LMPP), which is shown Figure 3.5(b). Setting the step size with 
respect to the distance from the MPP allows a reduction in steady state error and reduce oscillations around the MPP. This is discussed in more detail below.
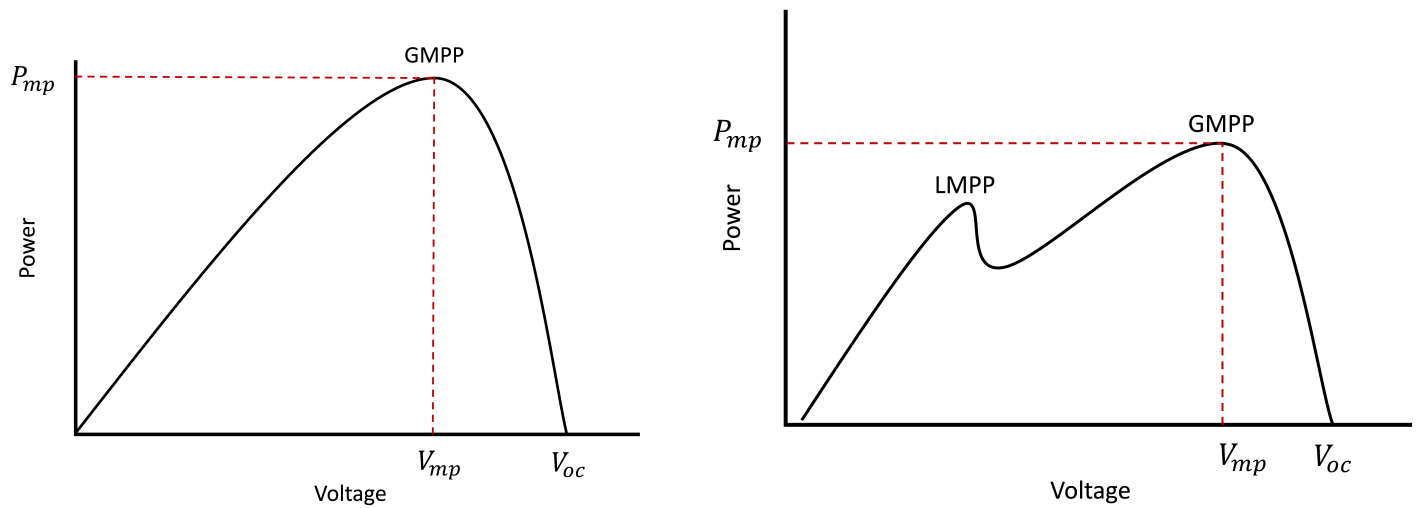

Figure 3.5: Maximum power points in (a) unshaded and (b) partially shaded conditions.

The dynamic MPPT model used in this thesis was proposed and simulated by [4]. They developed a variable step size algorithm that showed a reduced response time and achieved a higher efficiency than conventional perturb and observe and incremental conductance methods. Their method, derived from studies [40] [41], is different than a fixed step algorithm as the step size is adjusted in response to the rate of change of the irradiance. They noted that the conventional perturb and observe methods are more efficient for small irradiance changes around the MPP, while conventional incremental conductance methods are better suited for variable irradiance changes using larger step sizes. Small changes in irradiance produce small variations in the generated power between the measurement intervals and therefore do not require a large change in incremental step size. As expected, a large change in irradiance - perhaps caused by a rapid cloud cover - results in a large variation in power produced by the module. The system modifies the step size to best handle the large change to quickly determine the GMPP. This is illustrated using the flowchart which is further discussed in Appendix A.

The MPP found by the variable step MPPT algorithm is communicated to the external mode selection stage using bi-directional communication. The mode is determined based upon the maximum power production of the string and the load 
requirements, this is discussed further in the next section.

\subsection{Mode Selection and System Optimization}

The mode selection stage determines if the system should be operating in MPP mode or curtailment mode based on the string power at MPP and the maximum load power. Using bi-directional communication lines, the system optimizer compares the summation of the maximum power point produced by each module in the string with that of the load requested power. If the generation is less than or equal to the load request, the maximum power quantities are communicated to their respective modules without optimization. If generation exceeds the requested load power, the optimization engine will enable curtailment mode operation to avoid overgeneration.

The block diagram of the system optimizer is shown in Figure 3.6. The inputs to the system are the maximum power quantities for each module, as determined by the variable step MPPT algorithm, and the requested load power. For a string of $N$ modules, $N$ maximum power values will be communicated to the optimizer. A linear programming method is used to proportionally reduce the operating power point of each module based on the individual input MPP characteristics.

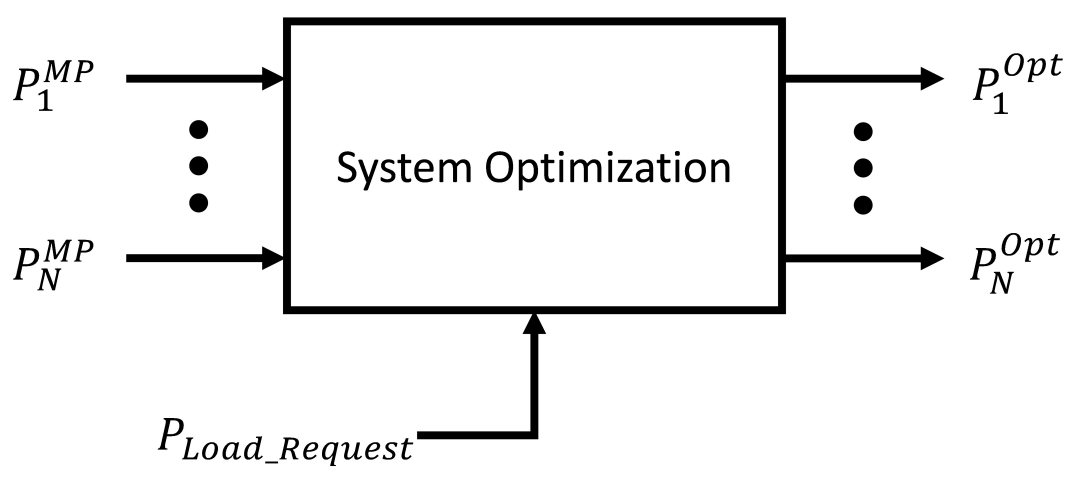

Figure 3.6: Block diagram of the system level optimizer.

Optimization is used to minimize a cost function, $f(x)$, subject to constraints imposed upon the system, further described in Appendix B. In this case, the operating point must be minimized such that the total string power equals the requested load value. Each of the operating powers determined by the optimizer are limited by the 
maximum and minimum power generation quantities, the modules maximum power and the constraint stating that the power must be greater than zero, respectively.

The optimization function is the summation of the maximum power point of each module $n$ in the string of $N$ modules subtracted by the requested load power:

$$
\sum_{n=1}^{N} P_{n}^{M P}-P_{\text {LoadRequest }}
$$

The output of the mode selection stage is the optimal power for each module in the string. The optimal power and voltage are returned to the appropriate module using physical or wireless bi-directional communication. The optimal power quantity for the module is used as an input to the fuzzy logic controller (FLC1) which performs ramp rate reductions.

\subsection{Designing the Fuzzy Logic Controller}

The power produced by PV systems is difficult to model as the dynamic generation is strongly nonlinear due to the input solar irradiance. For systems involving nonlinearities and lacking reliable analytical models, fuzzy logic control provides an inherent adaptability and control flexibility which is not present in conventional controllers. Designing a fuzzy logic controller for a complex model requires an understanding of how the inputs of the controller affect the output characteristics. This is the main merit over conventional techniques since qualitative knowledge and expertise about system behaviour can be incorporated. This knowledge is gained through an analysis of the output data. Here, the system was found to be very sensitive to rapid changes in power since the fraction $\frac{P_{n}}{P_{s t r}}$ is a function of two highly variable quantities. Periods of variable irradiance were further observed noting how the system responds to fast frequency fluctuations and the ideal case which eliminates high ramp rates. Deeper understanding of how the output is affected by the input allows for more sophisticated controller design.

For this system, four inputs are sufficient to drive the determination of an appro- 
priate reference voltage $V_{n}^{\text {ref }}$, for module $n$. The module and sting powers $P_{n}$ and $P_{s t r}$, respectively, are required. As ramp rate is the variable to be controlled, the rates of change of both module and total string power, $\frac{d}{d t} P_{n}$ and $\frac{d}{d t} P_{s t r}$, respectively, are also needed. The single output is the ratio $\left(\frac{P_{n}}{P_{s t r}}\right)^{\prime}$ which is multipled by the constant DC link voltage to obtain the reference voltage $V_{n}^{r e f}$. Since the currents $I_{n}$ through the modules are the same, and equal to the string current $I_{s t r}$, then $V_{n} P_{s t r}=V_{s t r} P_{n}$. Given the constraint on the string voltage as $V_{s t r}=120 \mathrm{VDC}$, the reference voltage after the fuzzy logic controller (FLC1) is:

$$
V_{\text {ref }}=\left(\frac{P_{n}}{P_{\text {str }}}\right)^{\prime} \times 120 \mathrm{~V}
$$

The fuzzy logic controller implements a fuzzy logic system, whose architecture is shown in Figure 3.7. Fuzzy logic introduces the concept of vagueness which differs from classical logic by existing within the range of 0 and 1. Fuzzy logic control was introduced by Dr. Lotfi Zadeh in 1965 to describe complex characteristics extending beyond the definition of classical logic. The process of designing the fuzzy logic controller is described in Appendix C.

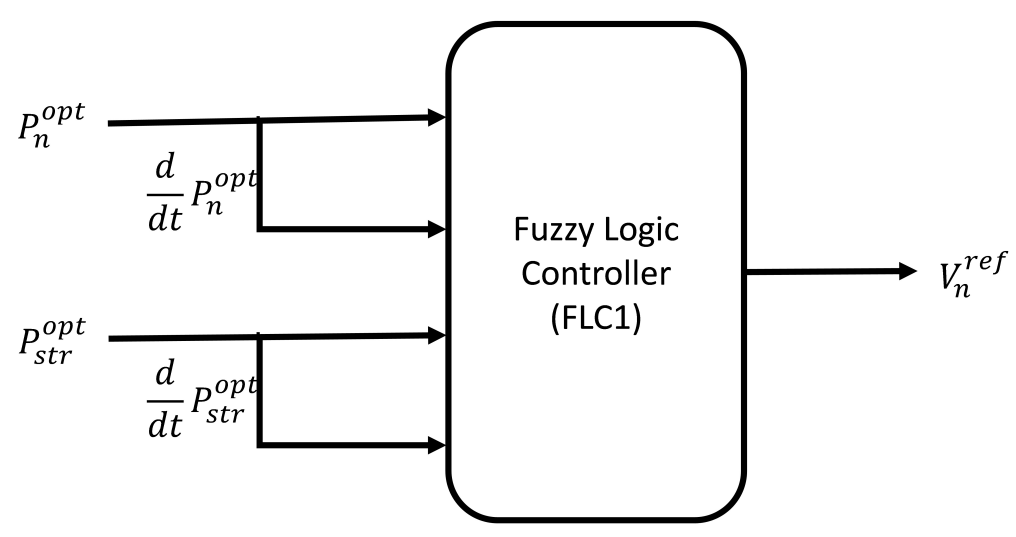

Figure 3.7: Block diagram of the proposed fuzzy logic controller.

The reference voltage determined by the fuzzy logic controller acts as an input to the DC regulation stage for grid connected and islanded systems. The output voltage is compared to the reference voltage to determine if it should be increased or decreased to meet the reference voltage. The design of the DC regulation stage is discussed in the next section. 


\subsection{Designing the DC Regulation Stage}

A buck boost converter can increase or decrease the output voltage to meet the requirements of the reference voltage. The reference voltage calculated by the fuzzy logic controller changes with respect to time, a DC converter such as a buck boost changes the output voltage to minimize the error between the calculated reference voltage and actual output voltage. A buck boost converter is required to ensure that the 120 VDC string voltage is maintained during operation. DC converters are tuned for the environment it functions in where the only variable conditions are the reference and output voltages. A grid connected system regulates the load thereby ensuring the design criteria such as the load is unchanged; a DC converter is designed for this operation and will function well. Islanded or grid disconnected systems experience variable load conditions, changing the load alters the design of the converter resulting in improperly tuned controller gains.

The components that make up a DC regulation stage are the controller, plant, and feedback loop, Figure 3.8. The feedback loop is an important design characteristic as the input and output values can be compared to determine the error $E(s)=V_{\text {ref }}-V_{\text {out }}$, which is the input to the controller stage. The controller, $G_{c}(s)$, is chosen to be a PI controller as it can maintain stability while minimizing the overshoot in the output response. The controllable parameter, the duty ratio, describes the on duration of the switches in the DC converter. The duty ratio is the input to the buck boost converter which controls the increase or decrease of the output voltage. Detailed buck boost converter design are found in Appendix D.

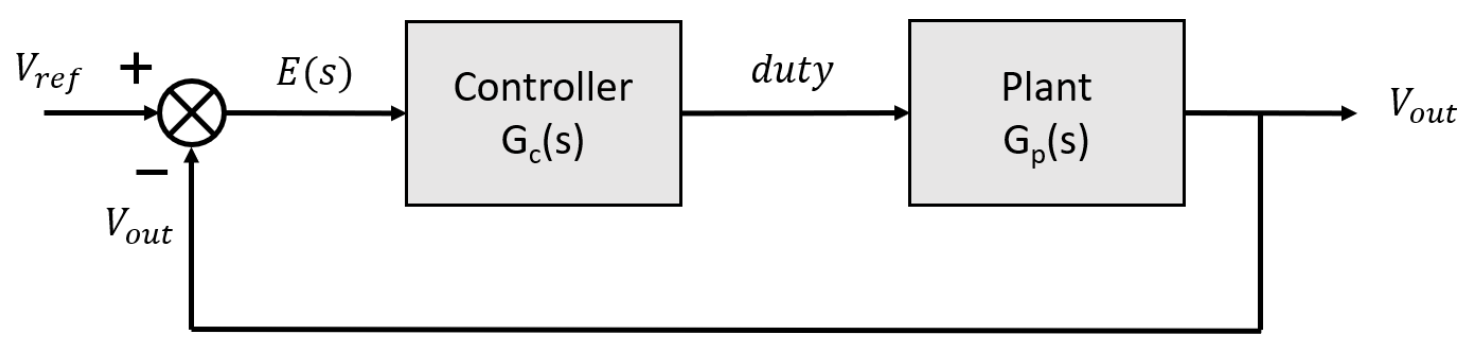

Figure 3.8: Feedback loop control system featuring controller and plant model. 
Islanded systems are susceptible to variable load conditions, the controller gains $K_{i}$ and $K_{p}$ must be re-tuned to accurately represent the changing load conditions, this is not customary in traditional DC converters. Conventional controllers such as proportional, proportional-integral, and proportional-integral-derivative are effective methods of controlling the duty cycle for DC regulation stages. When the design parameters are non-constant, for instance in the case with variable load conditions, the tuned controller gains are no longer optimized for the dynamic system thereby reducing the converter efficiency. Implementing a self-tuning gain controller allows for islanded systems to modify the tuned gain values to adapt to varying load conditions.

A fuzzy logic gain controller was implemented to manage load side variations to enhance conventional PI controller functionality [7]. The proportional and integral gains, $K_{p}$ and $K_{i}$ respectively, are the two parameters which will adaptively change with the varying load. The islanded system design, Figure 3.9, consists of the previous feedback DC regulation loop with an additional self-tuning controller placed before the PI controller. This model uses the error and the rate of change of the error as inputs to the fuzzy logic controller (FLC2) and the difference of $K_{i}$ and $K_{p}, \Delta K_{i}$ and $\Delta K_{p}$ respectively, as the outputs. The change quantities are added to the original gain values $K_{i}$ and $K_{p}$ to tune the controller gains in a changing load environment. FLC2 was designed by defining the membership functions and rule base of the system, similar to the work previously described in Chapter 3.4. Using a self-tuning gain controller reduces the losses due to unoptimized design parameters thereby increasing the efficiency in load varying systems. 


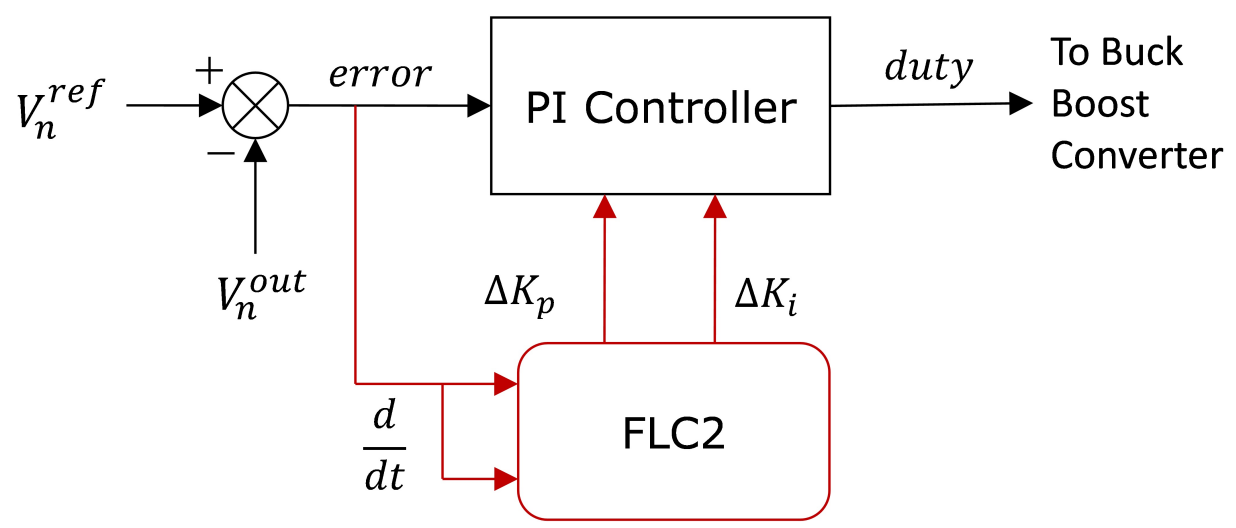

Figure 3.9: DC regulation stage block diagram with second fuzzy logic controller for islanded systems. 


\section{Chapter 4}

\section{Simulation Results and Discussion}

This chapter shows the simulations performed to validate the operations of each subsystem in the proof of concept MLPE design described in Chapter 3. The following results were produced in Matlab/Simulink 2019a using Simscape Electrical and Simscape Power Systems libraries as well as the Optimization and Fuzzy Logic Toolboxes also developed by Matlab. Further information regarding the simulation process is included in Appendix E. Unless stated otherwise, the results of this sections were simulated using measured spectral data collected in Ottawa Ontario using a Spectrafy SolarSIM irradiance measurement device. This chapter first summarizes the results obtained in each stage of device operation before comparing the total output power responses; the sections to be discussed are shown in Figure 4.1. 


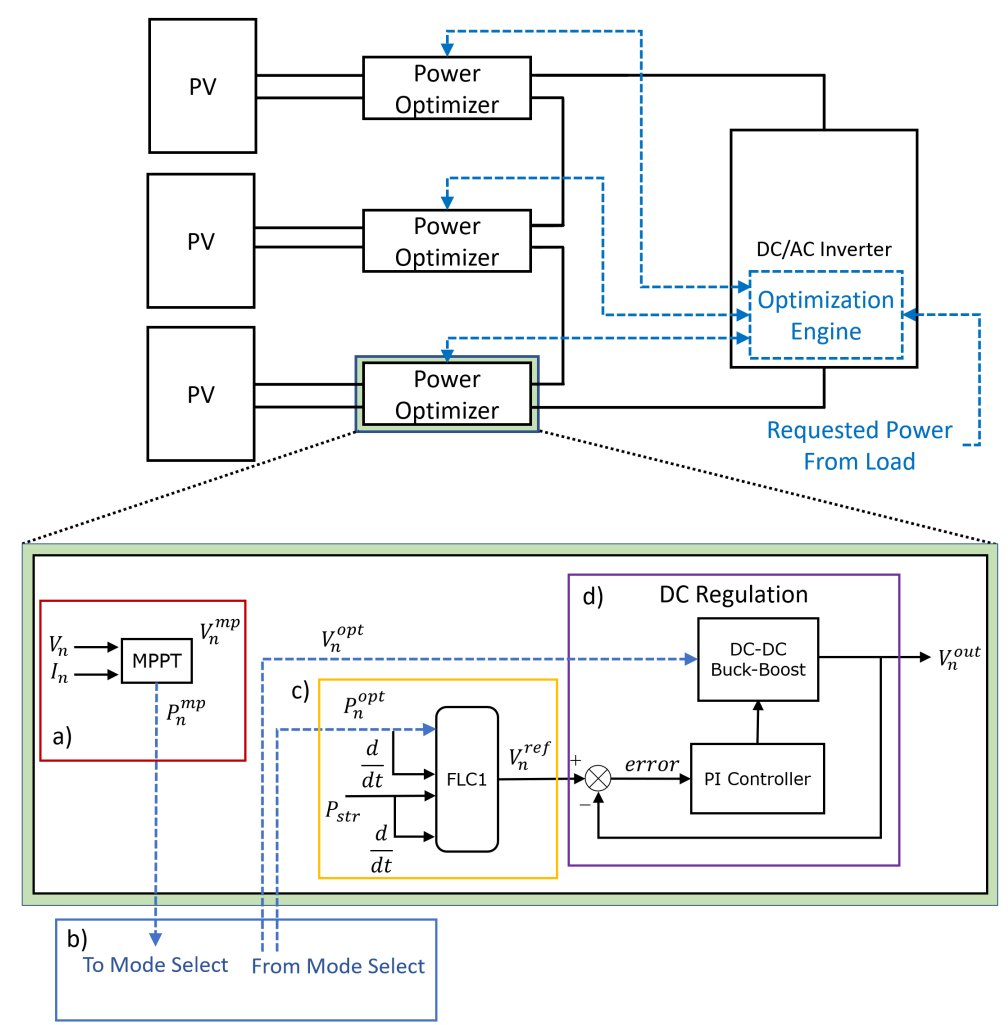

Figure 4.1: System level design with the four main operations: a) improved MPPT, b) system optimization, c) FLC ramp reduction, d) DC regulation.

\subsection{Panel Optimization}

Using a maximum power point tracking algorithm is vital for photovoltaic systems, but the choice of method depends largely on the specifications and needs of the design. The variable step perturb and observe $(\mathrm{P} \& \mathrm{O})$ algorithm described in section 3.2 was chosen to allow for better dynamic tracking across clear sky and variable irradiance conditions.

The impact of a variable step MPPT method was compared to a conventional P\&O approach using clear sky conditions, Figure 4.2. The tracked output voltage show similar results when simulated with both designs. As the benefit of the variable step MPPT algorithm presents most significantly during variable input conditions such as during rapid cloud shading; therefore, it is expected to see minimal improvements during clear sky conditions. 


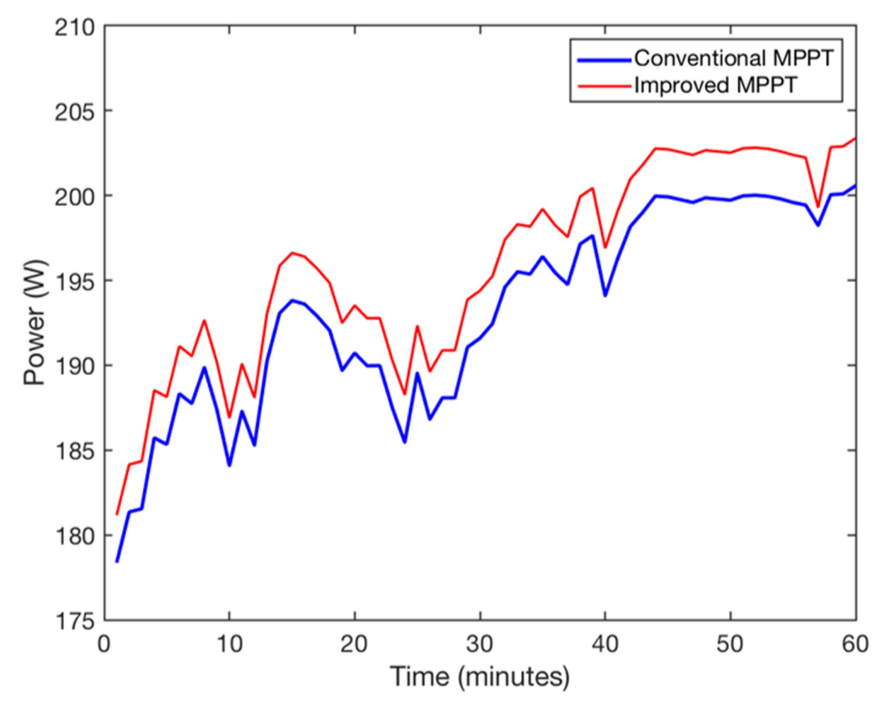

Figure 4.2: Improved MPPT operation in clear sky conditions.

Figure 4.3 shows the power generated by a one hour simulation on one panel in the string, the shape of the system is similar using both the conventional and improved MPPT methods. A high ramp rate is present at approximately three and seven minutes, as shown the improved method tracks a higher power quantity than the conventional approach. The variable step design manages the fast fluctuations by imposing a larger step size during higher ramp rates. During cloudy sky conditions the tracked power varies significantly however it is shown that a higher maximum power point is found using the improved model. The power produced during this interval operates well during rapid irradiance changes.

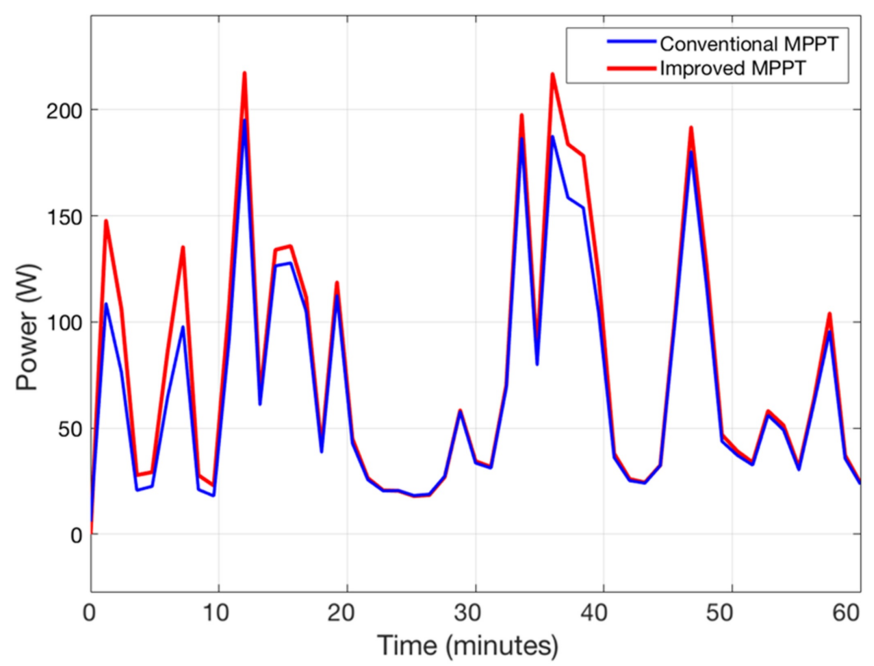

Figure 4.3: Improved MPPT operation in variable cloud conditions. 


\subsection{Mode Selection and System Optimization}

The mode selection stage determines the mode of operation, either MPP or curtailment mode, based on the string production at MPP and the maximum load power. During MPP mode, the mode select returns the tracked MPP to the appropriate MLPE device in the string. If curtailment operation is selected the central optimization engine determines the proportional contribution from each panel required to meet the maximum load requirements before returning the new optimal operation points to the respective module devices. In the next section, the focus will be on the dynamic control aspects, here the focus is on mode functionality.

When operating in MPP mode, the power produced by the individual panels is shown in Figure 4.4(a). A low requested string power, $200 \mathrm{~W}$, is imposed on the system to depict the faults with constant MPP operation. Figure 4.4(b) shows the power produced by the string greatly surpassing the requested value for approximately half of the operation period. Significant over generation can result in blackouts if the excess production is not properly managed.
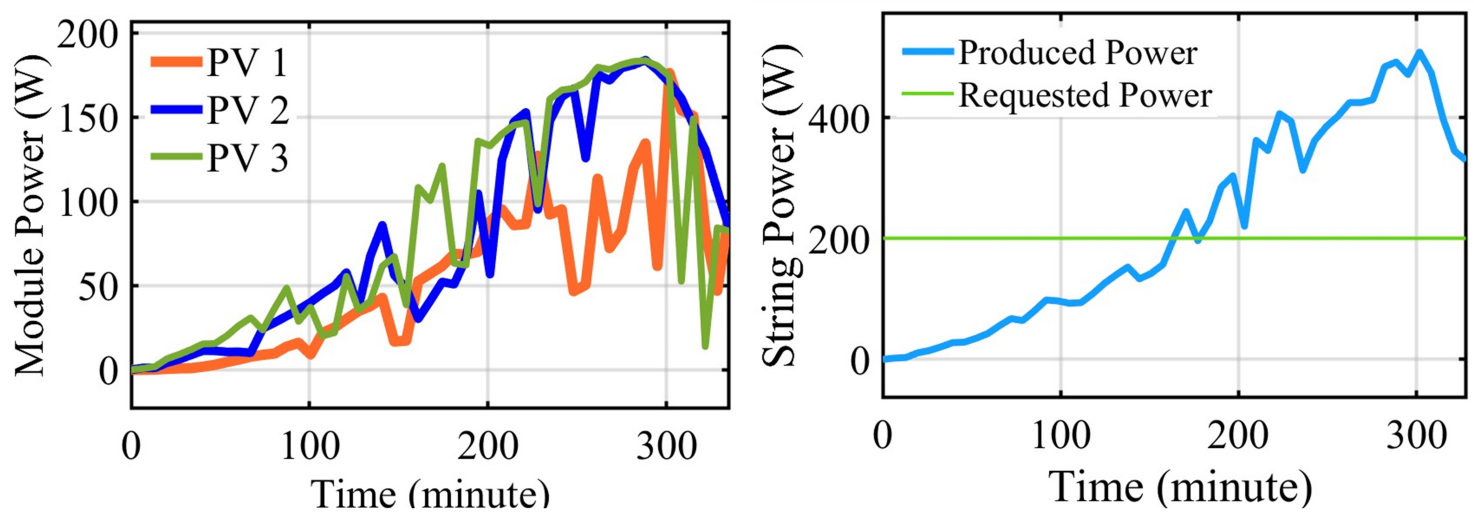

Figure 4.4: The power characteristics under MPP operation for (a) each module in the string and (b) the total string.

Curtailment mode is implemented to address overgeneration and stability concerns in the PV system. In this case the central optimization engine scales down the power production of each module so that the system meets load demands. The optimizer determines the shifts of each module's operating point to the right of the MPP, setting $V_{o p}$ and $I_{o p}$ as shown in Figure 4.5. Shifting to the right of the maximum 
power point was chosen in order to reduce the power quantity while maintaining approximately equal voltage.
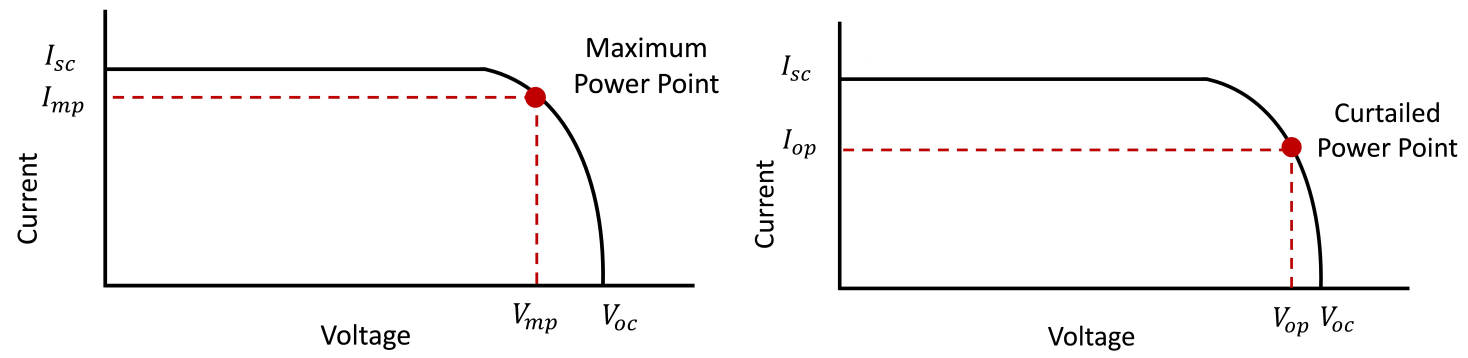

Figure 4.5: Current voltage characteristic curves while operating in (a) MPPT and (b) curtailment modes.

The result of operating in curtailment mode is shown in Figure 4.6 for a $200 \mathrm{~W}$ maximum. When the string power at MPP is greater than the requested string power the system operates in curtailment mode, thus mitigating over voltage concerns, details can be found in Appendix B. Figure 4.6(a) shows the operation of each module in the string. During MPP operation, between 0 and 160 minutes, each module is producing maximum power. Once the string power exceeds the power requested by the load, $200 \mathrm{~W}$, the power of the modules are reduced proportional to their maximum production. The results obtained through simulations show agreement between string power and requested power during periods of overgeneration. The mode selection accurately determines when to operate in MPP or curtailment mode based upon the dynamic PV generation and load conditions. Optimization is performed during curtailment mode to proportionally reduce the operating set points of each module in the string to meet the load demands.

This section focused on discussing the functionality of the mode selection stage. Both MPP and curtailment operations were discussed and validated using field data. The next section carefully studies the impact of the FLC on dynamic irradiance conditions. 

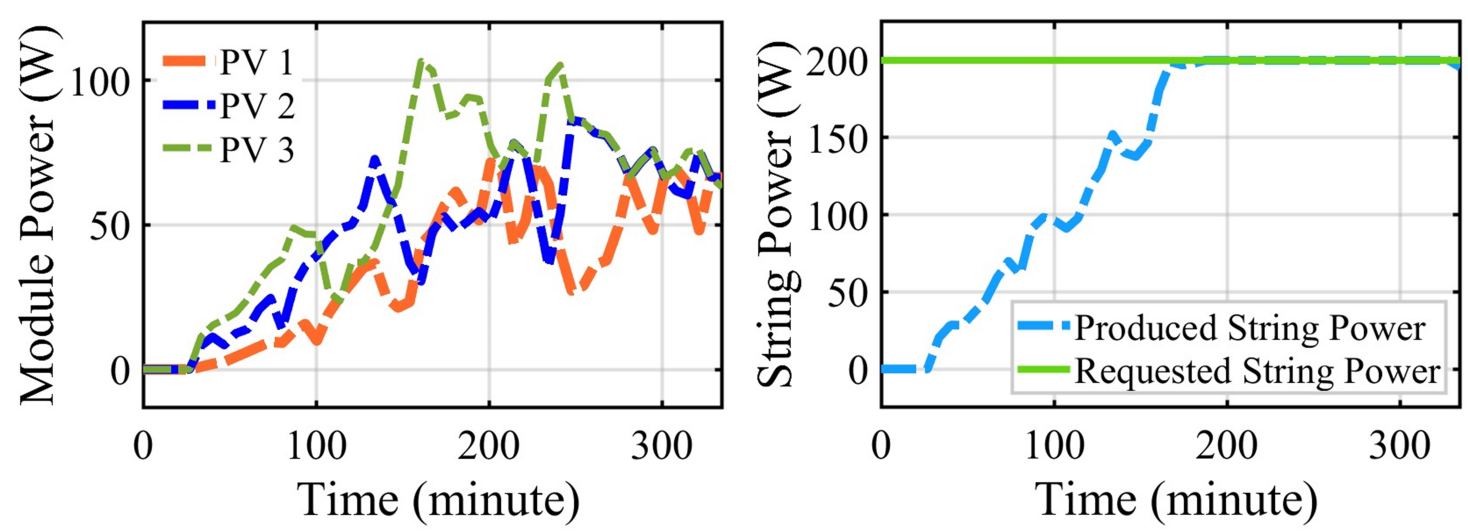

Figure 4.6: Power characteristics of the (a) individual modules and (b) entire string while when curtailment mode is enabled.

\subsection{Ramp Rate Reduction with Fuzzy Logic Con- trol}

We have considered the general behaviour from the operating mode perspective. Here we consider the dynamics from the control perspective, showing the improvement that can be obtained by a tuned fuzzy logic controller. Details of FLC1 can be found in Appendix C. The inputs to this subsystem are the operating power of the individual modules (as determined by the mode selection stage), the total string power, and their rates of change. These inputs are used to determine the power fraction that is multiplied by a constant DC link voltage to provide the reference voltage for the regulation stage.

This controller uses fuzzy logic to minimize the high ramp rates and voltage peaks caused by rapid irradiance fluctuations. The input to this subsystem is the operating power of the individual modules as determined by the centralized optimization stage. Using fuzzy logic, four input parameters are required to determine the power fraction to be multiplied by a constant DC link voltage to determine the appropriate reference voltage.

Figure 4.7 show the rates of change of the reference voltage determined by the FLC for one module in the string compared with rates directly calculated using Equation 3.2. These voltage ramp rates are numerically determined using experi- 
mental time series data collected in Ottawa Ontario in 2017 as input to the system. The ramp rates which are determined from the calculated reference voltage (dashed red curve) directly reflect the cloud induced ramping associated with solar irradiance, while those expressed by the FLC (solid blue curve) are shown to suppress these fluctuations. While this FLC is successful as a proof of concept design, there is room for improvement regarding the ease of implementation, the intelligence of the controller, and the computational speed. High ramping is present during periods of low irradiance when using the FLC design. This can be attributed to periods of negligible rates of change for one or both of the input power quantities. By design, when fuzzy logic controllers experience input quantities which confuse the rule base they choose a mid-range output, in this case a "Medium", thus resulting in higher than expected ramp rates during the beginning of operation. Updating the membership functions and rule base to better define the behaviour at low irradiance will address these discrepancies in future design iterations. Such improvements may address the current difficulties in very low irradiance conditions such as those experienced at the beginning and end of day.

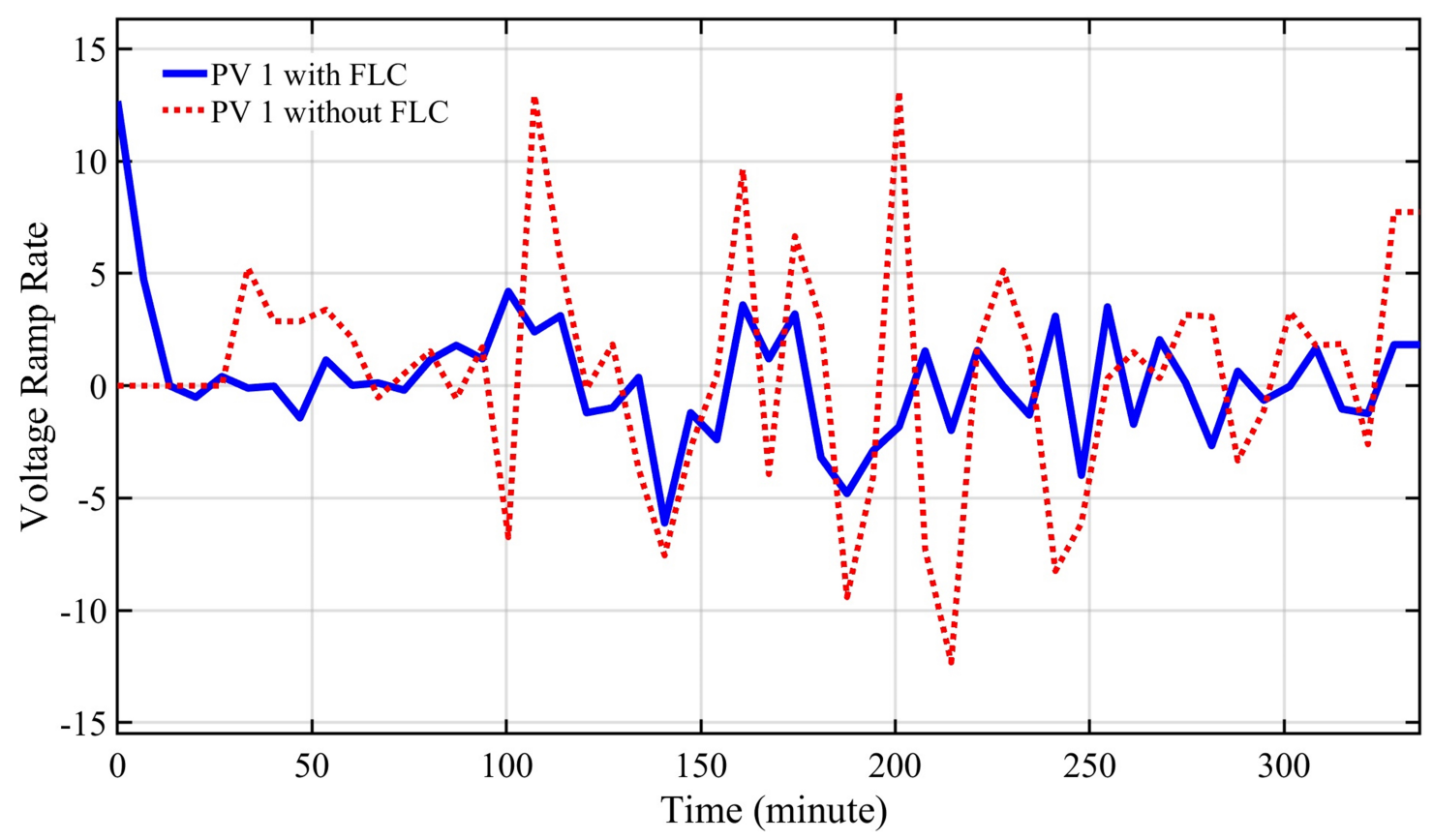

Figure 4.7: Ramp rate of reference voltage with and without the FLC1 stage enabled. 


\subsection{Regulation Stage}

The DC-DC buck boost converter can operate in two modes: one when connected to the grid and the other in grid isolated (islanded) systems. In a grid connected system, the PI controller gains will be adequately designed and tuned to operate well for the specific system and do not require further optimization. However, load variations in islanded systems, where grid impedances are high, produce a destabilizing transient disturbance. The PI controller, which determines the appropriate duty cycle for the buck boost, may not have the correct gains to meet the change in the system. To manage these fluctuations a second fuzzy logic controller, FLC2, has been introduced. Design details are provided in Appendix D.

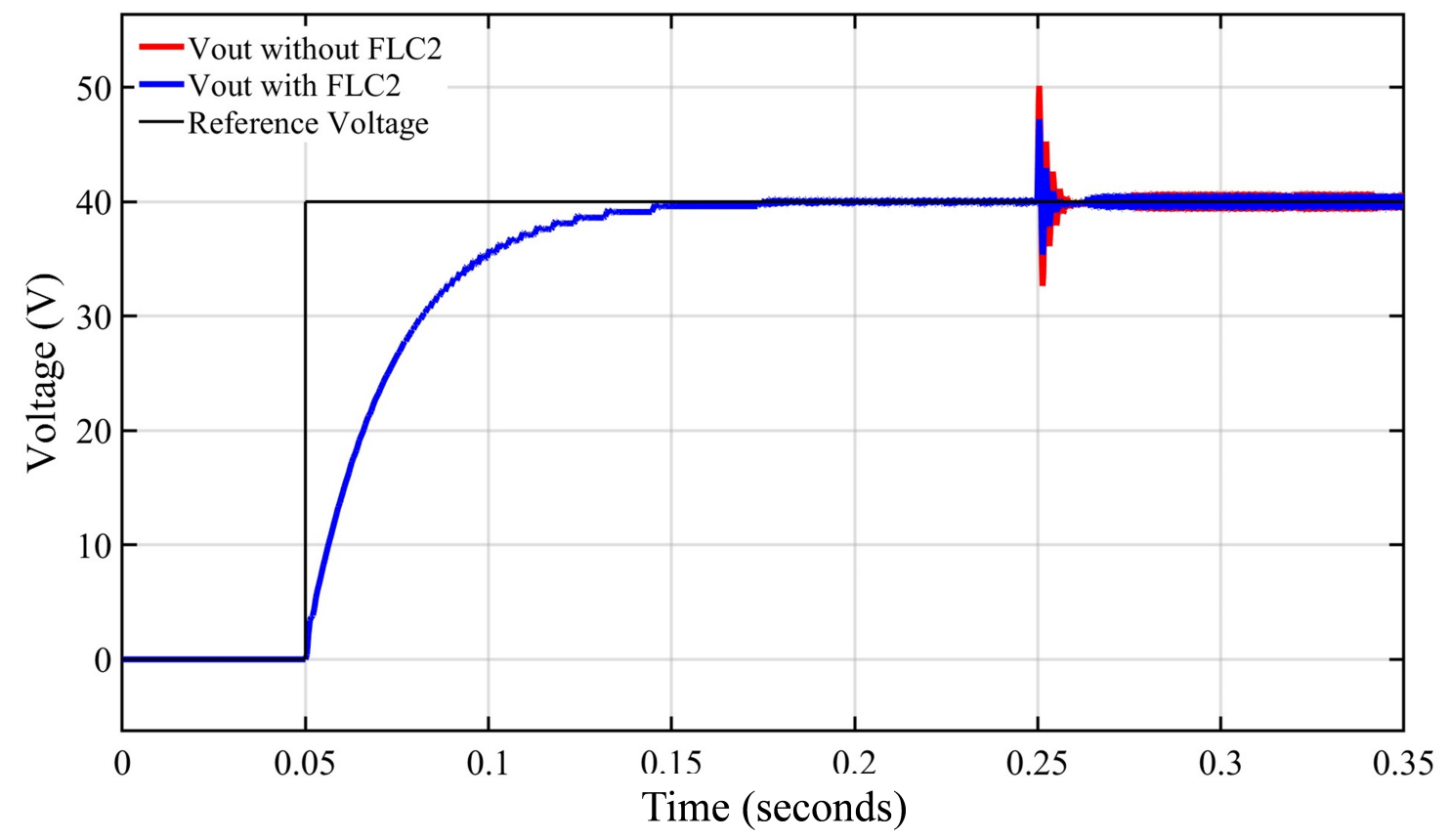

Figure 4.8: The effects of introducing a step response grid variability on a reference voltage with and without a self-tuning gain controller.

Figure 4.8 shows that the system operates similarly under constant load conditions, depicted between 0 and 0.25 seconds. When a load step response introduced at 0.25 seconds, which is correlated to a rapid increase in load resistance, the output voltage without FLC2 yields greater overshoot. The addition of FLC2 improves the dynamic response, although further investigation is clearly needed. Figure 4.9 zooms in on the region from 0.25 to 0.30 seconds to more clearly show the compara- 
ble ringing induced in both cases. Due to the uncertainties introduced by changing the load parameters, and thereby altering the design characteristics of the model, steady state error is inevitable. This proof of concept design proves that by introducing a self-tuning gain controller the error can be reduced, further optimization and tuning of FLC2 could further correct for this error.

As islanded systems are more influenced by variable load conditions, a more intelligent gain controller design should be implemented. A self-tuning gain controller using fuzzy logic allows for the designer to appropriately modify the controller gains to accurately reflect the changing load. The following section discusses the impact of the entire system design on output power production.

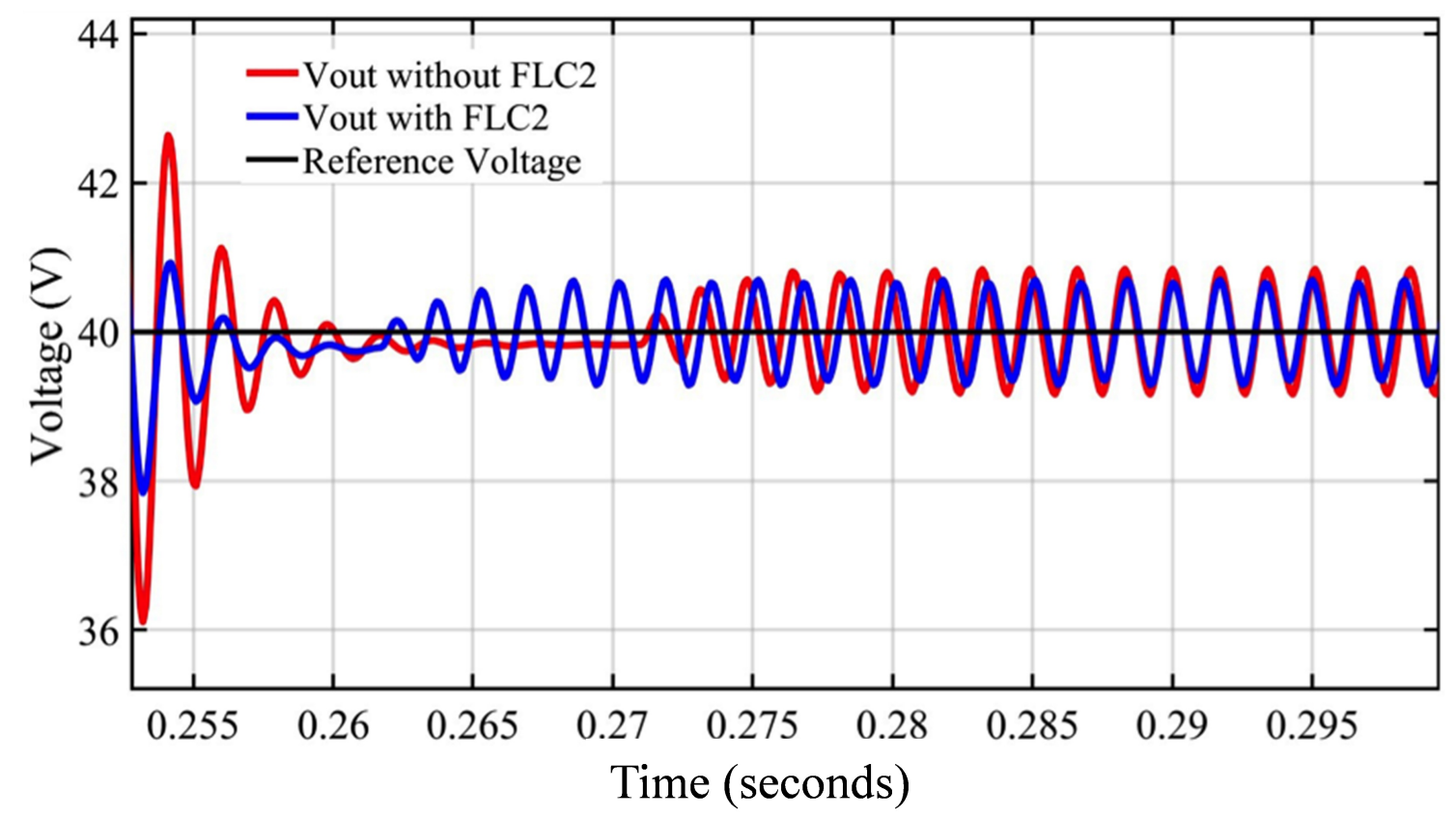

Figure 4.9: Oscillation experienced in output voltage under steady state operation.

\subsection{Output Power Comparisons}

The purpose of a power optimizer is to condition the DC power before the DC to AC inversion stage. The output power of the MLPO is discussed to prove the effect of the variable MPPT, mode selection, ramp rate reduction, and DC regulation stage on PV systems experiencing rapid cloud shading. 
The output power of the three-module power optimizer system has been determined under various control strategies. This is to allow for a proof of principle comparison to assess the design efficiency using variable input irradiance for a nominal $200 \mathrm{~W}$ curtailment. The results are shown in Figure 4.10 for the variable-time-step MPPT with simple DC regulation (red dashed curve) and the designed system with variable step MPPT, mode selection, ramp rate reduction, and DC regulation (blue curve).

The unoptimized curve, red, depicts traditional power optimizer functionality. The output voltage is regulated based upon the environmental conditions affecting the individual modules thereby reducing the negative partial shading effects of the string; however, it is important to note that this device only operates at the maximum power. As shown, the red curve greatly exceeds the requested load power of $200 \mathrm{~W}$ after 160 minutes of operation. This test depicts an increased production around midday caused by the expected high irradiance and a low consumption by users. A significant over production, shown in Figure 4.10, leads to system shutdown to eliminate the over-voltage concerns. The red curve is also heavily influenced by irradiance variability caused by rapid cloud shading as shown by the periods of high ramping such as at 172, 205, and 238 minutes.

The blue curve in Figure 4.10 represents the output string power of the power optimizer discussed in this thesis. Along with the variable step MPPT algorithm, the system also benefits from mode selection to determine the optimal operation in either MPP or curtailment mode. As shown, the device functions in MPP mode until 160 minutes, during this time the blue and red curves exhibit agreement with certain differences. The blue curve operating in MPP mode is smoother than the device without ramp rate reductions performed by FLC1. Periods of increased ramping such as 93 and 140 minutes are reduced yielding an output power which is less influenced by input irradaince variability. Furthermore, the blue curve is curtailed when the string power operating at MPP surpasses the requested maximum load power. The output power is greatly reduced to meet the load demands operating 
within an acceptable steady state error of $1.9 \%$.

The results show that the power optimizer design described in this thesis successfully operates in MPP and curtailment mode to eliminate significant over production during periods of low consumption. The voltage and power ramp rates are reduced to provide smoother transitions during rapid irradiance fluctuations. The output string power is regulated to maintain an appropriate steady state error around the requested load power while maintaining a constant string or DC link voltage in compliance with IEEE standards.

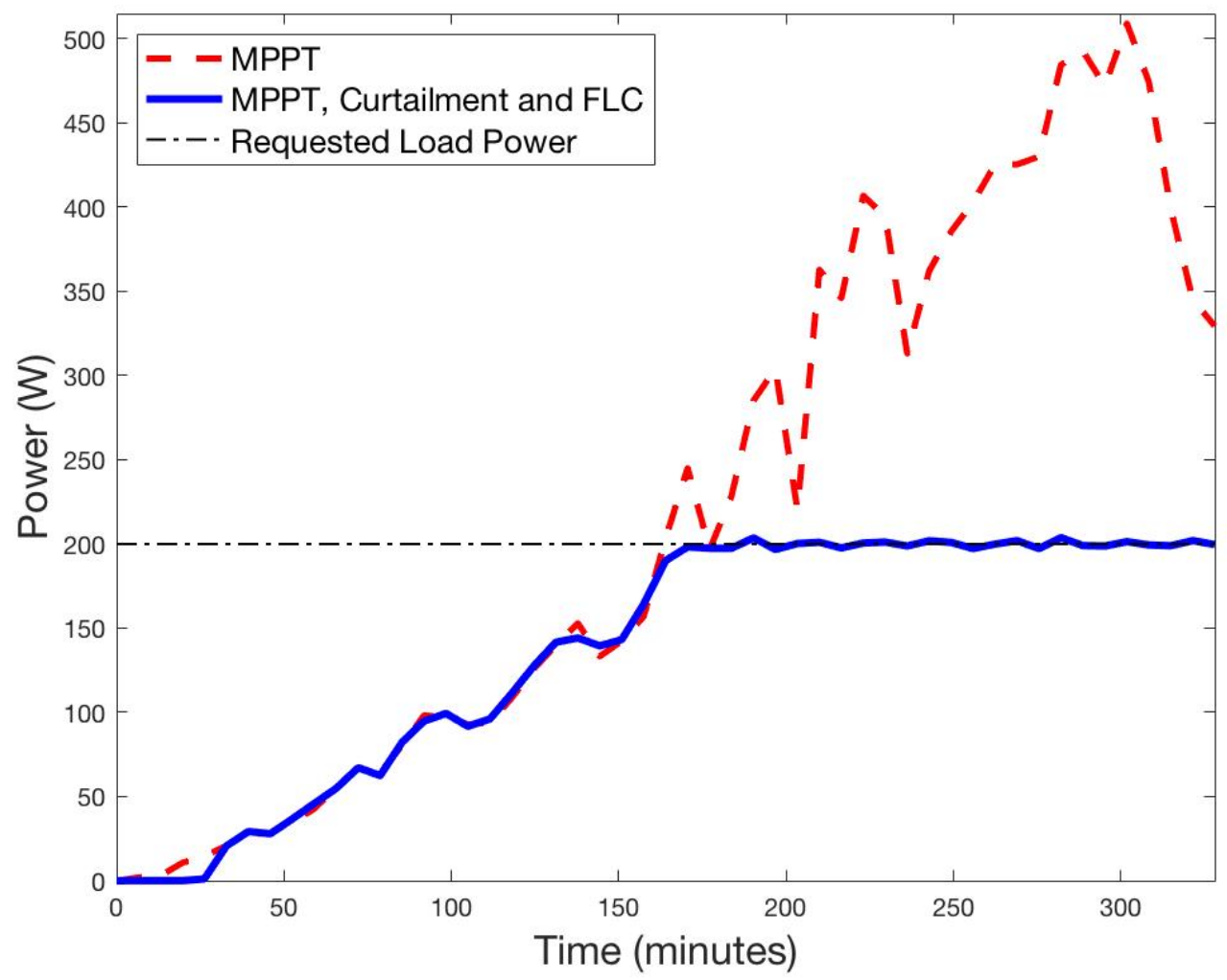

Figure 4.10: Output power comparisons of traditional MPPT and proof of concept architecture.

\subsection{Output Voltage Comparisons}

Maintaining a constant DC link voltage is a constraint imposed upon this system design. The summation of output voltage produced by each panel in the string must exist within the allowable per unit voltage range as determine by the North Amer- 
ican Electric Reliability Corporation (NERC). The standards described by NERC regarding the allowable range for the string voltage of grid connected PV is 0.90 to 1.10 per unit voltage [42]. Figure 4.11 shows that the improved power optimizer design produces output string voltage characteristics between 0.94 to 1.06 per unit voltage. The green band shows the NERC permissible range. This design operates within the allowable range as described by the standards for North American grids.

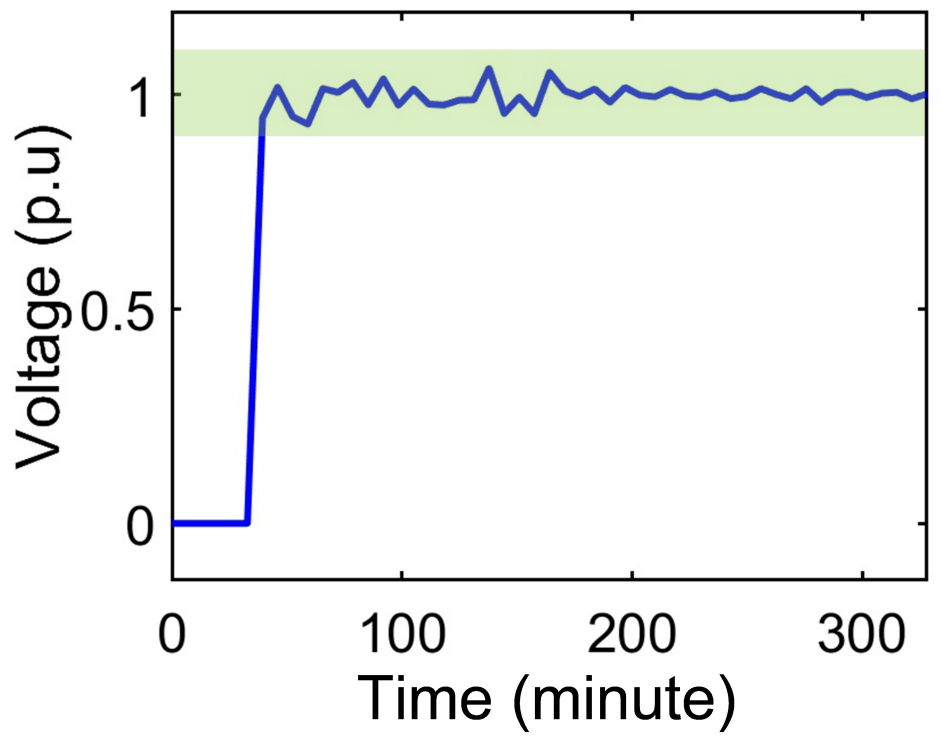

Figure 4.11: Output string voltage (DC link voltage) fluctuations during variable irradiance conditions. 


\section{Chapter 5}

\section{Conclusions}

Photovoltaic systems offer an attractive method of clean energy generation which is expected to experience significant growth within the energy mix. The intermittent nature of the solar resource limits the controlability of the PV production. Variable irradiance conditions, like those experienced during rapid cloud shading, introduce stability concerns that were addressed using a module-level power optimizer approach.

This design used a variable step MPPT algorithm to track the MPP with greater accuracy when operating in variable irradiance conditions. A mode selection stage compared the production of the string at MPP to the requested maximum load power to determine when to operate in MPP or curtailment mode. The central optimization engine used linear programming to proportionally reduce the MPP of each module in the string to meet the maximum power request. A FLC was designed to reduce the effects of high ramp rates caused by rapid cloud shading to produce a smooth reference voltage less influenced by irradiance variability. A self-tuning gain controller was designed for islanded systems using fuzzy logic to appropriately tune the controller gain characteristics during changing loads.

Variable step MPPT algorithms, such as that developed by [4], introduced an advanced method to track the maximum power with greater accuracy in changing irradiance conditions. The improved technique was compared to a conventional perturb and observe algorithm. The improved method determines a step size in the 
hill-climbing approach which changes with respect to the ramp rate of the input irradiance. The ramp rate will be large during periods of variable irradiance, this allows for the MPP to be tracked faster and with fewer computations, and the step size will be small when the irradiance is relatively constant. In clear sky conditions, the variable step method tracked the maximum power produced by the PV with slightly higher accuracy than the conventional method. Generally the tracking in clear sky conditions did not yield significantly better results than the conventional approach. During periods of highly variable sky conditions, like those in the presence of cumulus clouds, the improved method tracks higher MPPs than with basic perturb and observe.

The mode selection stage determines if the optimizer should operate within MPP mode, when the load requires maximum production, or curtailment mode, when the generation must be reduced to meet load demands. The mode select returns the optimal power and voltage quantities for each module in the string. The optimal voltage and power quantities, $V_{\text {opt }}$ and $P_{\text {opt }}$ respectively, reflect the maximum power values $V_{M P P}$ and $P_{M P P}$ when operating in MPP mode and the proportionally reduced $V_{\text {curt }}$ and $P_{\text {curt }}$ in curtailment mode operation.

Mode selection was validated using field data obtained in Ottawa Ontario. A low load power request was imposed on a system to detect operation in both modes. The mode selection effectively operated within MPP mode, thereby returning the MPP to the respective MLPO ramp reduction stage on each module (FLC1). Similarly, when the power produced by the string exceeded the maximum request the system switched to curtailment. When operating in this mode the maximum powers determined by the MPPT stage were reduced proportional to their MPP values to meet the maximum power demands thereby eliminating significant overgeneraton.

Fuzzy logic control uses non-classical logic which exists between the conventional binary results, 0 and 1 , to introduce vagueness into the control system. The idea of flexible control was an optimal choice for this system as the non-linearity of the input irradiance conditions are difficult to model. Rapid cloud cover introduces fast 
irradiance changes resulting in high ramp rates caused by shading at the cloud edge. The fuzzy logic controller design required an understanding of how the inputs affect the output as well as the desirable outcome of the controller for various conditions. The impact of the input characteristics - the optimized power of the module, the string power, and their rates of change - were observed using field data to determine the effect on the output reference voltage as defined by Equation 3.2. The fuzzy logic controller was designed to reduce or eliminate high ramp rates for a variety of input conditions. In the case of high ramping, the controller was designed to largely ignore the rapid change. A large quantity of rules, further described in Appendix C, were designed by testing field data and heuristic optimization to validate this proof of concept design. The output reference voltage is less affected by rapid irradiance changes caused by rapid cloud shading and reduced the ramp rates during MPP and curtailment mode to produce smoother transitions during clear and cloudy sky conditions.

A DC regulation stage increases or decreases the output voltage of the MLPO to meet the reference voltage determined by the fuzzy logic controller. A feedback loop, controller, and plant are designed for specific operation using parameters tuned for the system. As grid islanded systems are more susceptible to the impact of variable load conditions the PI controller gains become improperly tuned for the changing load environments. A self-tuning gain controller was designed using fuzzy logic to determine the appropriate change in controller gains $K_{p}$ and $K_{i}$ during load fluctuations. Tuning the controller gains increases the efficiency of the regulation stage, the self-tuning controller reduces the overshoot experienced during changing load conditions while reducing settling time and steady state ripple when compared to the untuned case.

This design could be further improved by considering a controller design with increased intelligence and adaptability, perhaps machine learning. During periods of overgeneration this design curtails power to reduce the production of unused power. A bi-directional charge controller could be implemented within this system to charge 
an energy storage device during periods of high generation and low consumption to mitigate undergeneration concerns.

This thesis details the background, design, and simulation results of an improved power optimizer for PV systems. The device effectively reduces the effects of rapid partial cloud shading on strings of varying lengths. Ramp rate reduction and active power curtailment offer a level of control not commonly available for intermittent renewable energy generators. This device increases the reliability of future renewable dependent power grids which are no longer limited by partially shaded environments. 


\section{Appendix A - Improved MPPT}

The variable step MPPT algorithm flowchart is shown in Figure A.1. This algorithm has been adapted from [4] and simulated by the author using Matlab/Simulink 2019a.

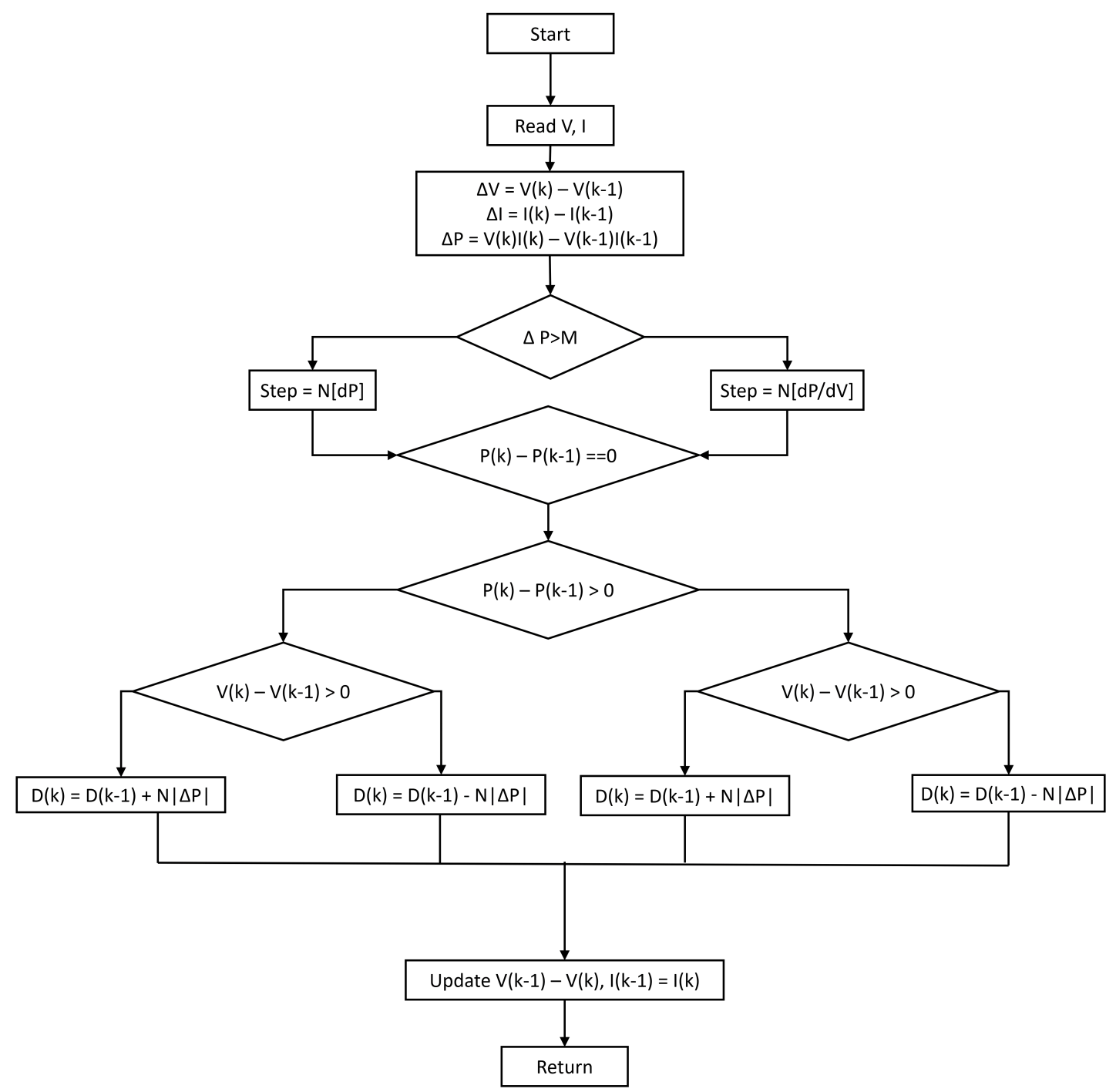

Figure A.1: Variable step MPPT algorithm [4] 
Similar to conventional hill-climbing methods, voltage and current are measured and the incremental changes for voltage, current, and power are calculated. The change in power is compared to a predetermined value which represents the expected MPP assuming a small step size. The new step size is used to perturb the system and determine if the maximum power constraints have been met, Figure A.2.

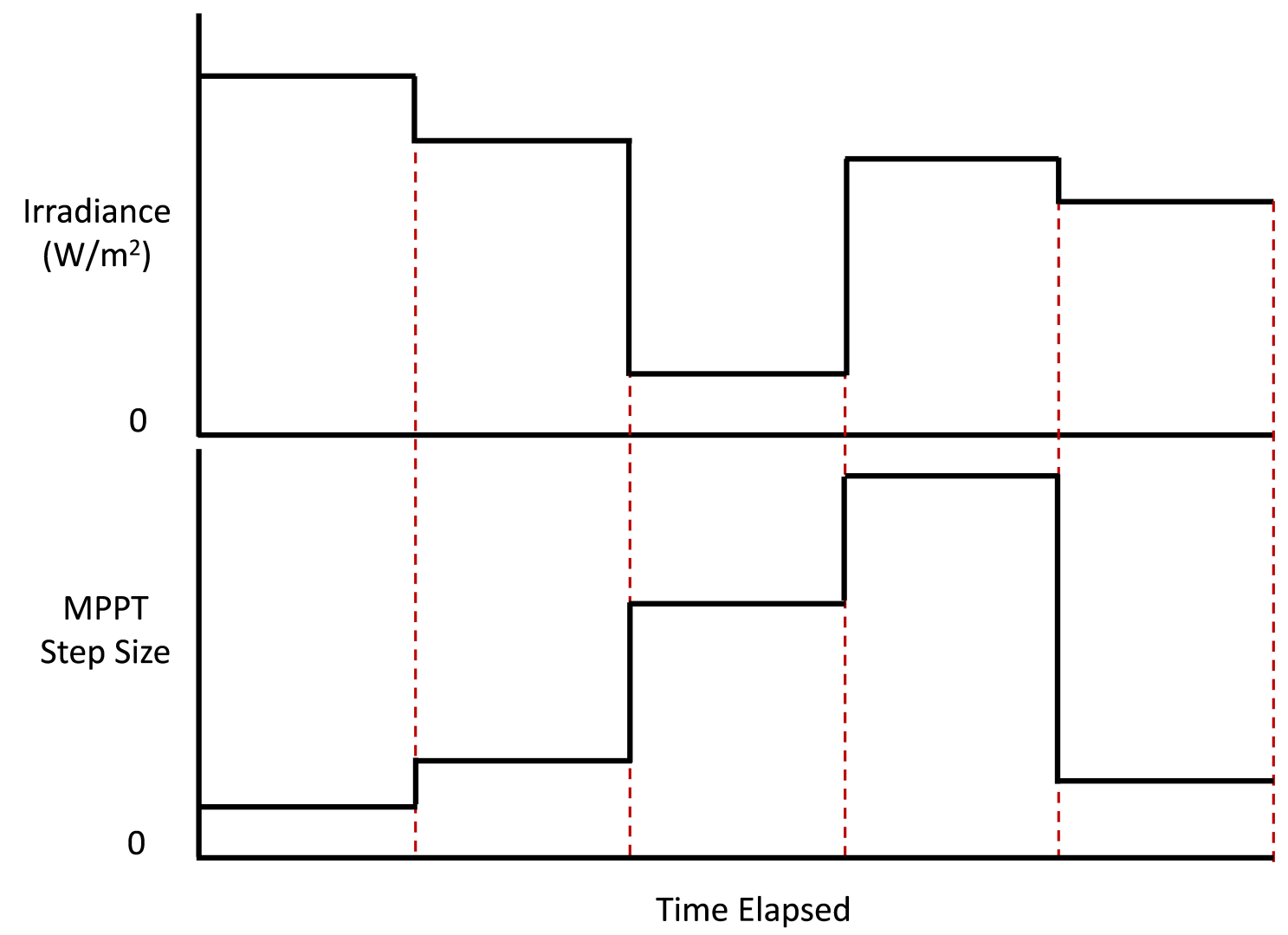

Figure A.2: The dffect of variable irradiance on step size. 


\section{Appendix B - System}

\section{Optimization}

Using the Matlab Optimization Toolbox, interior-point linear programming was performed using fmincon. The Matlab Optimization toolbox offers five methods of optimization using fmincon: interior-point, trust-region-reflective, sqp, sqp-legacy, and active-set. The interior-point algorithm was chosen as it effectively manages large and sparse problems making this approach scalable to strings of various sizes. Interior-point optimization can minimize the objective function with rapid speed while effectively recovering from $\mathrm{NaN}$ and INF inputs. Interior-point methods are often used to solve both linear and nonlinear convex optimization problems which contain inequalities as constraints.

The simulated optimization engine requires the requested load power and the minimum and maximum power quantities for each of the $N$ modules in the string. The central system optimizer, responsible for mode selection and curtailment, can be adapted for strings of various length. The optimized power quantities for each of the modules, $P_{n}^{o p t}$, are determined by the Opti.m function responsible for finding the minimum power of each module to meet the demands of the system. A minimum power generation of one watt is applied to each of the modules to ensure that the power greater than zero constraint is met. The requested load power is required to determine when the system must operate in maximum power point or curtailment mode.

The optimization function is the summation of the maximum power point of 
each module $n$ in the string of $N$ modules subtracted by the requested load power, Equation 3.1. The optimization algorithm is presented below. An initial value is required for each of the outputs, represented by a 1 x $N$ zero matrix. The equality and inequality constraints are represented by $A, b, A e q$, and beq; these values are empty matrices as the optimization depends on the allowable upper and lower bounds. The $l b \_u b$ quantities represent the bounds where the solution can exist; these values are determined by the MPP of each module and the minimum power constraint. The outputs of the optimizer are represented by $X_{n}$ for all modules in the string.

$$
\begin{aligned}
& 1 \text { function }[\mathrm{x} 1, \mathrm{x} 2, \mathrm{x} 3]=\operatorname{Opti}\left(\mathrm{x} 1 \_\min , \mathrm{x} 2 \_\min , \mathrm{x} 3 \_ \text {min, } \mathrm{x} 1 \_\right. \text {max } \\
& \left.\mathrm{x} 2 \_\max , \quad \mathrm{x} 3 \_\max , \mathrm{X}\right) \\
& 2 \quad \mathrm{x} 0=[0,0,0] ; \\
& 3 \quad \mathrm{~s}=\operatorname{abs}(\mathrm{x}(\% \mathrm{~d})+\mathrm{x}(\% \mathrm{~d})+\mathrm{x}(\mathrm{d})-\% \mathrm{~d}) ; \\
& 4 \quad \mathrm{f}=\operatorname{sprint}(\mathrm{s}, \quad 1,2,3, \mathrm{X}) \text {; } \\
& 5 \quad \mathrm{lb} \_\mathrm{ub}=\left[\mathrm{x} 1 \_\min , \mathrm{x} 1 \_\max ; \mathrm{x} 2 \_\min , \mathrm{x} 2 \_\max ; \mathrm{x} 3 \_\min , \mathrm{x} 3 \_\max \right] \text {; } \\
& 6 \quad \mathrm{x}=\operatorname{fmincon}\left(\mathrm{f}, \mathrm{x} 0,[],[],[],[], \mathrm{lb}_{-} \mathrm{ub}(:, 1), \mathrm{lb}_{-} \mathrm{ub}(:, 2)\right) \text {; } \\
& 7 \quad \mathrm{x} 1=\mathrm{x}(1) ; \\
& 8 \quad \mathrm{x} 2=\mathrm{x}(2) ; \\
& 9 \quad \mathrm{x} 3=\mathrm{x}(3) ; \\
& 10 \text { end }
\end{aligned}
$$

A three-module string was simulated using constant and step function input quantities. Larger strings with more modules were simulated to determine the abilities of the mode selection and central optimization stage. No additional latency was observed when testing up to fifteen modules per string; therefore, larger systems are only limited by the speed of bi-directional communication within the system. Figure B.1 shows the maximum power point in red and optimized power point in black for each module in the string as well as the total string power. During curtailment mode, each PV power is reduced proportionally to its production; therefore, higher producing modules contribute more power than lower producing panels. A 
step function was imposed on $P V_{1}$ reducing from $200 \mathrm{~W}$ to $100 \mathrm{~W}$ at 25 seconds, the remaining panels are producing constant power of $210 \mathrm{~W}$ and $80 \mathrm{~W}$ respectively. When the power produced by $P V_{1}$ is reduced, the other panels in the string increase to accommodate the change. The higher producing modules increase their production more than the lower producing panels in the string. The output string power maintains constant operation at the maximum $300 \mathrm{~W}$ even during variable power production.
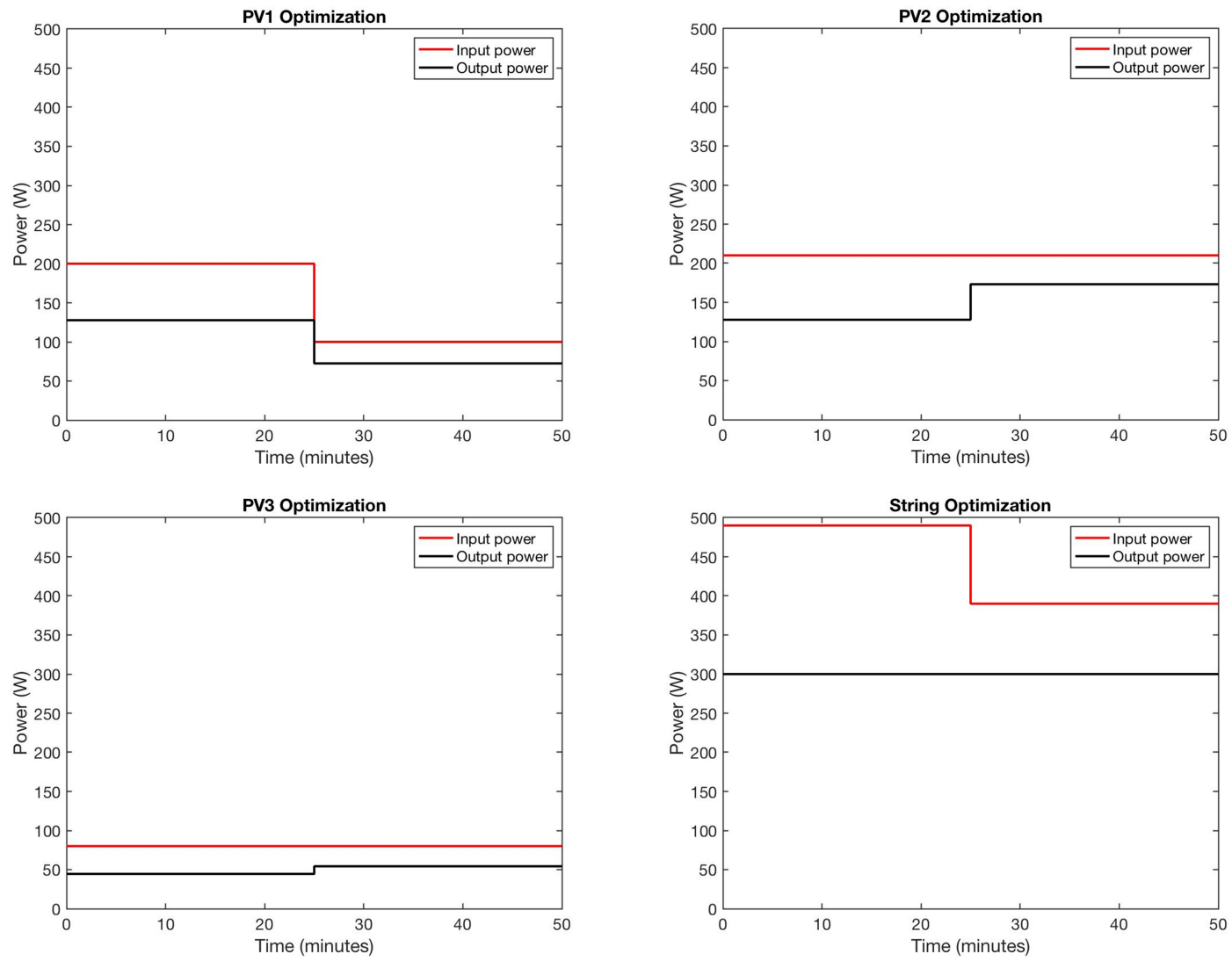

Figure B.1: Simulation results for the central optimization stage of a three PV string. 


\section{Appendix C - Fuzzy Logic Control (FLC1)}

The input to a fuzzy logic controller is a numeric value which is mapped to a linguistic variable using membership functions during the fuzzification stage, the inference engine determines the output response based on the input behaviour, and the output linguistic variable is converted to a numerical value in the defuzzification stage. A linguistic variable is used to describe a range of numeric quantities for each input or output. The number of linguistic variables and the nature of the membership functions is determined by the designer, based on system insight. Here, the linguistic variables are roughly assigned to crisp input numbers through the use of trapezoidal and triangular membership functions, shown in Figure C.1, for both power and voltage, as well as power-rates-of-change. Linguistic variables are convenient for fuzzy logic control as they describe a scalable range of numerical inputs thus providing increased adaptability during variable operating conditions. The trapezoidal and triangular functions were chosen to limit the possible overlap to only two linguistic variables.

As shown in Figure C.1(a) for power and voltage, five linguistic variables Low (L), Low-Medium (LM), Medium (M), Medium-High (MH), and High (H) are chosen to be sufficient to achieve the desired controller accuracy for the system. However, seven linguistic variables - Negative-High (NH), Negative-Medium (NM), Negative-Low (NL), Zero (ZE), Positive-Low (PL), Positive-Medium (PM), and Positive-High $(\mathrm{PH})$ - are needed for power-rates-of change values. 

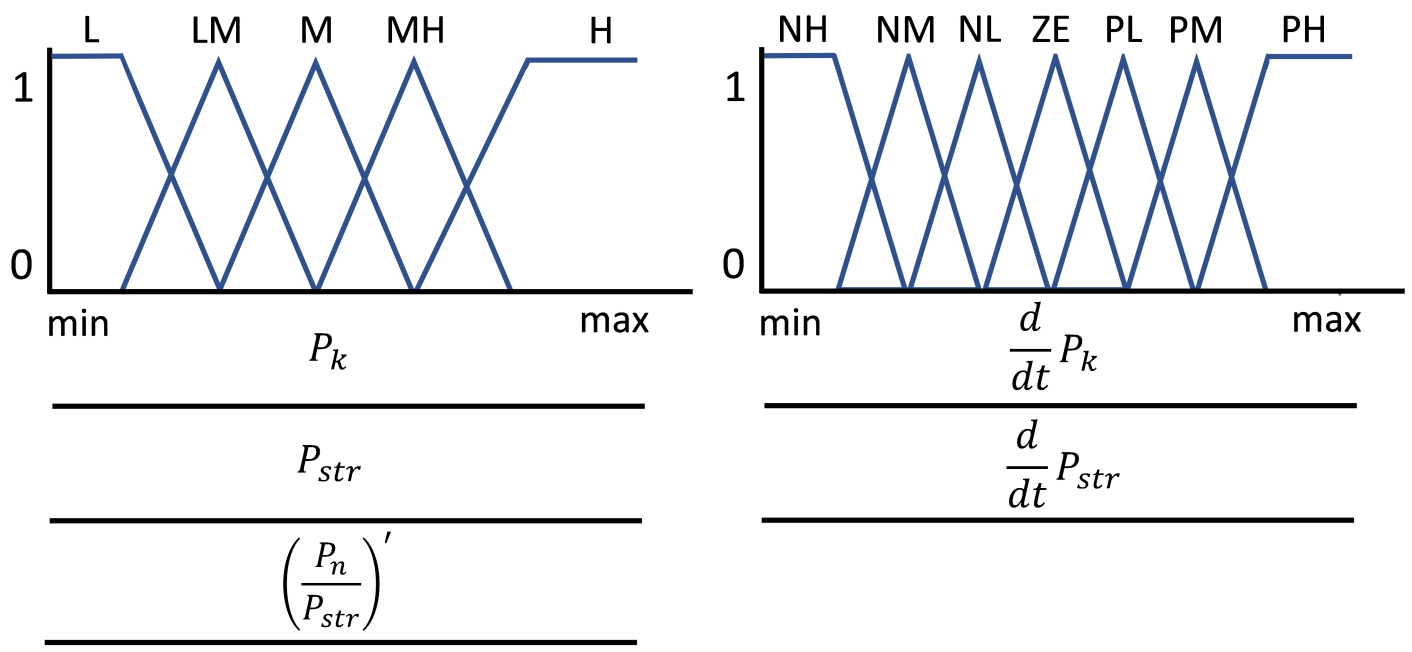

Figure C.1: Membership functions for designed for FLC1 for (a) the power and voltage linguistic variables and (b) the rates of change.

The inference engine determines the output response for specific conditions at each input quantity through a designed rule base. The quantity of linguistic variables used to describe the input and output characteristics affects the accuracy and the number of determined rules. The rules are setup as "If (input1) and (input2) and (input3) and (input4) then (output) occurs" for each of the combinations of linguistic variables. As expected, a large number of linguistic variables produces a larger number of rules. The quantity of variables must adequately describe the behaviour of the system; controllers with too few rules risk overgeneralizing and lacking detail while a large number of rules impacts the speed and computational requirements. The choice of representing the linguistic variables this way was determined experimentally, further information regarding the design and testing of various numbers of linguistic variables can be found below. This controller has four inputs with five and seven linguistic variables each resulting in a rule base of 1024 rules, represented by Figure C.2. 


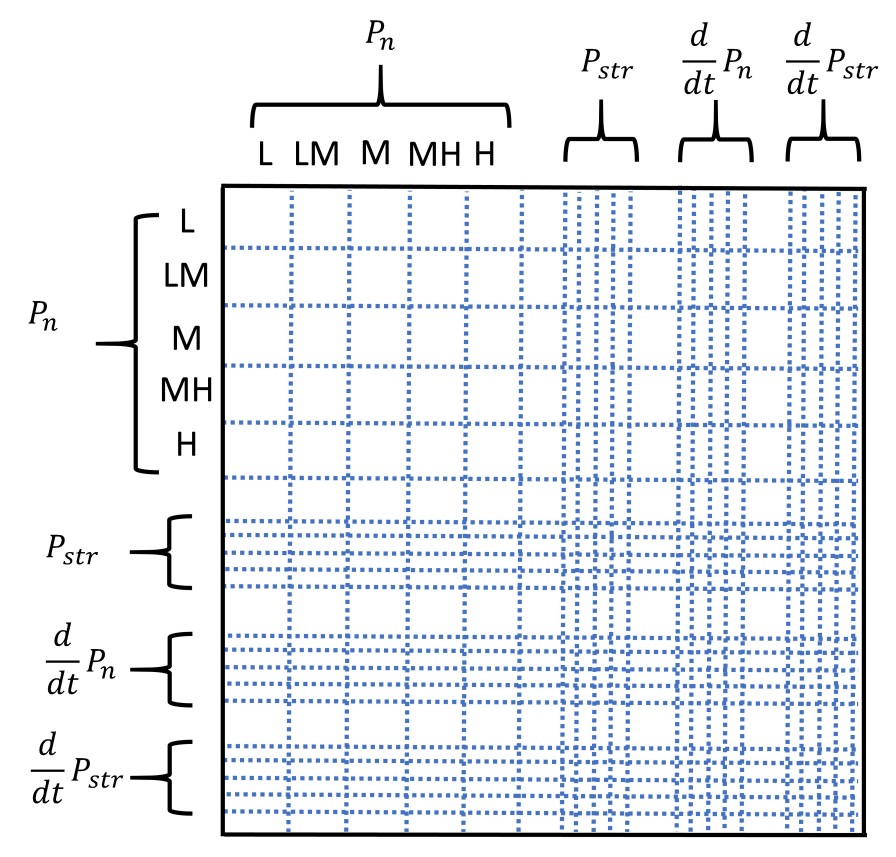

Figure C.2: Representation of the quantity of rules necessary to determine the response of the output based upon input conditions.

Once the degree of fit for the output is determined, the defuzzification process is used to convert a linguistic variable to a crisp numerical quantity. A variety of defuzzification methods are available such as maximum membership principle, centroid method, weighted average method, mean-max membership, center of sums, center of largest area, and first of maxima and last of maxima. For this design the centroid method, specifically the center of gravity centroid method, was chosen. The center of gravity divides the entire region into smaller portions using vertical sections. For each portion the area and center point are found before the center of gravity is determined using the following function where $\mu_{c}\left(x_{k}\right)$ is defined by a discrete membership function.

$$
x=\frac{\sum_{k=1}^{K} x_{k} \mu_{c}\left(x_{k}\right)}{\sum_{k=1}^{K} \mu_{c}\left(x_{k}\right)}
$$

The output in this case is represented by the function of power fraction $\left(\frac{P_{n}}{P_{s t r}}\right)^{\prime}$ thereby the crisp output value exists between zero and one. 
Variable string power conditions were used to test the impact of three fuzzy logic controller designs with different quantities of linguistic variables, Figure C.3. The output reference voltage (per unit voltage) was produced using three, five, and a combination of five and seven linguistic variables, Figure C.3(b). The uncontrolled case, the green curve, represents a system without a fuzzy logic controller or ramp rate reduction efforts. The uncontrolled voltage is largely affected by the changes in input conditions resulting in high ramp rates. Introducing a fuzzy logic controller with three linguistic variables for each input and output results in a reference voltage with reduced ramping when the rate of change is high. The reference voltage is limited by the few linguistic variables imposed on the controller thereby over generalizing the effect of ramp rates while being negatively impacted by high ramping. The five variable controller design produces lower voltage than the previous cases however little differentiation between the impact of low and high ramp rates is recorded. A consideration which has been neglected thus far surrounds the impact of both positive and negative rates of change. The combined five and seven variable design introduces additional descriptors to encompass the positive and negative ramping, as shown by the blue curve, the ramp rate is largely reduced. This design shows change when the ramp rates are low however experience limited change during highly positive or negative ramping.
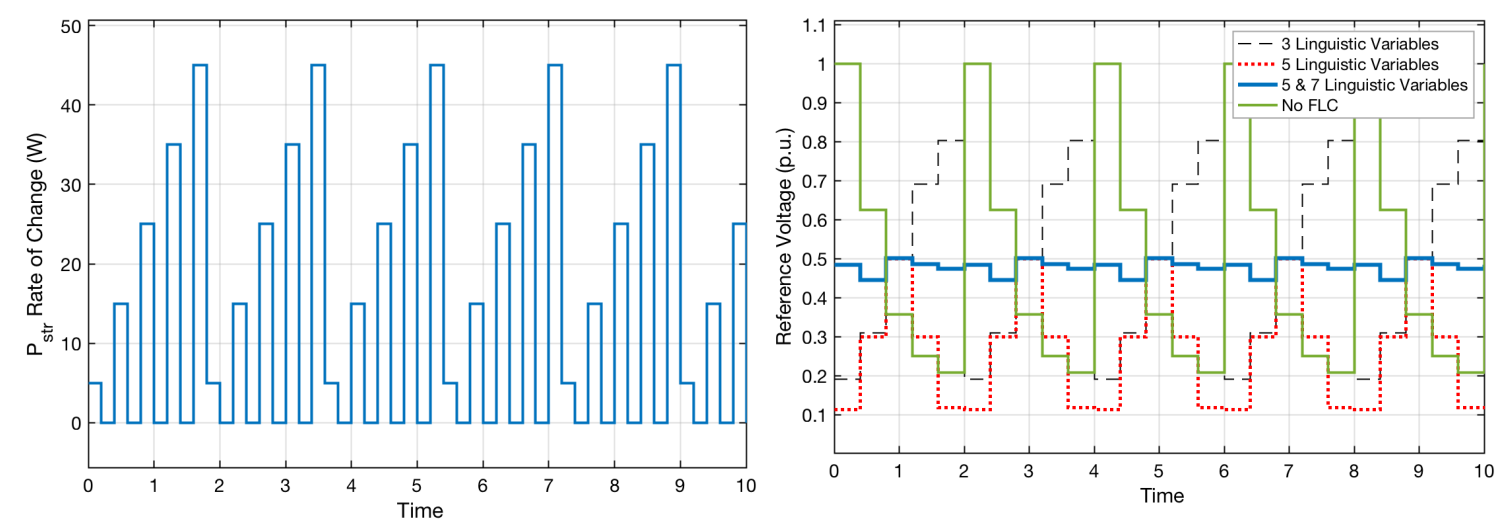

Figure C.3: (a) The input power change and (b) output response of FLC1 designs featuring different number of linguistic variables. 
The ramp rate reduction stage utilizes four inputs to determine the output ratio to be multiplied by the DC link voltage to obtain a reference voltage. The input quantities are numeric values which must be fuzzified and mapped to a linguistic variable using membership functions. Figure C.1 show the membership functions for the inputs and output. The triangular membership functions are equally distributed to described the interior linguistic variables while the trapezoidal functions are used to describe the maximum and minimum quantities. The range of the power values $P_{n}$ and $P_{s t r}$ are set by the rated power of the modules and string respectively. The maximum and minimum values for the rate of change were determined experimentally by observing the rates of change of field data.

To describe the functionality of FLC1 let's assume that the numeric quantities for module power, string power, rate of change of module power, and rate of change of string power are $30 \mathrm{~W}, 172 \mathrm{~W}, 8.3 \mathrm{~W}$, and $-38 \mathrm{~W}$ respectively, depicted in Figure C.4.
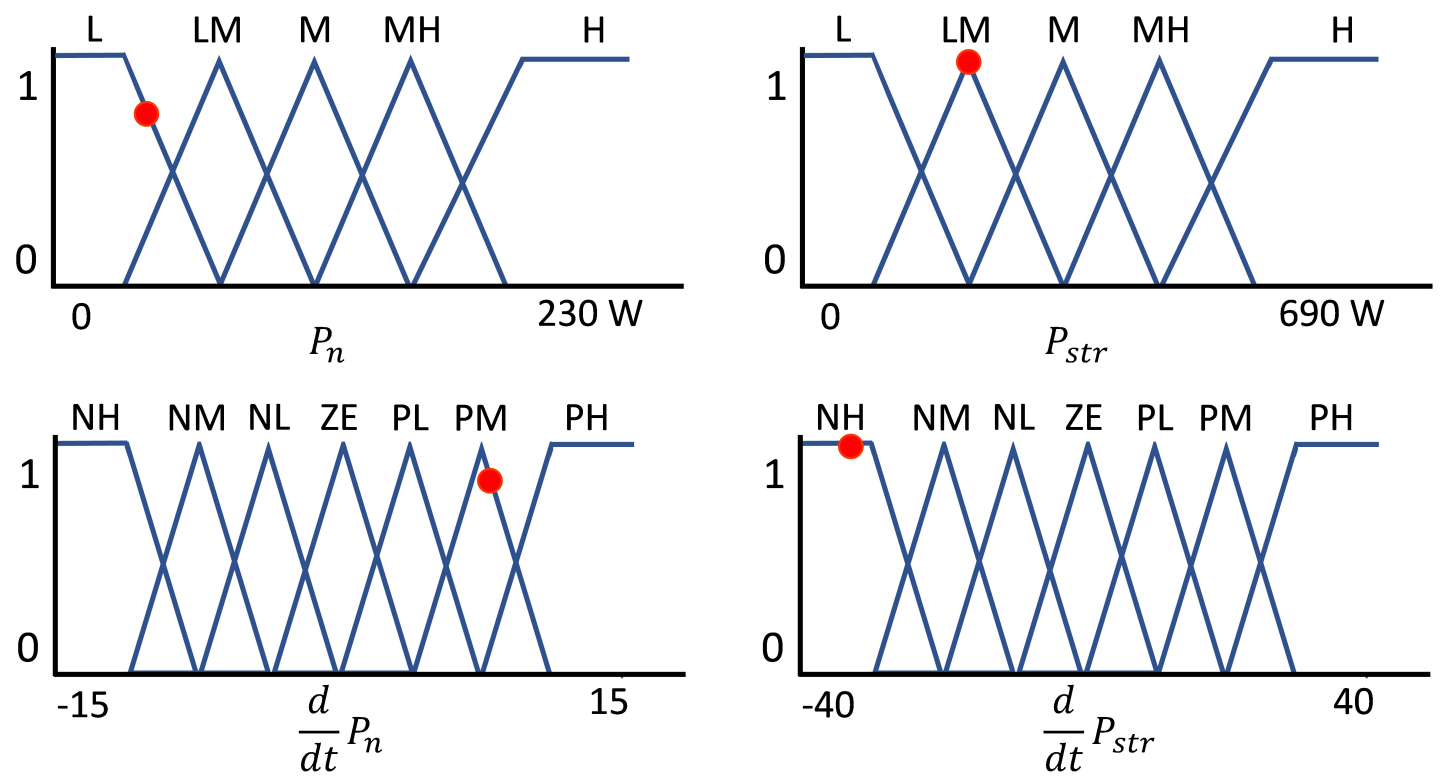

Figure C.4: Example of input quantities for FLC1.

Mapping the numeric values to linguistic variables is accomplished using membership functions. The fuzzy linguistic variables are summarized in the table below. 
Table C.1: An example of crisp input values and the fuzzified linguistic variables for each.

\begin{tabular}{|c|c|c|c|c|}
\hline & $P_{n}$ & $P_{\text {str }}$ & $\frac{d}{d t} P_{n}$ & $\frac{d}{d t} P_{s t r}$ \\
\hline Crisp Input & $30 \mathrm{~W}$ & $172 \mathrm{~W}$ & $8.3 \mathrm{~W}$ & $-38 \mathrm{~W}$ \\
\hline Linguistic Variable & $\mathrm{L}$ & $\mathrm{LM}$ & $\mathrm{PM}$ & $\mathrm{NH}$ \\
\hline
\end{tabular}

As a four input one output fuzzy logic model of this size is difficult to summarize, a two step simplification method is depicted in Figure C.5. Figure C.5(a) shows a rule base that is used to describe the impact of the rate of change for a power, $P_{X}$, where $X$ can represent either the module, $n$, or the string, str. This rule base determines the linguistic variable used to describe the power quantities when the impact of the rate of change is considered.

\begin{tabular}{|c|c|c|c|c|c|c|c|}
\hline$\gamma$ & $\mathrm{NH}$ & NM & NL & ZE & PL & PM & $\mathrm{PH}$ \\
\hline L & L & L & L & L & L & LM & L \\
\hline LM & LM & L & LM & LM & LM & M & LM \\
\hline M & M & LM & M & M & M & $\mathrm{MH}$ & M \\
\hline $\mathrm{MH}$ & $\mathrm{MH}$ & M & $\mathrm{MH}$ & $\mathrm{MH}$ & $\mathrm{MH}$ & $\mathrm{H}$ & $\mathrm{MH}$ \\
\hline H & $\mathrm{H}$ & $\mathrm{MH}$ & $\mathrm{H}$ & $\mathrm{H}$ & $\mathrm{H}$ & $\mathrm{H}$ & $\mathrm{H}$ \\
\hline
\end{tabular}

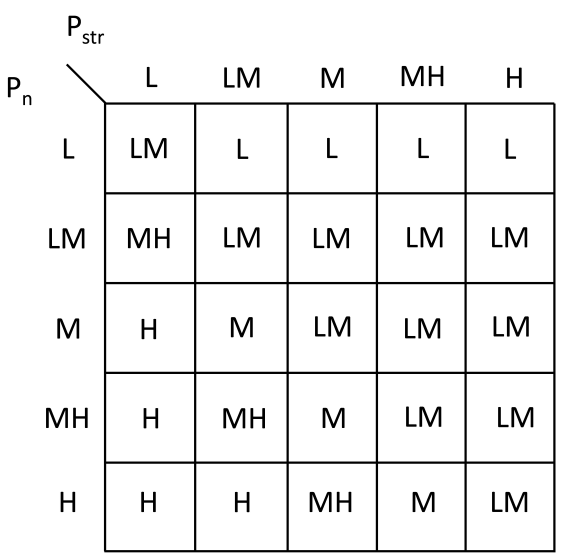

Figure C.5: Fuzzy logic rules for determining (a) the impact of the rate of change on power quantities and (b) the ratio $\left(\frac{P_{n}}{P_{s t r}}\right)^{\prime}$ required to calculate the reference voltage.

By design, the power should not change when experiencing a high positive or negative ramp rate. It is assumed that a change will occur when a positive or negative medium is imposed on the power value. Therefore, using the inputs described in Table C.1, the impact of the rate of change on the module and string power is summarized in Table C.2. 
Table C.2: Impact of rate of change determined using Figure C.5

\begin{tabular}{|c|c|c|}
\hline & $P_{n}$ & $P_{\text {str }}$ \\
\hline Initial Variable & $\mathrm{L}$ & $\mathrm{LM}$ \\
\hline Impact of Rate of Change & $\mathrm{PM}$ & $\mathrm{NH}$ \\
\hline \hline Result & $\mathrm{LM}$ & $\mathrm{LM}$ \\
\hline
\end{tabular}

Now that the rates have been considered, the ratio $\left(\frac{P_{n}}{P_{s t r}}\right)^{\prime}$ can be determined using the rule base in Figure C.5(b). Using the predetermined values it is shown that the output, $\left(\frac{P_{n}}{P_{s t r}}\right)^{\prime}$, is LM when $P_{n}$ and $P_{s t r}$ are LM and LM respectively.

This value then goes through the defuzzification step performed using the fuzzy logic toolbox equipped in Matlab/Simulink to produce a crisp value of 0.22 . This quantity is multiplied by the DC link voltage of $120 \mathrm{~V}$ to obtain the reference voltage of $\left(\frac{P_{n}}{P_{s t r}}\right)^{\prime} \times 120 \mathrm{~V}=26.4 \mathrm{~V}$

The rule base for the inference engine in FLC1 is tabulated below. Each of the rules were determined by observing the behaviour of reference voltage calculation using Equation 3.2 simulated using module field data obtained in Ottawa Ontario. The controller is designed to eliminate the impact of high ramp rates to produce smoother ramping during operation. Reducing ramp rates and voltage fluctuations increases the stability and reliability of the system.

Table C.3: Rule base generated for FLC1.

\begin{tabular}{|l|l|l|l|l|}
\hline \multicolumn{4}{|c|}{ Input } & Output \\
\hline$P_{n}$ & $P_{s t r}$ & $\frac{d}{d t} P_{n}$ & $\frac{d}{d t} P_{s t r}$ & $\left(\frac{P_{n}}{P_{s t r}}\right)^{\prime}$ \\
\hline \hline $\mathrm{L}$ & $\mathrm{L}$ & $\mathrm{NH}$ & $\mathrm{NH}$ & $\mathrm{LM}$ \\
\hline $\mathrm{L}$ & $\mathrm{L}$ & $\mathrm{NH}$ & $\mathrm{NM}$ & $\mathrm{LM}$ \\
\hline $\mathrm{L}$ & $\mathrm{L}$ & $\mathrm{NH}$ & $\mathrm{NL}$ & $\mathrm{LM}$ \\
\hline $\mathrm{L}$ & $\mathrm{L}$ & $\mathrm{NH}$ & $\mathrm{ZE}$ & $\mathrm{LM}$ \\
\hline $\mathrm{L}$ & $\mathrm{L}$ & $\mathrm{NH}$ & $\mathrm{PL}$ & $\mathrm{LM}$ \\
\hline $\mathrm{L}$ & $\mathrm{L}$ & $\mathrm{NH}$ & $\mathrm{PM}$ & $\mathrm{L}$ \\
\hline
\end{tabular}




\begin{tabular}{|l|l|l|l|l|}
\hline L & L & NH & PH & LM \\
\hline L & L & NM & NH & LM \\
\hline L & L & NM & NM & LM \\
\hline L & L & NM & NL & LM \\
\hline L & L & NM & ZE & LM \\
\hline L & L & NM & PL & LM \\
\hline L & L & NM & PM & L \\
\hline L & L & NM & PH & LM \\
\hline L & L & NL & NH & LM \\
\hline L & L & NL & NM & LM \\
\hline L & L & NL & NL & LM \\
\hline L & L & NL & ZE & LM \\
\hline L & L & NL & PL & LM \\
\hline L & L & NL & PM & L \\
\hline L & L & NL & PH & LM \\
\hline L & L & ZE & NH & LM \\
\hline L & L & ZE & NM & LM \\
\hline L & L & ZE & NL & LM \\
\hline L & L & ZE & ZE & LM \\
\hline L & L & ZE & PL & LM \\
\hline L & L & ZE & PM & L \\
\hline L & L & ZE & PH & LM \\
\hline L & L & PL & NH & LM \\
\hline L & L & PL & NM & LM \\
\hline L & L & PL & NL & LM \\
\hline L & PL & LM \\
\hline L & LM \\
\hline
\end{tabular}




\begin{tabular}{|c|c|c|c|c|}
\hline $\mathrm{L}$ & $\mathrm{L}$ & PL & $\mathrm{PH}$ & LM \\
\hline $\mathrm{L}$ & $\mathrm{L}$ & PM & $\mathrm{NH}$ & $\mathrm{MH}$ \\
\hline L & L & PM & NM & $\mathrm{MH}$ \\
\hline $\mathrm{L}$ & L & $\mathrm{PM}$ & NL & $\mathrm{MH}$ \\
\hline $\mathrm{L}$ & $\mathrm{L}$ & $\mathrm{PM}$ & ZE & $\mathrm{MH}$ \\
\hline L & L & $\mathrm{PM}$ & PL & $\mathrm{MH}$ \\
\hline $\mathrm{L}$ & $\mathrm{L}$ & PM & PM & LM \\
\hline $\mathrm{L}$ & $\mathrm{L}$ & PM & $\mathrm{PH}$ & $\mathrm{MH}$ \\
\hline $\mathrm{L}$ & $\mathrm{L}$ & $\mathrm{PH}$ & $\mathrm{NH}$ & LM \\
\hline L & $\mathrm{L}$ & $\mathrm{PH}$ & NM & LM \\
\hline $\mathrm{L}$ & $\mathrm{L}$ & $\mathrm{PH}$ & NL & LM \\
\hline L & $\mathrm{L}$ & $\mathrm{PH}$ & $\mathrm{ZE}$ & LM \\
\hline $\mathrm{L}$ & $\mathrm{L}$ & $\mathrm{PH}$ & $\mathrm{PL}$ & LM \\
\hline $\mathrm{L}$ & $\mathrm{L}$ & $\mathrm{PH}$ & PM & $\mathrm{L}$ \\
\hline $\mathrm{L}$ & $\mathrm{L}$ & $\mathrm{PH}$ & $\mathrm{PH}$ & LM \\
\hline $\mathrm{L}$ & LM & $\mathrm{NH}$ & $\mathrm{NH}$ & $\mathrm{L}$ \\
\hline $\mathrm{L}$ & LM & $\mathrm{NH}$ & $\mathrm{NM}$ & LM \\
\hline $\mathrm{L}$ & LM & $\mathrm{NH}$ & NL & $\mathrm{L}$ \\
\hline $\mathrm{L}$ & LM & $\mathrm{NH}$ & $\mathrm{ZE}$ & $\mathrm{L}$ \\
\hline $\mathrm{L}$ & LM & $\mathrm{NH}$ & $\mathrm{PL}$ & $\mathrm{L}$ \\
\hline $\mathrm{L}$ & LM & $\mathrm{NH}$ & $\mathrm{PM}$ & $\mathrm{L}$ \\
\hline $\mathrm{L}$ & LM & $\mathrm{NH}$ & $\mathrm{PH}$ & $\mathrm{L}$ \\
\hline $\mathrm{L}$ & LM & NM & $\mathrm{NH}$ & L \\
\hline $\mathrm{L}$ & LM & $\mathrm{NM}$ & $\mathrm{NM}$ & LM \\
\hline L & LM & $\mathrm{NM}$ & NL & $\mathrm{L}$ \\
\hline $\mathrm{L}$ & LM & NM & $\mathrm{ZE}$ & $\mathrm{L}$ \\
\hline $\mathrm{L}$ & LM & NM & $\mathrm{PL}$ & $\mathrm{L}$ \\
\hline L & LM & NM & $\mathrm{PM}$ & $\mathrm{L}$ \\
\hline
\end{tabular}




\begin{tabular}{|l|l|l|l|l|}
\hline L & LM & NM & PH & L \\
\hline L & LM & NL & NH & L \\
\hline L & LM & NL & NM & LM \\
\hline L & LM & NL & NL & L \\
\hline L & LM & NL & ZE & L \\
\hline L & LM & NL & PL & L \\
\hline L & LM & NL & PM & L \\
\hline L & LM & NL & PH & L \\
\hline L & LM & ZE & NH & L \\
\hline L & LM & ZE & NM & LM \\
\hline L & LM & ZE & NL & L \\
\hline L & LM & ZE & ZE & L \\
\hline L & LM & ZE & PL & L \\
\hline L & LM & ZE & PM & L \\
\hline L & LM & ZE & PH & L \\
\hline L & LM & PL & NH & L \\
\hline L & LM & PL & NM & LM \\
\hline L & LM & PL & NL & L \\
\hline L & LM & PL & ZE & L \\
\hline L & LM & PL & PL & L \\
\hline L & LM & PL & PM & L \\
\hline L & LM & PL & PH & L \\
\hline L & LM & PM & NH & LM \\
\hline L & LM & PM & NM & MH \\
\hline L & LM & PM & NL & LM \\
\hline L & PM & PM & PL & LM \\
\hline L & PM & PM & LM \\
\hline L & LM & & \\
\hline
\end{tabular}




\begin{tabular}{|c|c|c|c|c|}
\hline $\mathrm{L}$ & LM & $\mathrm{PM}$ & $\mathrm{PH}$ & $\mathrm{LM}$ \\
\hline L & LM & $\mathrm{PH}$ & $\mathrm{NH}$ & $\mathrm{L}$ \\
\hline L & LM & $\mathrm{PH}$ & NM & LM \\
\hline $\mathrm{L}$ & LM & $\mathrm{PH}$ & NL & $\mathrm{L}$ \\
\hline $\mathrm{L}$ & LM & $\mathrm{PH}$ & ZE & $\mathrm{L}$ \\
\hline L & LM & $\mathrm{PH}$ & PL & L \\
\hline $\mathrm{L}$ & LM & $\mathrm{PH}$ & $\mathrm{PM}$ & $\mathrm{L}$ \\
\hline $\mathrm{L}$ & LM & $\mathrm{PH}$ & $\mathrm{PH}$ & $\mathrm{L}$ \\
\hline $\mathrm{L}$ & $\mathrm{M}$ & $\mathrm{NH}$ & $\mathrm{NH}$ & $\mathrm{L}$ \\
\hline $\mathrm{L}$ & $\mathrm{M}$ & $\mathrm{NH}$ & $\mathrm{NM}$ & $\mathrm{L}$ \\
\hline $\mathrm{L}$ & $\mathrm{M}$ & $\mathrm{NH}$ & NL & $\mathrm{L}$ \\
\hline L & M & $\mathrm{NH}$ & $\mathrm{ZE}$ & $\mathrm{L}$ \\
\hline $\mathrm{L}$ & $\mathrm{M}$ & $\mathrm{NH}$ & PL & $\mathrm{L}$ \\
\hline $\mathrm{L}$ & $\mathrm{M}$ & $\mathrm{NH}$ & $\mathrm{PM}$ & $\mathrm{L}$ \\
\hline $\mathrm{L}$ & $\mathrm{M}$ & $\mathrm{NH}$ & $\mathrm{PH}$ & $\mathrm{L}$ \\
\hline $\mathrm{L}$ & $\mathrm{M}$ & NM & $\mathrm{NH}$ & $\mathrm{L}$ \\
\hline $\mathrm{L}$ & $\mathrm{M}$ & NM & NM & $\mathrm{L}$ \\
\hline $\mathrm{L}$ & $\mathrm{M}$ & NM & NL & $\mathrm{L}$ \\
\hline $\mathrm{L}$ & $\mathrm{M}$ & NM & $\mathrm{ZE}$ & $\mathrm{L}$ \\
\hline $\mathrm{L}$ & $\mathrm{M}$ & NM & PL & $\mathrm{L}$ \\
\hline $\mathrm{L}$ & $\mathrm{M}$ & NM & $\mathrm{PM}$ & $\mathrm{L}$ \\
\hline $\mathrm{L}$ & $\mathrm{M}$ & NM & $\mathrm{PH}$ & $\mathrm{L}$ \\
\hline $\mathrm{L}$ & $\mathrm{M}$ & $\mathrm{NL}$ & $\mathrm{NH}$ & $\mathrm{L}$ \\
\hline $\mathrm{L}$ & $\mathrm{M}$ & NL & $\mathrm{NM}$ & $\mathrm{L}$ \\
\hline $\mathrm{L}$ & $\mathrm{M}$ & NL & NL & $\mathrm{L}$ \\
\hline $\mathrm{L}$ & $\mathrm{M}$ & $\mathrm{NL}$ & $\mathrm{ZE}$ & $\mathrm{L}$ \\
\hline $\mathrm{L}$ & $\mathrm{M}$ & NL & $\mathrm{PL}$ & $\mathrm{L}$ \\
\hline $\mathrm{L}$ & $\mathrm{M}$ & $\mathrm{NL}$ & PM & $\mathrm{L}$ \\
\hline
\end{tabular}




\begin{tabular}{|c|c|c|c|c|}
\hline $\mathrm{L}$ & $\mathrm{M}$ & $\mathrm{NL}$ & $\mathrm{PH}$ & $\mathrm{L}$ \\
\hline L & M & $\mathrm{ZE}$ & $\mathrm{NH}$ & $\mathrm{L}$ \\
\hline L & $\mathrm{M}$ & $\mathrm{ZE}$ & NM & $\mathrm{L}$ \\
\hline $\mathrm{L}$ & $\mathrm{M}$ & $\mathrm{ZE}$ & NL & $\mathrm{L}$ \\
\hline $\mathrm{L}$ & $\mathrm{M}$ & $\mathrm{ZE}$ & ZE & $\mathrm{L}$ \\
\hline L & $\mathrm{M}$ & ZE & PL & L \\
\hline $\mathrm{L}$ & $\mathrm{M}$ & $\mathrm{ZE}$ & $\mathrm{PM}$ & $\mathrm{L}$ \\
\hline $\mathrm{L}$ & $\mathrm{M}$ & $\mathrm{ZE}$ & $\mathrm{PH}$ & $\mathrm{L}$ \\
\hline $\mathrm{L}$ & $\mathrm{M}$ & $\mathrm{PL}$ & $\mathrm{NH}$ & $\mathrm{L}$ \\
\hline $\mathrm{L}$ & $\mathrm{M}$ & $\mathrm{PL}$ & NM & $\mathrm{L}$ \\
\hline $\mathrm{L}$ & $\mathrm{M}$ & $\mathrm{PL}$ & NL & $\mathrm{L}$ \\
\hline L & M & PL & $\mathrm{ZE}$ & $\mathrm{L}$ \\
\hline $\mathrm{L}$ & $\mathrm{M}$ & $\mathrm{PL}$ & PL & $\mathrm{L}$ \\
\hline $\mathrm{L}$ & $\mathrm{M}$ & $\mathrm{PL}$ & $\mathrm{PM}$ & $\mathrm{L}$ \\
\hline $\mathrm{L}$ & $\mathrm{M}$ & $\mathrm{PL}$ & $\mathrm{PH}$ & $\mathrm{L}$ \\
\hline $\mathrm{L}$ & $\mathrm{M}$ & PM & $\mathrm{NH}$ & LM \\
\hline $\mathrm{L}$ & $\mathrm{M}$ & $\mathrm{PM}$ & NM & LM \\
\hline $\mathrm{L}$ & $\mathrm{M}$ & $\mathrm{PM}$ & NL & $\mathrm{LM}$ \\
\hline $\mathrm{L}$ & $\mathrm{M}$ & $\mathrm{PM}$ & $\mathrm{ZE}$ & $\mathrm{LM}$ \\
\hline $\mathrm{L}$ & $\mathrm{M}$ & $\mathrm{PM}$ & $\mathrm{PL}$ & LM \\
\hline $\mathrm{L}$ & $\mathrm{M}$ & $\mathrm{PM}$ & $\mathrm{PM}$ & LM \\
\hline $\mathrm{L}$ & $\mathrm{M}$ & PM & $\mathrm{PH}$ & $\mathrm{LM}$ \\
\hline $\mathrm{L}$ & $\mathrm{M}$ & $\mathrm{PH}$ & $\mathrm{NH}$ & $\mathrm{L}$ \\
\hline $\mathrm{L}$ & $\mathrm{M}$ & $\mathrm{PH}$ & $\mathrm{NM}$ & $\mathrm{L}$ \\
\hline $\mathrm{L}$ & $\mathrm{M}$ & $\mathrm{PH}$ & NL & $\mathrm{L}$ \\
\hline $\mathrm{L}$ & $\mathrm{M}$ & $\mathrm{PH}$ & $\mathrm{ZE}$ & $\mathrm{L}$ \\
\hline $\mathrm{L}$ & $\mathrm{M}$ & $\mathrm{PH}$ & $\mathrm{PL}$ & $\mathrm{L}$ \\
\hline $\mathrm{L}$ & $\mathrm{M}$ & $\mathrm{PH}$ & PM & $\mathrm{L}$ \\
\hline
\end{tabular}




\begin{tabular}{|l|l|l|l|l|}
\hline L & M & PH & PH & L \\
\hline L & MH & NH & NH & L \\
\hline L & MH & NH & NM & L \\
\hline L & MH & NH & NL & L \\
\hline L & MH & NH & ZE & L \\
\hline L & MH & NH & PL & L \\
\hline L & MH & NH & PM & L \\
\hline L & MH & NH & PH & L \\
\hline L & MH & NM & NH & L \\
\hline L & MH & NM & NM & L \\
\hline L & MH & NM & NL & L \\
\hline L & MH & NM & ZE & L \\
\hline L & MH & NM & PL & L \\
\hline L & MH & NM & PM & L \\
\hline L & MH & NM & PH & L \\
\hline L & MH & NL & NH & L \\
\hline L & MH & NL & NM & L \\
\hline L & MH & NL & NL & L \\
\hline L & MH & NL & ZE & L \\
\hline L & MH & NL & PL & L \\
\hline L & MH & NL & PM & L \\
\hline L & MH & NL & PH & L \\
\hline L & MH & ZE & NH & L \\
\hline L & MH & ZE & NM & L \\
\hline L & MH & ZE & NL & L \\
\hline L & ZE & ZE & L \\
\hline L & PL & L \\
\hline L & NH & L \\
\hline
\end{tabular}




\begin{tabular}{|c|c|c|c|c|}
\hline $\mathrm{L}$ & $\mathrm{MH}$ & $\mathrm{ZE}$ & $\mathrm{PH}$ & $\mathrm{L}$ \\
\hline L & $\mathrm{MH}$ & PL & $\mathrm{NH}$ & $\mathrm{L}$ \\
\hline L & $\mathrm{MH}$ & PL & NM & $\mathrm{L}$ \\
\hline $\mathrm{L}$ & $\mathrm{MH}$ & PL & NL & $\mathrm{L}$ \\
\hline $\mathrm{L}$ & $\mathrm{MH}$ & PL & ZE & $\mathrm{L}$ \\
\hline L & $\mathrm{MH}$ & PL & PL & L \\
\hline $\mathrm{L}$ & $\mathrm{MH}$ & PL & $\mathrm{PM}$ & $\mathrm{L}$ \\
\hline $\mathrm{L}$ & $\mathrm{MH}$ & PL & $\mathrm{PH}$ & $\mathrm{L}$ \\
\hline $\mathrm{L}$ & $\mathrm{MH}$ & $\mathrm{PM}$ & $\mathrm{NH}$ & LM \\
\hline $\mathrm{L}$ & $\mathrm{MH}$ & PM & $\mathrm{NM}$ & LM \\
\hline $\mathrm{L}$ & $\mathrm{MH}$ & PM & NL & LM \\
\hline L & $\mathrm{MH}$ & PM & $\mathrm{ZE}$ & LM \\
\hline $\mathrm{L}$ & $\mathrm{MH}$ & PM & PL & LM \\
\hline $\mathrm{L}$ & $\mathrm{MH}$ & PM & $\mathrm{PM}$ & LM \\
\hline $\mathrm{L}$ & $\mathrm{MH}$ & PM & $\mathrm{PH}$ & LM \\
\hline $\mathrm{L}$ & $\mathrm{MH}$ & $\mathrm{PH}$ & $\mathrm{NH}$ & $\mathrm{L}$ \\
\hline $\mathrm{L}$ & $\mathrm{MH}$ & $\mathrm{PH}$ & NM & $\mathrm{L}$ \\
\hline $\mathrm{L}$ & $\mathrm{MH}$ & $\mathrm{PH}$ & NL & $\mathrm{L}$ \\
\hline $\mathrm{L}$ & $\mathrm{MH}$ & $\mathrm{PH}$ & $\mathrm{ZE}$ & $\mathrm{L}$ \\
\hline $\mathrm{L}$ & $\mathrm{MH}$ & $\mathrm{PH}$ & PL & $\mathrm{L}$ \\
\hline $\mathrm{L}$ & $\mathrm{MH}$ & $\mathrm{PH}$ & $\mathrm{PM}$ & $\mathrm{L}$ \\
\hline $\mathrm{L}$ & $\mathrm{MH}$ & $\mathrm{PH}$ & $\mathrm{PH}$ & $\mathrm{L}$ \\
\hline $\mathrm{L}$ & $\mathrm{H}$ & $\mathrm{NH}$ & $\mathrm{NH}$ & $\mathrm{L}$ \\
\hline $\mathrm{L}$ & $\mathrm{H}$ & $\mathrm{NH}$ & $\mathrm{NM}$ & $\mathrm{L}$ \\
\hline $\mathrm{L}$ & $\mathrm{H}$ & $\mathrm{NH}$ & NL & $\mathrm{L}$ \\
\hline $\mathrm{L}$ & $\mathrm{H}$ & $\mathrm{NH}$ & $\mathrm{ZE}$ & $\mathrm{L}$ \\
\hline $\mathrm{L}$ & $\mathrm{H}$ & $\mathrm{NH}$ & $\mathrm{PL}$ & $\mathrm{L}$ \\
\hline $\mathrm{L}$ & $\mathrm{H}$ & $\mathrm{NH}$ & PM & $\mathrm{L}$ \\
\hline
\end{tabular}




\begin{tabular}{|l|l|l|l|l|}
\hline L & H & NH & PH & L \\
\hline L & H & NM & NH & L \\
\hline L & H & NM & NM & L \\
\hline L & H & NM & NL & L \\
\hline L & H & NM & ZE & L \\
\hline L & H & NM & PL & L \\
\hline L & H & NM & PM & L \\
\hline L & H & NM & PH & L \\
\hline L & H & NL & NH & L \\
\hline L & H & NL & NM & L \\
\hline L & H & NL & NL & L \\
\hline L & H & NL & ZE & L \\
\hline L & H & NL & PL & L \\
\hline L & H & NL & PM & L \\
\hline L & H & NL & PH & L \\
\hline L & H & ZE & NH & L \\
\hline L & H & ZE & NM & L \\
\hline L & H & ZE & NL & L \\
\hline L & H & ZE & ZE & L \\
\hline L & H & ZE & PL & L \\
\hline L & H & ZE & PM & L \\
\hline L & H & ZE & PH & L \\
\hline L & H & PL & NH & L \\
\hline L & H & PL & NM & L \\
\hline L & H & PL & NL & L \\
\hline L & P & ZE & L \\
\hline L & PL & L \\
\hline
\end{tabular}




\begin{tabular}{|l|l|l|l|l|}
\hline L & H & PL & PH & L \\
\hline L & H & PM & NH & LM \\
\hline L & H & PM & NM & LM \\
\hline L & H & PM & NL & LM \\
\hline L & H & PM & ZE & LM \\
\hline L & H & PM & PL & LM \\
\hline L & H & PM & PM & LM \\
\hline L & H & PM & PH & LM \\
\hline L & H & PH & NH & L \\
\hline L & H & PH & NM & L \\
\hline L & H & PH & NL & L \\
\hline L & H & PH & ZE & L \\
\hline L & H & PH & PL & L \\
\hline L & H & PH & PM & L \\
\hline L & H & PH & PH & L \\
\hline LM & L & NH & NH & MH \\
\hline LM & L & NH & NM & MH \\
\hline LM & L & NH & NL & MH \\
\hline LM & L & NH & ZE & MH \\
\hline LM & L & NH & PL & MH \\
\hline LM & L & NH & PM & LM \\
\hline LM & L & NH & PH & MH \\
\hline LM & L & NM & NH & LM \\
\hline LM & L & NM & NM & LM \\
\hline LM & L & NM & NL & LM \\
\hline LM & L & NM & ZE & LM \\
\hline LM & L & PL & LM \\
\hline LM & N & L \\
\hline
\end{tabular}




\begin{tabular}{|l|l|l|l|l|}
\hline LM & L & NM & PH & LM \\
\hline LM & L & NL & NH & MH \\
\hline LM & L & NL & NM & MH \\
\hline LM & L & NL & NL & MH \\
\hline LM & L & NL & ZE & MH \\
\hline LM & L & NL & PL & MH \\
\hline LM & L & NL & PM & LM \\
\hline LM & L & NL & PH & MH \\
\hline LM & L & ZE & NH & MH \\
\hline LM & L & ZE & NM & MH \\
\hline LM & L & ZE & NL & MH \\
\hline LM & L & ZE & ZE & MH \\
\hline LM & L & ZE & PL & MH \\
\hline LM & L & ZE & PM & LM \\
\hline LM & L & ZE & PH & MH \\
\hline LM & L & PL & NH & MH \\
\hline LM & L & PL & NM & MH \\
\hline LM & L & PL & NL & MH \\
\hline LM & L & PL & ZE & MH \\
\hline LM & L & PL & PL & MH \\
\hline LM & L & PL & PM & LM \\
\hline LM & L & PL & PH & MH \\
\hline LM & L & PM & NH & M \\
\hline LM & L & PM & NM & M \\
\hline LM & L & PM & NL & M \\
\hline LM & L & PM & ZE & M \\
\hline LM & L & PM & M \\
\hline
\end{tabular}




\begin{tabular}{|c|c|c|c|c|}
\hline LM & $\mathrm{L}$ & PM & $\mathrm{PH}$ & $\mathrm{M}$ \\
\hline LM & L & $\mathrm{PH}$ & $\mathrm{NH}$ & $\mathrm{MH}$ \\
\hline LM & L & $\mathrm{PH}$ & $\mathrm{NM}$ & $\mathrm{MH}$ \\
\hline LM & $\mathrm{L}$ & $\mathrm{PH}$ & NL & $\mathrm{MH}$ \\
\hline LM & $\mathrm{L}$ & $\mathrm{PH}$ & ZE & $\mathrm{MH}$ \\
\hline LM & L & $\mathrm{PH}$ & PL & $\mathrm{MH}$ \\
\hline LM & L & $\mathrm{PH}$ & PM & LM \\
\hline LM & $\mathrm{L}$ & $\mathrm{PH}$ & $\mathrm{PH}$ & $\mathrm{MH}$ \\
\hline LM & LM & $\mathrm{NH}$ & $\mathrm{NH}$ & LM \\
\hline LM & LM & $\mathrm{NH}$ & NM & $\mathrm{MH}$ \\
\hline LM & LM & $\mathrm{NH}$ & NL & LM \\
\hline LM & LM & $\mathrm{NH}$ & ZE & LM \\
\hline LM & LM & $\mathrm{NH}$ & PL & LM \\
\hline LM & LM & $\mathrm{NH}$ & PM & LM \\
\hline LM & LM & $\mathrm{NH}$ & $\mathrm{PH}$ & LM \\
\hline LM & LM & $\mathrm{NM}$ & $\mathrm{NH}$ & $\mathrm{L}$ \\
\hline LM & LM & NM & NM & LM \\
\hline LM & LM & NM & NL & $\mathrm{L}$ \\
\hline LM & LM & $\mathrm{NM}$ & ZE & $\mathrm{L}$ \\
\hline LM & LM & $\mathrm{NM}$ & PL & L \\
\hline LM & LM & $\mathrm{NM}$ & PM & L \\
\hline LM & LM & NM & $\mathrm{PH}$ & $\mathrm{L}$ \\
\hline LM & LM & NL & $\mathrm{NH}$ & LM \\
\hline LM & LM & NL & NM & $\mathrm{MH}$ \\
\hline LM & LM & NL & NL & LM \\
\hline LM & LM & NL & ZE & LM \\
\hline LM & LM & NL & PL & LM \\
\hline LM & LM & NL & $\mathrm{PM}$ & LM \\
\hline
\end{tabular}




\begin{tabular}{|c|c|c|c|c|}
\hline LM & LM & NL & $\mathrm{PH}$ & LM \\
\hline LM & LM & $\mathrm{ZE}$ & $\mathrm{NH}$ & LM \\
\hline LM & LM & $\mathrm{ZE}$ & NM & $\mathrm{MH}$ \\
\hline LM & LM & $\mathrm{ZE}$ & NL & LM \\
\hline $\mathrm{LM}$ & LM & $\mathrm{ZE}$ & $\mathrm{ZE}$ & LM \\
\hline LM & LM & $\mathrm{ZE}$ & PL & LM \\
\hline LM & LM & $\mathrm{ZE}$ & PM & LM \\
\hline LM & LM & $\mathrm{ZE}$ & $\mathrm{PH}$ & LM \\
\hline $\mathrm{LM}$ & LM & PL & $\mathrm{NH}$ & LM \\
\hline LM & LM & PL & NM & $\mathrm{MH}$ \\
\hline LM & LM & PL & NL & LM \\
\hline LM & LM & PL & $\mathrm{ZE}$ & LM \\
\hline LM & LM & PL & PL & LM \\
\hline LM & LM & PL & $\mathrm{PM}$ & LM \\
\hline LM & LM & PL & $\mathrm{PH}$ & LM \\
\hline $\mathrm{LM}$ & LM & $\mathrm{PM}$ & $\mathrm{NH}$ & $\mathrm{M}$ \\
\hline LM & LM & PM & $\mathrm{NM}$ & $\mathrm{H}$ \\
\hline LM & LM & PM & NL & $\mathrm{M}$ \\
\hline $\mathrm{LM}$ & LM & $\mathrm{PM}$ & $\mathrm{ZE}$ & M \\
\hline LM & LM & PM & PL & M \\
\hline LM & LM & $\mathrm{PM}$ & $\mathrm{PM}$ & LM \\
\hline LM & LM & $\mathrm{PM}$ & $\mathrm{PH}$ & $\mathrm{M}$ \\
\hline $\mathrm{LM}$ & LM & $\mathrm{PH}$ & $\mathrm{NH}$ & LM \\
\hline LM & LM & $\mathrm{PH}$ & NM & $\mathrm{MH}$ \\
\hline LM & LM & $\mathrm{PH}$ & NL & LM \\
\hline LM & LM & $\mathrm{PH}$ & $\mathrm{ZE}$ & LM \\
\hline LM & LM & $\mathrm{PH}$ & PL & LM \\
\hline LM & LM & $\mathrm{PH}$ & PM & LM \\
\hline
\end{tabular}




\begin{tabular}{|c|c|c|c|c|}
\hline LM & LM & $\mathrm{PH}$ & $\mathrm{PH}$ & LM \\
\hline LM & M & $\mathrm{NH}$ & $\mathrm{NH}$ & LM \\
\hline LM & M & $\mathrm{NH}$ & $\mathrm{NM}$ & LM \\
\hline LM & M & $\mathrm{NH}$ & NL & LM \\
\hline LM & M & $\mathrm{NH}$ & $\mathrm{ZE}$ & LM \\
\hline LM & M & $\mathrm{NH}$ & PL & LM \\
\hline LM & M & $\mathrm{NH}$ & $\mathrm{PM}$ & LM \\
\hline $\mathrm{LM}$ & M & $\mathrm{NH}$ & $\mathrm{PH}$ & LM \\
\hline LM & $\mathrm{M}$ & NM & $\mathrm{NH}$ & $\mathrm{L}$ \\
\hline LM & M & NM & $\mathrm{NM}$ & $\mathrm{L}$ \\
\hline LM & M & NM & NL & $\mathrm{L}$ \\
\hline LM & M & NM & $\mathrm{ZE}$ & $\mathrm{L}$ \\
\hline LM & M & NM & PL & $\mathrm{L}$ \\
\hline $\mathrm{LM}$ & M & NM & $\mathrm{PM}$ & $\mathrm{L}$ \\
\hline LM & M & NM & $\mathrm{PH}$ & $\mathrm{L}$ \\
\hline LM & $\mathrm{M}$ & NL & $\mathrm{NH}$ & LM \\
\hline LM & M & NL & $\mathrm{NM}$ & LM \\
\hline $\mathrm{LM}$ & M & NL & NL & LM \\
\hline LM & M & NL & $\mathrm{ZE}$ & LM \\
\hline $\mathrm{LM}$ & $\mathrm{M}$ & NL & PL & LM \\
\hline LM & $\mathrm{M}$ & NL & $\mathrm{PM}$ & LM \\
\hline $\mathrm{LM}$ & M & NL & $\mathrm{PH}$ & LM \\
\hline LM & M & $\mathrm{ZE}$ & $\mathrm{NH}$ & LM \\
\hline $\mathrm{LM}$ & M & $\mathrm{ZE}$ & NM & LM \\
\hline LM & M & $\mathrm{ZE}$ & NL & LM \\
\hline LM & M & $\mathrm{ZE}$ & $\mathrm{ZE}$ & LM \\
\hline LM & $\mathrm{M}$ & $\mathrm{ZE}$ & PL & LM \\
\hline LM & M & $\mathrm{ZE}$ & PM & LM \\
\hline
\end{tabular}




\begin{tabular}{|c|c|c|c|c|}
\hline LM & M & $\mathrm{ZE}$ & $\mathrm{PH}$ & LM \\
\hline LM & M & PL & $\mathrm{NH}$ & LM \\
\hline LM & M & PL & NM & LM \\
\hline LM & M & PL & NL & LM \\
\hline LM & M & PL & $\mathrm{ZE}$ & LM \\
\hline LM & M & PL & PL & LM \\
\hline LM & M & PL & PM & LM \\
\hline LM & M & PL & $\mathrm{PH}$ & LM \\
\hline LM & M & PM & $\mathrm{NH}$ & LM \\
\hline LM & M & PM & $\mathrm{NM}$ & M \\
\hline LM & M & $\mathrm{PM}$ & NL & LM \\
\hline LM & $\mathrm{M}$ & $\mathrm{PM}$ & $\mathrm{ZE}$ & LM \\
\hline LM & M & PM & PL & LM \\
\hline LM & M & $\mathrm{PM}$ & $\mathrm{PM}$ & LM \\
\hline LM & M & $\mathrm{PM}$ & $\mathrm{PH}$ & LM \\
\hline $\mathrm{LM}$ & M & $\mathrm{PH}$ & $\mathrm{NH}$ & LM \\
\hline LM & M & $\mathrm{PH}$ & $\mathrm{NM}$ & LM \\
\hline $\mathrm{LM}$ & M & $\mathrm{PH}$ & NL & LM \\
\hline $\mathrm{LM}$ & M & $\mathrm{PH}$ & $\mathrm{ZE}$ & LM \\
\hline LM & M & $\mathrm{PH}$ & PL & LM \\
\hline LM & M & $\mathrm{PH}$ & $\mathrm{PM}$ & LM \\
\hline LM & M & $\mathrm{PH}$ & $\mathrm{PH}$ & LM \\
\hline $\mathrm{LM}$ & $\mathrm{MH}$ & $\mathrm{NH}$ & $\mathrm{NH}$ & LM \\
\hline $\mathrm{LM}$ & $\mathrm{MH}$ & $\mathrm{NH}$ & $\mathrm{NM}$ & LM \\
\hline $\mathrm{LM}$ & $\mathrm{MH}$ & $\mathrm{NH}$ & NL & LM \\
\hline LM & $\mathrm{MH}$ & $\mathrm{NH}$ & $\mathrm{ZE}$ & LM \\
\hline $\mathrm{LM}$ & $\mathrm{MH}$ & $\mathrm{NH}$ & PL & LM \\
\hline LM & $\mathrm{MH}$ & $\mathrm{NH}$ & PM & LM \\
\hline
\end{tabular}




\begin{tabular}{|c|c|c|c|c|}
\hline LM & $\mathrm{MH}$ & $\mathrm{NH}$ & $\mathrm{PH}$ & LM \\
\hline LM & $\mathrm{MH}$ & $\mathrm{NM}$ & $\mathrm{NH}$ & $\mathrm{L}$ \\
\hline LM & $\mathrm{MH}$ & $\mathrm{NM}$ & $\mathrm{NM}$ & $\mathrm{L}$ \\
\hline LM & $\mathrm{MH}$ & $\mathrm{NM}$ & NL & L \\
\hline LM & $\mathrm{MH}$ & $\mathrm{NM}$ & $\mathrm{ZE}$ & $\mathrm{L}$ \\
\hline LM & $\mathrm{MH}$ & $\mathrm{NM}$ & PL & $\mathrm{L}$ \\
\hline LM & $\mathrm{MH}$ & $\mathrm{NM}$ & $\mathrm{PM}$ & $\mathrm{L}$ \\
\hline LM & $\mathrm{MH}$ & $\mathrm{NM}$ & $\mathrm{PH}$ & $\mathrm{L}$ \\
\hline LM & $\mathrm{MH}$ & NL & $\mathrm{NH}$ & LM \\
\hline LM & $\mathrm{MH}$ & NL & $\mathrm{NM}$ & LM \\
\hline LM & $\mathrm{MH}$ & NL & NL & LM \\
\hline LM & $\mathrm{MH}$ & NL & ZE & LM \\
\hline LM & $\mathrm{MH}$ & $\mathrm{NL}$ & PL & LM \\
\hline LM & $\mathrm{MH}$ & NL & PM & LM \\
\hline LM & $\mathrm{MH}$ & NL & $\mathrm{PH}$ & LM \\
\hline LM & $\mathrm{MH}$ & ZE & $\mathrm{NH}$ & LM \\
\hline LM & $\mathrm{MH}$ & $\mathrm{ZE}$ & NM & LM \\
\hline LM & $\mathrm{MH}$ & $\mathrm{ZE}$ & NL & LM \\
\hline LM & $\mathrm{MH}$ & ZE & ZE & LM \\
\hline LM & $\mathrm{MH}$ & ZE & PL & LM \\
\hline LM & $\mathrm{MH}$ & $\mathrm{ZE}$ & PM & LM \\
\hline LM & $\mathrm{MH}$ & ZE & $\mathrm{PH}$ & LM \\
\hline LM & $\mathrm{MH}$ & $\mathrm{PL}$ & $\mathrm{NH}$ & LM \\
\hline LM & $\mathrm{MH}$ & PL & $\mathrm{NM}$ & LM \\
\hline LM & $\mathrm{MH}$ & PL & NL & LM \\
\hline LM & $\mathrm{MH}$ & PL & $\mathrm{ZE}$ & LM \\
\hline LM & $\mathrm{MH}$ & PL & PL & LM \\
\hline LM & $\mathrm{MH}$ & PL & PM & LM \\
\hline
\end{tabular}




\begin{tabular}{|c|c|c|c|c|}
\hline LM & $\mathrm{MH}$ & PL & $\mathrm{PH}$ & LM \\
\hline LM & $\mathrm{MH}$ & PM & $\mathrm{NH}$ & LM \\
\hline LM & $\mathrm{MH}$ & PM & NM & LM \\
\hline LM & $\mathrm{MH}$ & PM & NL & LM \\
\hline LM & $\mathrm{MH}$ & $\mathrm{PM}$ & $\mathrm{ZE}$ & LM \\
\hline LM & $\mathrm{MH}$ & PM & PL & LM \\
\hline LM & $\mathrm{MH}$ & PM & $\mathrm{PM}$ & LM \\
\hline LM & $\mathrm{MH}$ & PM & $\mathrm{PH}$ & LM \\
\hline LM & $\mathrm{MH}$ & $\mathrm{PH}$ & $\mathrm{NH}$ & LM \\
\hline LM & $\mathrm{MH}$ & $\mathrm{PH}$ & NM & LM \\
\hline LM & $\mathrm{MH}$ & $\mathrm{PH}$ & $\mathrm{NL}$ & LM \\
\hline L & $\mathrm{MH}$ & $\mathrm{PH}$ & $\mathrm{ZE}$ & LM \\
\hline LM & $\mathrm{MH}$ & $\mathrm{PH}$ & PL & LM \\
\hline LM & $\mathrm{MH}$ & $\mathrm{PH}$ & PM & LM \\
\hline LM & $\mathrm{MH}$ & $\mathrm{PH}$ & $\mathrm{PH}$ & LM \\
\hline LM & $\mathrm{H}$ & $\mathrm{NH}$ & $\mathrm{NH}$ & LM \\
\hline LM & $\mathrm{H}$ & $\mathrm{NH}$ & $\mathrm{NM}$ & LM \\
\hline LM & $\mathrm{H}$ & $\mathrm{NH}$ & NL & LM \\
\hline LM & $\mathrm{H}$ & $\mathrm{NH}$ & $\mathrm{ZE}$ & LM \\
\hline LM & $\mathrm{H}$ & $\mathrm{NH}$ & PL & LM \\
\hline LM & $\mathrm{H}$ & $\mathrm{NH}$ & PM & LM \\
\hline LM & $\mathrm{H}$ & $\mathrm{NH}$ & $\mathrm{PH}$ & LM \\
\hline LM & $\mathrm{H}$ & NM & $\mathrm{NH}$ & $\mathrm{L}$ \\
\hline LM & $\mathrm{H}$ & NM & NM & $\mathrm{L}$ \\
\hline LM & $\mathrm{H}$ & $\mathrm{NM}$ & NL & $\mathrm{L}$ \\
\hline LM & $\mathrm{H}$ & NM & $\mathrm{ZE}$ & $\mathrm{L}$ \\
\hline LM & $\mathrm{H}$ & $\mathrm{NM}$ & $\mathrm{PL}$ & $\mathrm{L}$ \\
\hline LM & $\mathrm{H}$ & NM & $\mathrm{PM}$ & $\mathrm{L}$ \\
\hline
\end{tabular}




\begin{tabular}{|l|l|l|l|l|}
\hline LM & H & NM & PH & L \\
\hline LM & H & NL & NH & LM \\
\hline LM & H & NL & NM & LM \\
\hline LM & H & NL & NL & LM \\
\hline LM & H & NL & ZE & LM \\
\hline LM & H & NL & PL & LM \\
\hline LM & H & NL & PM & LM \\
\hline LM & H & NL & PH & LM \\
\hline LM & H & ZE & NH & LM \\
\hline LM & H & ZE & NM & LM \\
\hline LM & H & ZE & NL & LM \\
\hline LM & H & ZE & ZE & LM \\
\hline LM & H & ZE & PL & LM \\
\hline LM & H & ZE & PM & LM \\
\hline LM & H & ZE & PH & LM \\
\hline LM & H & PL & NH & LM \\
\hline LM & H & PL & NM & LM \\
\hline LM & H & PL & NL & LM \\
\hline LM & H & PL & ZE & LM \\
\hline LM & H & PL & PL & LM \\
\hline LM & H & PL & PM & LM \\
\hline LM & H & PL & PH & LM \\
\hline LM & H & PM & NH & LM \\
\hline LM & H & PM & NM & LM \\
\hline LM & H & PM & NL & LM \\
\hline LM & H & PM & ZE & LM \\
\hline LM & H & PM & PL & LM \\
\hline
\end{tabular}




\begin{tabular}{|c|c|c|c|c|}
\hline LM & $\mathrm{H}$ & PM & $\mathrm{PH}$ & LM \\
\hline LM & $\mathrm{H}$ & $\mathrm{PH}$ & $\mathrm{NH}$ & LM \\
\hline LM & $\mathrm{H}$ & $\mathrm{PH}$ & NM & LM \\
\hline LM & $\mathrm{H}$ & $\mathrm{PH}$ & NL & LM \\
\hline LM & $\mathrm{H}$ & $\mathrm{PH}$ & ZE & LM \\
\hline LM & $\mathrm{H}$ & $\mathrm{PH}$ & PL & LM \\
\hline LM & $\mathrm{H}$ & $\mathrm{PH}$ & $\mathrm{PM}$ & LM \\
\hline LM & $\mathrm{H}$ & $\mathrm{PH}$ & $\mathrm{PH}$ & LM \\
\hline M & L & $\mathrm{NH}$ & $\mathrm{NH}$ & $\mathrm{H}$ \\
\hline M & $\mathrm{L}$ & $\mathrm{NH}$ & NM & $\mathrm{H}$ \\
\hline M & $\mathrm{L}$ & $\mathrm{NH}$ & NL & $\mathrm{H}$ \\
\hline M & L & $\mathrm{NH}$ & ZE & $\mathrm{H}$ \\
\hline M & $\mathrm{L}$ & $\mathrm{NH}$ & PL & $\mathrm{H}$ \\
\hline M & L & $\mathrm{NH}$ & PM & $\mathrm{H}$ \\
\hline M & L & $\mathrm{NH}$ & $\mathrm{PH}$ & $\mathrm{H}$ \\
\hline M & L & NM & $\mathrm{NH}$ & $\mathrm{MH}$ \\
\hline M & $\mathrm{L}$ & NM & NM & $\mathrm{MH}$ \\
\hline M & $\mathrm{L}$ & $\mathrm{NM}$ & NL & $\mathrm{MH}$ \\
\hline M & $\mathrm{L}$ & NM & ZE & $\mathrm{MH}$ \\
\hline M & $\mathrm{L}$ & NM & PL & $\mathrm{MH}$ \\
\hline M & $\mathrm{L}$ & NM & $\mathrm{PM}$ & LM \\
\hline M & L & NM & $\mathrm{PH}$ & $\mathrm{MH}$ \\
\hline M & $\mathrm{L}$ & NL & $\mathrm{NH}$ & $\mathrm{H}$ \\
\hline M & $\mathrm{L}$ & NL & NM & $\mathrm{H}$ \\
\hline M & $\mathrm{L}$ & NL & $\mathrm{NL}$ & $\mathrm{H}$ \\
\hline M & $\mathrm{L}$ & NL & $\mathrm{ZE}$ & $\mathrm{H}$ \\
\hline M & $\mathrm{L}$ & NL & PL & $\mathrm{H}$ \\
\hline M & L & NL & PM & $\mathrm{M}$ \\
\hline
\end{tabular}




\begin{tabular}{|c|c|c|c|c|}
\hline M & $\mathrm{L}$ & NL & $\mathrm{PH}$ & $\mathrm{H}$ \\
\hline $\mathrm{M}$ & $\mathrm{L}$ & ZE & $\mathrm{NH}$ & $\mathrm{H}$ \\
\hline M & $\mathrm{L}$ & ZE & NM & $\mathrm{H}$ \\
\hline M & L & $\mathrm{ZE}$ & NL & $\mathrm{H}$ \\
\hline M & $\mathrm{L}$ & $\mathrm{ZE}$ & $\mathrm{ZE}$ & $\mathrm{H}$ \\
\hline M & $\mathrm{L}$ & ZE & $\mathrm{PL}$ & $\mathrm{H}$ \\
\hline M & $\mathrm{L}$ & ZE & PM & $\mathrm{M}$ \\
\hline M & $\mathrm{L}$ & ZE & $\mathrm{PH}$ & $\mathrm{H}$ \\
\hline M & $\mathrm{L}$ & PL & $\mathrm{NH}$ & $\mathrm{H}$ \\
\hline M & L & PL & NM & $\mathrm{H}$ \\
\hline M & $\mathrm{L}$ & PL & NL & $\mathrm{H}$ \\
\hline M & L & PL & $\mathrm{ZE}$ & $\mathrm{H}$ \\
\hline M & $\mathrm{L}$ & PL & $\mathrm{PL}$ & $\mathrm{H}$ \\
\hline M & $\mathrm{L}$ & PL & PM & $\mathrm{M}$ \\
\hline M & $\mathrm{L}$ & PL & $\mathrm{PH}$ & $\mathrm{H}$ \\
\hline M & $\mathrm{L}$ & PM & $\mathrm{NH}$ & $\mathrm{H}$ \\
\hline M & $\mathrm{L}$ & PM & NM & $\mathrm{H}$ \\
\hline M & $\mathrm{L}$ & PM & NL & $\mathrm{H}$ \\
\hline M & $\mathrm{L}$ & PM & $\mathrm{ZE}$ & $\mathrm{H}$ \\
\hline M & $\mathrm{L}$ & PM & PL & $\mathrm{H}$ \\
\hline M & $\mathrm{L}$ & PM & $\mathrm{PM}$ & $\mathrm{MH}$ \\
\hline M & L & PM & $\mathrm{PH}$ & $\mathrm{H}$ \\
\hline M & $\mathrm{L}$ & $\mathrm{PH}$ & $\mathrm{NH}$ & $\mathrm{H}$ \\
\hline M & $\mathrm{L}$ & $\mathrm{PH}$ & $\mathrm{NM}$ & $\mathrm{H}$ \\
\hline M & $\mathrm{L}$ & $\mathrm{PH}$ & NL & $\mathrm{H}$ \\
\hline M & $\mathrm{L}$ & $\mathrm{PH}$ & $\mathrm{ZE}$ & $\mathrm{H}$ \\
\hline M & $\mathrm{L}$ & $\mathrm{PH}$ & $\mathrm{PL}$ & $\mathrm{H}$ \\
\hline M & $\mathrm{L}$ & $\mathrm{PH}$ & $\mathrm{PM}$ & M \\
\hline
\end{tabular}




\begin{tabular}{|c|c|c|c|c|}
\hline M & $\mathrm{L}$ & $\mathrm{PH}$ & PH & $\mathrm{H}$ \\
\hline $\mathrm{M}$ & LM & $\mathrm{NH}$ & $\mathrm{NH}$ & $\mathrm{M}$ \\
\hline M & LM & $\mathrm{NH}$ & $\mathrm{NM}$ & $\mathrm{H}$ \\
\hline M & LM & $\mathrm{NH}$ & NL & $\mathrm{M}$ \\
\hline M & LM & $\mathrm{NH}$ & $\mathrm{ZE}$ & $\mathrm{M}$ \\
\hline M & LM & $\mathrm{NH}$ & $\mathrm{PL}$ & $\mathrm{M}$ \\
\hline M & LM & $\mathrm{NH}$ & $\mathrm{PM}$ & LM \\
\hline M & LM & $\mathrm{NH}$ & $\mathrm{PH}$ & $\mathrm{M}$ \\
\hline M & LM & NM & $\mathrm{NH}$ & LM \\
\hline M & LM & NM & $\mathrm{NM}$ & $\mathrm{MH}$ \\
\hline M & LM & $\mathrm{NM}$ & NL & LM \\
\hline M & LM & NM & $\mathrm{ZE}$ & LM \\
\hline M & LM & $\mathrm{NM}$ & $\mathrm{PL}$ & LM \\
\hline M & LM & $\mathrm{NM}$ & $\mathrm{PM}$ & LM \\
\hline M & LM & $\mathrm{NM}$ & $\mathrm{PH}$ & LM \\
\hline M & LM & NL & $\mathrm{NH}$ & M \\
\hline M & LM & NL & NM & $\mathrm{H}$ \\
\hline M & LM & NL & NL & $\mathrm{M}$ \\
\hline M & LM & NL & $\mathrm{ZE}$ & M \\
\hline M & LM & NL & PL & $\mathrm{M}$ \\
\hline M & LM & NL & $\mathrm{PM}$ & LM \\
\hline M & LM & NL & $\mathrm{PH}$ & $\mathrm{M}$ \\
\hline M & LM & $\mathrm{ZE}$ & $\mathrm{NH}$ & $\mathrm{M}$ \\
\hline M & $\mathrm{LM}$ & $\mathrm{ZE}$ & $\mathrm{NM}$ & $\mathrm{H}$ \\
\hline M & LM & ZE & NL & $\mathrm{M}$ \\
\hline M & LM & $\mathrm{ZE}$ & $\mathrm{ZE}$ & $\mathrm{M}$ \\
\hline M & LM & $\mathrm{ZE}$ & $\mathrm{PL}$ & $\mathrm{M}$ \\
\hline M & LM & $\mathrm{ZE}$ & $\mathrm{PM}$ & LM \\
\hline
\end{tabular}




\begin{tabular}{|c|c|c|c|c|}
\hline M & LM & $\mathrm{ZE}$ & $\mathrm{PH}$ & $\mathrm{M}$ \\
\hline M & LM & PL & $\mathrm{NH}$ & M \\
\hline M & LM & PL & $\mathrm{NM}$ & $\mathrm{H}$ \\
\hline M & LM & PL & NL & $\mathrm{M}$ \\
\hline M & LM & PL & ZE & M \\
\hline M & LM & PL & PL & M \\
\hline M & LM & PL & $\mathrm{PM}$ & LM \\
\hline M & LM & PL & $\mathrm{PH}$ & M \\
\hline $\mathrm{M}$ & LM & PM & $\mathrm{NH}$ & $\mathrm{MH}$ \\
\hline M & LM & PM & $\mathrm{NM}$ & $\mathrm{H}$ \\
\hline $\mathrm{M}$ & LM & $\mathrm{PM}$ & NL & $\mathrm{MH}$ \\
\hline M & LM & PM & ZE & $\mathrm{MH}$ \\
\hline $\mathrm{M}$ & LM & PM & PL & $\mathrm{MH}$ \\
\hline $\mathrm{M}$ & LM & PM & PM & $\mathrm{M}$ \\
\hline $\mathrm{M}$ & LM & PM & $\mathrm{PH}$ & $\mathrm{MH}$ \\
\hline $\mathrm{M}$ & LM & PH & $\mathrm{NH}$ & M \\
\hline $\mathrm{M}$ & LM & $\mathrm{PH}$ & $\mathrm{NM}$ & $\mathrm{H}$ \\
\hline M & LM & $\mathrm{PH}$ & NL & $\mathrm{M}$ \\
\hline M & LM & PH & ZE & $\mathrm{M}$ \\
\hline $\mathrm{M}$ & LM & $\mathrm{PH}$ & PL & $\mathrm{M}$ \\
\hline M & LM & PH & PM & LM \\
\hline M & LM & $\mathrm{PH}$ & $\mathrm{PH}$ & M \\
\hline $\mathrm{M}$ & $\mathrm{M}$ & $\mathrm{NH}$ & $\mathrm{NH}$ & LM \\
\hline M & M & $\mathrm{NH}$ & NM & $\mathrm{M}$ \\
\hline M & $\mathrm{M}$ & $\mathrm{NH}$ & NL & LM \\
\hline M & M & $\mathrm{NH}$ & ZE & LM \\
\hline M & M & $\mathrm{NH}$ & PL & LM \\
\hline M & $\mathrm{M}$ & $\mathrm{NH}$ & PM & LM \\
\hline
\end{tabular}




\begin{tabular}{|c|c|c|c|c|}
\hline M & $\mathrm{M}$ & $\mathrm{NH}$ & $\mathrm{PH}$ & LM \\
\hline $\mathrm{M}$ & $\mathrm{M}$ & NM & $\mathrm{NH}$ & LM \\
\hline M & M & NM & NM & LM \\
\hline M & M & NM & NL & LM \\
\hline M & $\mathrm{M}$ & NM & $\mathrm{ZE}$ & LM \\
\hline M & $\mathrm{M}$ & NM & PL & LM \\
\hline M & $\mathrm{M}$ & NM & $\mathrm{PM}$ & LM \\
\hline M & $\mathrm{M}$ & NM & $\mathrm{PH}$ & LM \\
\hline M & $\mathrm{M}$ & NL & $\mathrm{NH}$ & LM \\
\hline M & M & NL & NM & M \\
\hline M & $\mathrm{M}$ & NL & $\mathrm{NL}$ & LM \\
\hline M & M & NL & $\mathrm{ZE}$ & LM \\
\hline M & $\mathrm{M}$ & NL & PL & LM \\
\hline M & $\mathrm{M}$ & NL & PM & LM \\
\hline M & $\mathrm{M}$ & NL & $\mathrm{PH}$ & LM \\
\hline M & $\mathrm{M}$ & $\mathrm{ZE}$ & $\mathrm{NH}$ & LM \\
\hline M & $\mathrm{M}$ & $\mathrm{ZE}$ & $\mathrm{NM}$ & $\mathrm{M}$ \\
\hline M & $\mathrm{M}$ & $\mathrm{ZE}$ & NL & LM \\
\hline M & $\mathrm{M}$ & ZE & ZE & LM \\
\hline M & $\mathrm{M}$ & $\mathrm{ZE}$ & PL & LM \\
\hline M & M & ZE & PM & LM \\
\hline M & M & ZE & $\mathrm{PH}$ & LM \\
\hline M & $\mathrm{M}$ & PL & $\mathrm{NH}$ & LM \\
\hline M & $\mathrm{M}$ & PL & $\mathrm{NM}$ & $\mathrm{M}$ \\
\hline M & $\mathrm{M}$ & PL & NL & LM \\
\hline M & $\mathrm{M}$ & PL & $\mathrm{ZE}$ & LM \\
\hline M & $\mathrm{M}$ & PL & PL & LM \\
\hline M & M & PL & PM & LM \\
\hline
\end{tabular}




\begin{tabular}{|c|c|c|c|c|}
\hline M & M & PL & $\mathrm{PH}$ & LM \\
\hline M & $\mathrm{M}$ & $\mathrm{PM}$ & $\mathrm{NH}$ & $\mathrm{M}$ \\
\hline M & M & PM & $\mathrm{NM}$ & $\mathrm{MH}$ \\
\hline M & $\mathrm{M}$ & PM & NL & $\mathrm{M}$ \\
\hline M & M & PM & ZE & M \\
\hline M & M & PM & PL & M \\
\hline M & $\mathrm{M}$ & PM & $\mathrm{PM}$ & LM \\
\hline M & M & PM & $\mathrm{PH}$ & M \\
\hline $\mathrm{M}$ & $\mathrm{M}$ & $\mathrm{PH}$ & $\mathrm{NH}$ & LM \\
\hline M & M & $\mathrm{PH}$ & $\mathrm{NM}$ & M \\
\hline $\mathrm{M}$ & $\mathrm{M}$ & $\mathrm{PH}$ & NL & LM \\
\hline M & M & PH & ZE & LM \\
\hline $\mathrm{M}$ & $\mathrm{M}$ & $\mathrm{PH}$ & PL & LM \\
\hline $\mathrm{M}$ & $\mathrm{M}$ & $\mathrm{PH}$ & PM & LM \\
\hline $\mathrm{M}$ & $\mathrm{M}$ & PH & $\mathrm{PH}$ & LM \\
\hline $\mathrm{M}$ & $\mathrm{MH}$ & $\mathrm{NH}$ & $\mathrm{NH}$ & LM \\
\hline $\mathrm{M}$ & $\mathrm{MH}$ & $\mathrm{NH}$ & $\mathrm{NM}$ & LM \\
\hline $\mathrm{M}$ & $\mathrm{MH}$ & $\mathrm{NH}$ & NL & LM \\
\hline M & $\mathrm{MH}$ & $\mathrm{NH}$ & ZE & LM \\
\hline $\mathrm{M}$ & $\mathrm{MH}$ & $\mathrm{NH}$ & PL & LM \\
\hline M & $\mathrm{MH}$ & $\mathrm{NH}$ & PM & LM \\
\hline M & $\mathrm{MH}$ & $\mathrm{NH}$ & $\mathrm{PH}$ & LM \\
\hline $\mathrm{M}$ & $\mathrm{MH}$ & $\mathrm{NM}$ & $\mathrm{NH}$ & LM \\
\hline M & $\mathrm{MH}$ & $\mathrm{NM}$ & NM & LM \\
\hline M & $\mathrm{MH}$ & $\mathrm{NM}$ & NL & LM \\
\hline M & $\mathrm{MH}$ & $\mathrm{NM}$ & $\mathrm{ZE}$ & LM \\
\hline M & $\mathrm{MH}$ & $\mathrm{NM}$ & $\mathrm{PL}$ & LM \\
\hline M & $\mathrm{MH}$ & $\mathrm{NM}$ & PM & LM \\
\hline
\end{tabular}




\begin{tabular}{|c|c|c|c|c|}
\hline M & $\mathrm{MH}$ & NM & $\mathrm{PH}$ & LM \\
\hline $\mathrm{M}$ & $\mathrm{MH}$ & NL & $\mathrm{NH}$ & LM \\
\hline M & $\mathrm{MH}$ & NL & NM & LM \\
\hline M & $\mathrm{MH}$ & NL & NL & LM \\
\hline M & $\mathrm{MH}$ & NL & ZE & LM \\
\hline M & $\mathrm{MH}$ & NL & PL & LM \\
\hline M & $\mathrm{MH}$ & NL & $\mathrm{PM}$ & LM \\
\hline M & $\mathrm{MH}$ & NL & PH & LM \\
\hline M & $\mathrm{MH}$ & $\mathrm{ZE}$ & $\mathrm{NH}$ & LM \\
\hline M & $\mathrm{MH}$ & ZE & NM & LM \\
\hline M & $\mathrm{MH}$ & ZE & $\mathrm{NL}$ & LM \\
\hline M & $\mathrm{MH}$ & $\mathrm{ZE}$ & $\mathrm{ZE}$ & LM \\
\hline M & $\mathrm{MH}$ & $\mathrm{ZE}$ & PL & LM \\
\hline M & $\mathrm{MH}$ & $\mathrm{ZE}$ & PM & LM \\
\hline M & $\mathrm{MH}$ & ZE & PH & LM \\
\hline M & $\mathrm{MH}$ & PL & $\mathrm{NH}$ & LM \\
\hline M & $\mathrm{MH}$ & PL & $\mathrm{NM}$ & LM \\
\hline M & $\mathrm{MH}$ & PL & NL & LM \\
\hline M & $\mathrm{MH}$ & PL & ZE & LM \\
\hline M & $\mathrm{MH}$ & PL & PL & LM \\
\hline M & $\mathrm{MH}$ & PL & PM & LM \\
\hline M & $\mathrm{MH}$ & PL & $\mathrm{PH}$ & LM \\
\hline M & $\mathrm{MH}$ & PM & $\mathrm{NH}$ & LM \\
\hline M & $\mathrm{MH}$ & PM & $\mathrm{NM}$ & M \\
\hline M & $\mathrm{MH}$ & PM & NL & LM \\
\hline M & $\mathrm{MH}$ & PM & $\mathrm{ZE}$ & LM \\
\hline M & $\mathrm{MH}$ & PM & PL & LM \\
\hline M & $\mathrm{MH}$ & PM & PM & LM \\
\hline
\end{tabular}




\begin{tabular}{|c|c|c|c|c|}
\hline M & $\mathrm{MH}$ & $\mathrm{PM}$ & $\mathrm{PH}$ & LM \\
\hline $\mathrm{M}$ & $\mathrm{MH}$ & $\mathrm{PH}$ & $\mathrm{NH}$ & LM \\
\hline M & $\mathrm{MH}$ & $\mathrm{PH}$ & NM & LM \\
\hline M & $\mathrm{MH}$ & $\mathrm{PH}$ & NL & LM \\
\hline M & $\mathrm{MH}$ & $\mathrm{PH}$ & $\mathrm{ZE}$ & LM \\
\hline M & $\mathrm{MH}$ & $\mathrm{PH}$ & PL & LM \\
\hline M & $\mathrm{MH}$ & $\mathrm{PH}$ & $\mathrm{PM}$ & LM \\
\hline M & $\mathrm{MH}$ & $\mathrm{PH}$ & $\mathrm{PH}$ & LM \\
\hline M & $\mathrm{H}$ & $\mathrm{NH}$ & $\mathrm{NH}$ & LM \\
\hline M & $\mathrm{H}$ & $\mathrm{NH}$ & NM & LM \\
\hline M & $\mathrm{H}$ & $\mathrm{NH}$ & $\mathrm{NL}$ & LM \\
\hline M & $\mathrm{H}$ & $\mathrm{NH}$ & $\mathrm{ZE}$ & LM \\
\hline M & $\mathrm{H}$ & $\mathrm{NH}$ & PL & LM \\
\hline M & $\mathrm{H}$ & $\mathrm{NH}$ & $\mathrm{PM}$ & LM \\
\hline M & $\mathrm{H}$ & $\mathrm{NH}$ & $\mathrm{PH}$ & LM \\
\hline M & $\mathrm{H}$ & NM & $\mathrm{NH}$ & LM \\
\hline M & $\mathrm{H}$ & NM & $\mathrm{NM}$ & LM \\
\hline M & $\mathrm{H}$ & NM & NL & LM \\
\hline M & $\mathrm{H}$ & NM & ZE & LM \\
\hline M & $\mathrm{H}$ & NM & $\mathrm{PL}$ & LM \\
\hline M & $\mathrm{H}$ & NM & PM & LM \\
\hline M & $\mathrm{H}$ & NM & $\mathrm{PH}$ & LM \\
\hline M & $\mathrm{H}$ & NL & $\mathrm{NH}$ & LM \\
\hline M & $\mathrm{H}$ & NL & $\mathrm{NM}$ & LM \\
\hline M & $\mathrm{H}$ & NL & NL & LM \\
\hline M & $\mathrm{H}$ & NL & $\mathrm{ZE}$ & LM \\
\hline M & $\mathrm{H}$ & NL & PL & LM \\
\hline M & $\mathrm{H}$ & NL & PM & LM \\
\hline
\end{tabular}




\begin{tabular}{|c|c|c|c|c|}
\hline M & $\mathrm{H}$ & NL & $\mathrm{PH}$ & LM \\
\hline $\mathrm{M}$ & $\mathrm{H}$ & ZE & $\mathrm{NH}$ & LM \\
\hline M & $\mathrm{H}$ & ZE & NM & LM \\
\hline M & $\mathrm{H}$ & ZE & NL & LM \\
\hline M & $\mathrm{H}$ & $\mathrm{ZE}$ & $\mathrm{ZE}$ & LM \\
\hline M & $\mathrm{H}$ & ZE & PL & LM \\
\hline M & $\mathrm{H}$ & ZE & $\mathrm{PM}$ & LM \\
\hline M & $\mathrm{H}$ & ZE & $\mathrm{PH}$ & LM \\
\hline M & $\mathrm{H}$ & PL & $\mathrm{NH}$ & LM \\
\hline M & $\mathrm{H}$ & PL & NM & LM \\
\hline M & $\mathrm{H}$ & PL & $\mathrm{NL}$ & LM \\
\hline M & $\mathrm{H}$ & PL & $\mathrm{ZE}$ & LM \\
\hline M & $\mathrm{H}$ & PL & PL & LM \\
\hline M & $\mathrm{H}$ & PL & $\mathrm{PM}$ & LM \\
\hline M & $\mathrm{H}$ & PL & PH & LM \\
\hline M & $\mathrm{H}$ & $\mathrm{PM}$ & $\mathrm{NH}$ & LM \\
\hline M & $\mathrm{H}$ & $\mathrm{PM}$ & $\mathrm{NM}$ & LM \\
\hline M & $\mathrm{H}$ & $\mathrm{PM}$ & NL & LM \\
\hline M & $\mathrm{H}$ & PM & ZE & LM \\
\hline M & $\mathrm{H}$ & $\mathrm{PM}$ & PL & LM \\
\hline M & $\mathrm{H}$ & $\mathrm{PM}$ & PM & LM \\
\hline M & $\mathrm{H}$ & $\mathrm{PM}$ & $\mathrm{PH}$ & LM \\
\hline M & $\mathrm{H}$ & $\mathrm{PH}$ & $\mathrm{NH}$ & LM \\
\hline M & $\mathrm{H}$ & $\mathrm{PH}$ & NM & LM \\
\hline M & $\mathrm{H}$ & $\mathrm{PH}$ & NL & LM \\
\hline M & $\mathrm{H}$ & $\mathrm{PH}$ & $\mathrm{ZE}$ & LM \\
\hline M & $\mathrm{H}$ & $\mathrm{PH}$ & PL & LM \\
\hline M & $\mathrm{H}$ & $\mathrm{PH}$ & PM & LM \\
\hline
\end{tabular}




\begin{tabular}{|c|c|c|c|c|}
\hline M & $\mathrm{H}$ & $\mathrm{PH}$ & $\mathrm{PH}$ & LM \\
\hline MH & L & $\mathrm{NH}$ & $\mathrm{NH}$ & $\mathrm{H}$ \\
\hline $\mathrm{MH}$ & $\mathrm{L}$ & $\mathrm{NH}$ & NM & $\mathrm{H}$ \\
\hline $\mathrm{MH}$ & $\mathrm{L}$ & $\mathrm{NH}$ & NL & $\mathrm{H}$ \\
\hline $\mathrm{MH}$ & $\mathrm{L}$ & $\mathrm{NH}$ & $\mathrm{ZE}$ & $\mathrm{H}$ \\
\hline $\mathrm{MH}$ & $\mathrm{L}$ & $\mathrm{NH}$ & PL & $\mathrm{H}$ \\
\hline $\mathrm{MH}$ & $\mathrm{L}$ & $\mathrm{NH}$ & $\mathrm{PM}$ & $\mathrm{MH}$ \\
\hline $\mathrm{MH}$ & $\mathrm{L}$ & $\mathrm{NH}$ & $\mathrm{PH}$ & $\mathrm{H}$ \\
\hline $\mathrm{MH}$ & $\mathrm{L}$ & $\mathrm{NM}$ & $\mathrm{NH}$ & $\mathrm{H}$ \\
\hline $\mathrm{MH}$ & $\mathrm{L}$ & NM & NM & $\mathrm{H}$ \\
\hline $\mathrm{MH}$ & $\mathrm{L}$ & NM & NL & $\mathrm{H}$ \\
\hline MH & L & NM & $\mathrm{ZE}$ & $\mathrm{H}$ \\
\hline $\mathrm{MH}$ & $\mathrm{L}$ & $\mathrm{NM}$ & $\mathrm{PL}$ & $\mathrm{H}$ \\
\hline $\mathrm{MH}$ & $\mathrm{L}$ & $\mathrm{NM}$ & PM & $\mathrm{M}$ \\
\hline $\mathrm{MH}$ & L & NM & $\mathrm{PH}$ & $\mathrm{H}$ \\
\hline $\mathrm{MH}$ & $\mathrm{L}$ & NL & $\mathrm{NH}$ & $\mathrm{H}$ \\
\hline $\mathrm{MH}$ & $\mathrm{L}$ & NL & $\mathrm{NM}$ & $\mathrm{H}$ \\
\hline $\mathrm{MH}$ & $\mathrm{L}$ & NL & NL & $\mathrm{H}$ \\
\hline $\mathrm{MH}$ & $\mathrm{L}$ & NL & $\mathrm{ZE}$ & $\mathrm{H}$ \\
\hline $\mathrm{MH}$ & $\mathrm{L}$ & NL & PL & $\mathrm{H}$ \\
\hline $\mathrm{MH}$ & $\mathrm{L}$ & NL & $\mathrm{PM}$ & $\mathrm{MH}$ \\
\hline $\mathrm{MH}$ & $\mathrm{L}$ & NL & $\mathrm{PH}$ & $\mathrm{H}$ \\
\hline $\mathrm{MH}$ & $\mathrm{L}$ & $\mathrm{ZE}$ & $\mathrm{NH}$ & $\mathrm{H}$ \\
\hline $\mathrm{MH}$ & $\mathrm{L}$ & $\mathrm{ZE}$ & NM & $\mathrm{H}$ \\
\hline $\mathrm{MH}$ & $\mathrm{L}$ & $\mathrm{ZE}$ & NL & $\mathrm{H}$ \\
\hline $\mathrm{MH}$ & $\mathrm{L}$ & ZE & $\mathrm{ZE}$ & $\mathrm{H}$ \\
\hline $\mathrm{MH}$ & $\mathrm{L}$ & $\mathrm{ZE}$ & $\mathrm{PL}$ & $\mathrm{H}$ \\
\hline $\mathrm{MH}$ & $\mathrm{L}$ & $\mathrm{ZE}$ & $\mathrm{PM}$ & $\mathrm{MH}$ \\
\hline
\end{tabular}




\begin{tabular}{|c|c|c|c|c|}
\hline $\mathrm{MH}$ & $\mathrm{L}$ & $\mathrm{ZE}$ & $\mathrm{PH}$ & $\mathrm{H}$ \\
\hline MH & $\mathrm{L}$ & PL & $\mathrm{NH}$ & $\mathrm{H}$ \\
\hline $\mathrm{MH}$ & $\mathrm{L}$ & PL & NM & $\mathrm{H}$ \\
\hline $\mathrm{MH}$ & L & PL & NL & $\mathrm{H}$ \\
\hline $\mathrm{MH}$ & $\mathrm{L}$ & PL & $\mathrm{ZE}$ & $\mathrm{H}$ \\
\hline MH & L & PL & PL & $\mathrm{H}$ \\
\hline $\mathrm{MH}$ & $\mathrm{L}$ & PL & PM & $\mathrm{M}$ \\
\hline $\mathrm{MH}$ & $\mathrm{L}$ & PL & $\mathrm{PH}$ & $\mathrm{H}$ \\
\hline MH & $\mathrm{L}$ & $\mathrm{PM}$ & $\mathrm{NH}$ & $\mathrm{H}$ \\
\hline $\mathrm{MH}$ & $\mathrm{L}$ & PM & NM & $\mathrm{H}$ \\
\hline MH & $\mathrm{L}$ & PM & NL & $\mathrm{H}$ \\
\hline $\mathrm{MH}$ & L & PM & $\mathrm{ZE}$ & $\mathrm{H}$ \\
\hline $\mathrm{MH}$ & L & PM & PL & $\mathrm{H}$ \\
\hline $\mathrm{MH}$ & $\mathrm{L}$ & PM & $\mathrm{PM}$ & $\mathrm{H}$ \\
\hline $\mathrm{MH}$ & $\mathrm{L}$ & PM & $\mathrm{PH}$ & $\mathrm{H}$ \\
\hline $\mathrm{MH}$ & $\mathrm{L}$ & $\mathrm{PH}$ & $\mathrm{NH}$ & $\mathrm{H}$ \\
\hline MH & $\mathrm{L}$ & $\mathrm{PH}$ & NM & $\mathrm{H}$ \\
\hline $\mathrm{MH}$ & $\mathrm{L}$ & $\mathrm{PH}$ & NL & $\mathrm{H}$ \\
\hline $\mathrm{MH}$ & $\mathrm{L}$ & $\mathrm{PH}$ & $\mathrm{ZE}$ & $\mathrm{H}$ \\
\hline MH & L & $\mathrm{PH}$ & PL & $\mathrm{H}$ \\
\hline MH & L & $\mathrm{PH}$ & PM & $\mathrm{M}$ \\
\hline $\mathrm{MH}$ & L & $\mathrm{PH}$ & $\mathrm{PH}$ & $\mathrm{H}$ \\
\hline MH & LM & $\mathrm{NH}$ & $\mathrm{NH}$ & $\mathrm{MH}$ \\
\hline $\mathrm{MH}$ & LM & $\mathrm{NH}$ & NM & $\mathrm{H}$ \\
\hline $\mathrm{MH}$ & LM & $\mathrm{NH}$ & NL & $\mathrm{MH}$ \\
\hline MH & LM & $\mathrm{NH}$ & $\mathrm{ZE}$ & $\mathrm{MH}$ \\
\hline $\mathrm{MH}$ & LM & $\mathrm{NH}$ & $\mathrm{PL}$ & $\mathrm{MH}$ \\
\hline MH & LM & $\mathrm{NH}$ & $\mathrm{PM}$ & M \\
\hline
\end{tabular}




\begin{tabular}{|c|c|c|c|c|}
\hline MH & LM & $\mathrm{NH}$ & $\mathrm{PH}$ & MH \\
\hline $\mathrm{MH}$ & LM & $\mathrm{NM}$ & $\mathrm{NH}$ & M \\
\hline MH & LM & $\mathrm{NM}$ & NM & $\mathrm{H}$ \\
\hline MH & LM & $\mathrm{NM}$ & NL & M \\
\hline $\mathrm{MH}$ & LM & $\mathrm{NM}$ & $\mathrm{ZE}$ & $\mathrm{M}$ \\
\hline $\mathrm{MH}$ & LM & $\mathrm{NM}$ & PL & M \\
\hline $\mathrm{MH}$ & LM & $\mathrm{NM}$ & $\mathrm{PM}$ & LM \\
\hline MH & LM & $\mathrm{NM}$ & $\mathrm{PH}$ & M \\
\hline $\mathrm{MH}$ & LM & NL & $\mathrm{NH}$ & $\mathrm{MH}$ \\
\hline $\mathrm{MH}$ & LM & NL & $\mathrm{NM}$ & $\mathrm{H}$ \\
\hline MH & LM & NL & NL & $\mathrm{MH}$ \\
\hline $\mathrm{MH}$ & LM & NL & ZE & $\mathrm{MH}$ \\
\hline $\mathrm{MH}$ & LM & NL & PL & $\mathrm{MH}$ \\
\hline $\mathrm{MH}$ & LM & NL & PM & LM \\
\hline $\mathrm{MH}$ & LM & NL & $\mathrm{PH}$ & MH \\
\hline $\mathrm{MH}$ & LM & ZE & $\mathrm{NH}$ & MH \\
\hline $\mathrm{MH}$ & LM & $\mathrm{ZE}$ & NM & $\mathrm{H}$ \\
\hline $\mathrm{MH}$ & LM & $\mathrm{ZE}$ & NL & $\mathrm{MH}$ \\
\hline MH & LM & ZE & ZE & $\mathrm{MH}$ \\
\hline $\mathrm{MH}$ & LM & ZE & PL & $\mathrm{MH}$ \\
\hline $\mathrm{MH}$ & LM & $\mathrm{ZE}$ & PM & M \\
\hline MH & LM & ZE & $\mathrm{PH}$ & MH \\
\hline $\mathrm{MH}$ & LM & $\mathrm{PL}$ & $\mathrm{NH}$ & $\mathrm{MH}$ \\
\hline $\mathrm{MH}$ & LM & PL & $\mathrm{NM}$ & $\mathrm{H}$ \\
\hline $\mathrm{MH}$ & LM & PL & NL & MH \\
\hline MH & LM & PL & ZE & $\mathrm{MH}$ \\
\hline MH & LM & PL & PL & $\mathrm{MH}$ \\
\hline MHn & LM & PL & PM & M \\
\hline
\end{tabular}




\begin{tabular}{|c|c|c|c|c|}
\hline $\mathrm{MH}$ & LM & PL & $\mathrm{PH}$ & MH \\
\hline $\mathrm{MH}$ & LM & $\mathrm{PM}$ & $\mathrm{NH}$ & $\mathrm{H}$ \\
\hline MH & LM & PM & $\mathrm{NM}$ & $\mathrm{H}$ \\
\hline $\mathrm{MH}$ & LM & PM & NL & $\mathrm{H}$ \\
\hline $\mathrm{MH}$ & LM & PM & $\mathrm{ZE}$ & $\mathrm{H}$ \\
\hline MH & LM & PM & PL & $\mathrm{H}$ \\
\hline $\mathrm{MH}$ & LM & PM & $\mathrm{PM}$ & M \\
\hline $\mathrm{MH}$ & LM & PM & $\mathrm{PH}$ & $\mathrm{H}$ \\
\hline $\mathrm{MH}$ & LM & $\mathrm{PH}$ & $\mathrm{NH}$ & $\mathrm{MH}$ \\
\hline $\mathrm{MH}$ & LM & $\mathrm{PH}$ & $\mathrm{NM}$ & $\mathrm{H}$ \\
\hline $\mathrm{MH}$ & LM & $\mathrm{PH}$ & NL & $\mathrm{MH}$ \\
\hline $\mathrm{MH}$ & LM & PH & ZE & $\mathrm{MH}$ \\
\hline $\mathrm{MH}$ & LM & $\mathrm{PH}$ & PL & $\mathrm{MH}$ \\
\hline $\mathrm{MH}$ & LM & $\mathrm{PH}$ & PM & $\mathrm{M}$ \\
\hline $\mathrm{MH}$ & LM & PH & $\mathrm{PH}$ & $\mathrm{MH}$ \\
\hline $\mathrm{MH}$ & M & $\mathrm{NH}$ & $\mathrm{NH}$ & M \\
\hline $\mathrm{MH}$ & M & $\mathrm{NH}$ & NM & $\mathrm{MH}$ \\
\hline $\mathrm{MH}$ & $\mathrm{M}$ & $\mathrm{NH}$ & NL & M \\
\hline $\mathrm{MH}$ & $\mathrm{M}$ & $\mathrm{NH}$ & ZE & $\mathrm{M}$ \\
\hline MH & $\mathrm{M}$ & $\mathrm{NH}$ & PL & $\mathrm{M}$ \\
\hline $\mathrm{MH}$ & M & $\mathrm{NH}$ & PM & LM \\
\hline $\mathrm{MH}$ & M & $\mathrm{NH}$ & $\mathrm{PH}$ & M \\
\hline MH & $\mathrm{M}$ & $\mathrm{NM}$ & $\mathrm{NH}$ & LM \\
\hline $\mathrm{MH}$ & $\mathrm{M}$ & $\mathrm{NM}$ & $\mathrm{NM}$ & $\mathrm{M}$ \\
\hline $\mathrm{MH}$ & $\mathrm{M}$ & $\mathrm{NM}$ & NL & LM \\
\hline MH & M & $\mathrm{NM}$ & ZE & LM \\
\hline MH & M & $\mathrm{NM}$ & PL & LM \\
\hline $\mathrm{MH}$ & M & $\mathrm{NM}$ & PM & LM \\
\hline
\end{tabular}




\begin{tabular}{|c|c|c|c|c|}
\hline $\mathrm{MH}$ & $\mathrm{M}$ & NM & $\mathrm{PH}$ & LM \\
\hline MH & M & NL & $\mathrm{NH}$ & M \\
\hline $\mathrm{MH}$ & M & $\mathrm{NL}$ & NM & $\mathrm{MH}$ \\
\hline $\mathrm{MH}$ & $\mathrm{M}$ & NL & NL & $\mathrm{M}$ \\
\hline $\mathrm{MH}$ & $\mathrm{M}$ & NL & ZE & $\mathrm{M}$ \\
\hline MH & M & NL & PL & M \\
\hline $\mathrm{MH}$ & $\mathrm{M}$ & NL & $\mathrm{PM}$ & LM \\
\hline $\mathrm{MH}$ & $\mathrm{M}$ & $\mathrm{NL}$ & $\mathrm{PH}$ & $\mathrm{M}$ \\
\hline $\mathrm{MH}$ & $\mathrm{M}$ & $\mathrm{ZE}$ & $\mathrm{NH}$ & $\mathrm{M}$ \\
\hline MH & M & ZE & NM & $\mathrm{MH}$ \\
\hline $\mathrm{MH}$ & $\mathrm{M}$ & $\mathrm{ZE}$ & NL & $\mathrm{M}$ \\
\hline $\mathrm{MH}$ & M & $\mathrm{ZE}$ & $\mathrm{ZE}$ & M \\
\hline $\mathrm{MH}$ & $\mathrm{M}$ & $\mathrm{ZE}$ & PL & $\mathrm{M}$ \\
\hline $\mathrm{MH}$ & $\mathrm{M}$ & $\mathrm{ZE}$ & $\mathrm{PM}$ & LM \\
\hline $\mathrm{MH}$ & $\mathrm{M}$ & $\mathrm{ZE}$ & $\mathrm{PH}$ & $\mathrm{M}$ \\
\hline $\mathrm{MH}$ & $\mathrm{M}$ & PL & $\mathrm{NH}$ & $\mathrm{M}$ \\
\hline MH & $\mathrm{M}$ & PL & NM & $\mathrm{MH}$ \\
\hline MH & $\mathrm{M}$ & PL & NL & $\mathrm{M}$ \\
\hline $\mathrm{MH}$ & $\mathrm{M}$ & PL & $\mathrm{ZE}$ & $\mathrm{M}$ \\
\hline $\mathrm{MH}$ & $\mathrm{M}$ & PL & PL & $\mathrm{M}$ \\
\hline MH & $\mathrm{M}$ & PL & PM & LM \\
\hline $\mathrm{MH}$ & $\mathrm{M}$ & PL & $\mathrm{PH}$ & $\mathrm{M}$ \\
\hline MH & $\mathrm{M}$ & PM & $\mathrm{NH}$ & $\mathrm{M}$ \\
\hline $\mathrm{MH}$ & $\mathrm{M}$ & PM & NM & $\mathrm{H}$ \\
\hline MH & $\mathrm{M}$ & PM & NL & $\mathrm{M}$ \\
\hline MH & $\mathrm{M}$ & $\mathrm{PM}$ & $\mathrm{ZE}$ & $\mathrm{M}$ \\
\hline $\mathrm{MH}$ & $\mathrm{M}$ & PM & $\mathrm{PL}$ & $\mathrm{M}$ \\
\hline MH & M & $\mathrm{PM}$ & $\mathrm{PM}$ & M \\
\hline
\end{tabular}




\begin{tabular}{|c|c|c|c|c|}
\hline $\mathrm{MH}$ & M & PM & $\mathrm{PH}$ & M \\
\hline $\mathrm{MH}$ & $\mathrm{M}$ & $\mathrm{PH}$ & $\mathrm{NH}$ & M \\
\hline $\mathrm{MH}$ & M & $\mathrm{PH}$ & $\mathrm{NM}$ & $\mathrm{MH}$ \\
\hline $\mathrm{MH}$ & $\mathrm{M}$ & $\mathrm{PH}$ & NL & $\mathrm{M}$ \\
\hline $\mathrm{MH}$ & $\mathrm{M}$ & $\mathrm{PH}$ & $\mathrm{ZE}$ & $\mathrm{M}$ \\
\hline MH & M & $\mathrm{PH}$ & PL & M \\
\hline $\mathrm{MH}$ & $\mathrm{M}$ & $\mathrm{PH}$ & $\mathrm{PM}$ & LM \\
\hline MH & M & $\mathrm{PH}$ & $\mathrm{PH}$ & M \\
\hline $\mathrm{MH}$ & $\mathrm{MH}$ & $\mathrm{NH}$ & $\mathrm{NH}$ & LM \\
\hline $\mathrm{MH}$ & $\mathrm{MH}$ & $\mathrm{NH}$ & $\mathrm{NM}$ & M \\
\hline $\mathrm{MH}$ & $\mathrm{MH}$ & $\mathrm{NH}$ & NL & LM \\
\hline $\mathrm{MH}$ & $\mathrm{MH}$ & $\mathrm{NH}$ & $\mathrm{ZE}$ & LM \\
\hline $\mathrm{MH}$ & $\mathrm{MH}$ & $\mathrm{NH}$ & PL & LM \\
\hline $\mathrm{MH}$ & $\mathrm{MH}$ & $\mathrm{NH}$ & $\mathrm{PM}$ & LM \\
\hline $\mathrm{MH}$ & $\mathrm{MH}$ & $\mathrm{NH}$ & $\mathrm{PH}$ & LM \\
\hline $\mathrm{MH}$ & $\mathrm{MH}$ & $\mathrm{NM}$ & $\mathrm{NH}$ & LM \\
\hline $\mathrm{MH}$ & $\mathrm{MH}$ & $\mathrm{NM}$ & $\mathrm{NM}$ & LM \\
\hline $\mathrm{MH}$ & $\mathrm{MH}$ & $\mathrm{NM}$ & NL & LM \\
\hline $\mathrm{MH}$ & $\mathrm{MH}$ & $\mathrm{NM}$ & $\mathrm{ZE}$ & LM \\
\hline $\mathrm{MH}$ & $\mathrm{MH}$ & $\mathrm{NM}$ & PL & LM \\
\hline $\mathrm{MH}$ & $\mathrm{MH}$ & $\mathrm{NM}$ & $\mathrm{PM}$ & LM \\
\hline MH & $\mathrm{MH}$ & $\mathrm{NM}$ & $\mathrm{PH}$ & LM \\
\hline $\mathrm{MH}$ & $\mathrm{MH}$ & NL & $\mathrm{NH}$ & LM \\
\hline $\mathrm{MH}$ & $\mathrm{MH}$ & NL & $\mathrm{NM}$ & $\mathrm{M}$ \\
\hline $\mathrm{MH}$ & $\mathrm{MH}$ & NL & NL & LM \\
\hline MH & $\mathrm{MH}$ & $\mathrm{NL}$ & $\mathrm{ZE}$ & LM \\
\hline $\mathrm{MH}$ & $\mathrm{MH}$ & $\mathrm{NL}$ & $\mathrm{PL}$ & LM \\
\hline MH & $\mathrm{MH}$ & $\mathrm{NL}$ & $\mathrm{PM}$ & LM \\
\hline
\end{tabular}




\begin{tabular}{|c|c|c|c|c|}
\hline MH & $\mathrm{MH}$ & NL & $\mathrm{PH}$ & LM \\
\hline $\mathrm{MH}$ & $\mathrm{MH}$ & $\mathrm{ZE}$ & $\mathrm{NH}$ & LM \\
\hline $\mathrm{MH}$ & $\mathrm{MH}$ & $\mathrm{ZE}$ & $\mathrm{NM}$ & M \\
\hline $\mathrm{MH}$ & $\mathrm{MH}$ & $\mathrm{ZE}$ & NL & LM \\
\hline $\mathrm{MH}$ & $\mathrm{MH}$ & $\mathrm{ZE}$ & $\mathrm{ZE}$ & LM \\
\hline MH & $\mathrm{MH}$ & ZE & PL & LM \\
\hline $\mathrm{MH}$ & $\mathrm{MH}$ & $\mathrm{ZE}$ & $\mathrm{PM}$ & LM \\
\hline $\mathrm{MH}$ & $\mathrm{MH}$ & ZE & $\mathrm{PH}$ & LM \\
\hline $\mathrm{MH}$ & $\mathrm{MH}$ & PL & $\mathrm{NH}$ & LM \\
\hline $\mathrm{MH}$ & $\mathrm{MH}$ & PL & $\mathrm{NM}$ & $\mathrm{M}$ \\
\hline MH & $\mathrm{MH}$ & PL & NL & LM \\
\hline $\mathrm{MH}$ & $\mathrm{MH}$ & PL & ZE & LM \\
\hline $\mathrm{MH}$ & $\mathrm{MH}$ & PL & PL & LM \\
\hline $\mathrm{MH}$ & $\mathrm{MH}$ & PL & PM & LM \\
\hline $\mathrm{MH}$ & $\mathrm{MH}$ & PL & $\mathrm{PH}$ & LM \\
\hline $\mathrm{MH}$ & $\mathrm{MH}$ & PM & $\mathrm{NH}$ & M \\
\hline $\mathrm{MH}$ & $\mathrm{MH}$ & $\mathrm{PM}$ & NM & $\mathrm{M}$ \\
\hline $\mathrm{MH}$ & $\mathrm{MH}$ & PM & NL & M \\
\hline $\mathrm{MH}$ & $\mathrm{MH}$ & PM & ZE & M \\
\hline MH & $\mathrm{MH}$ & PM & PL & $\mathrm{M}$ \\
\hline $\mathrm{MH}$ & $\mathrm{MH}$ & PM & PM & LM \\
\hline $\mathrm{MH}$ & $\mathrm{MH}$ & PM & $\mathrm{PH}$ & M \\
\hline $\mathrm{MH}$ & $\mathrm{MH}$ & $\mathrm{PH}$ & $\mathrm{NH}$ & LM \\
\hline $\mathrm{MH}$ & $\mathrm{MH}$ & PH & $\mathrm{NM}$ & $\mathrm{M}$ \\
\hline $\mathrm{MH}$ & $\mathrm{MH}$ & PH & NL & LM \\
\hline MH & $\mathrm{MH}$ & $\mathrm{PH}$ & ZE & LM \\
\hline MH & $\mathrm{MH}$ & $\mathrm{PH}$ & PL & LM \\
\hline $\mathrm{MH}$ & $\mathrm{MH}$ & PH & PM & LM \\
\hline
\end{tabular}




\begin{tabular}{|c|c|c|c|c|}
\hline $\mathrm{MH}$ & $\mathrm{MH}$ & $\mathrm{PH}$ & $\mathrm{PH}$ & LM \\
\hline $\mathrm{MH}$ & $\mathrm{H}$ & $\mathrm{NH}$ & $\mathrm{NH}$ & LM \\
\hline MH & $\mathrm{H}$ & $\mathrm{NH}$ & $\mathrm{NM}$ & LM \\
\hline $\mathrm{MH}$ & $\mathrm{H}$ & $\mathrm{NH}$ & NL & LM \\
\hline $\mathrm{MH}$ & $\mathrm{H}$ & $\mathrm{NH}$ & $\mathrm{ZE}$ & LM \\
\hline MH & $\mathrm{H}$ & $\mathrm{NH}$ & PL & LM \\
\hline $\mathrm{MH}$ & $\mathrm{H}$ & $\mathrm{NH}$ & $\mathrm{PM}$ & LM \\
\hline $\mathrm{MH}$ & $\mathrm{H}$ & $\mathrm{NH}$ & $\mathrm{PH}$ & LM \\
\hline $\mathrm{MH}$ & $\mathrm{H}$ & $\mathrm{NM}$ & $\mathrm{NH}$ & LM \\
\hline $\mathrm{MH}$ & $\mathrm{H}$ & $\mathrm{NM}$ & $\mathrm{NM}$ & LM \\
\hline $\mathrm{MH}$ & $\mathrm{H}$ & $\mathrm{NM}$ & NL & LM \\
\hline $\mathrm{MH}$ & $\mathrm{H}$ & $\mathrm{NM}$ & ZE & LM \\
\hline $\mathrm{MH}$ & $\mathrm{H}$ & $\mathrm{NM}$ & PL & LM \\
\hline $\mathrm{MH}$ & $\mathrm{H}$ & $\mathrm{NM}$ & PM & LM \\
\hline $\mathrm{MH}$ & $\mathrm{H}$ & $\mathrm{NM}$ & $\mathrm{PH}$ & LM \\
\hline $\mathrm{MH}$ & $\mathrm{H}$ & NL & $\mathrm{NH}$ & LM \\
\hline $\mathrm{MH}$ & $\mathrm{H}$ & $\mathrm{NL}$ & NM & LM \\
\hline $\mathrm{MH}$ & $\mathrm{H}$ & NL & NL & LM \\
\hline $\mathrm{MH}$ & $\mathrm{H}$ & NL & ZE & LM \\
\hline MH & $\mathrm{H}$ & NL & PL & LM \\
\hline $\mathrm{MH}$ & $\mathrm{H}$ & NL & PM & LM \\
\hline $\mathrm{MH}$ & $\mathrm{H}$ & NL & $\mathrm{PH}$ & LM \\
\hline $\mathrm{MH}$ & $\mathrm{H}$ & $\mathrm{ZE}$ & $\mathrm{NH}$ & LM \\
\hline $\mathrm{MH}$ & $\mathrm{H}$ & ZE & $\mathrm{NM}$ & LM \\
\hline $\mathrm{MH}$ & $\mathrm{H}$ & $\mathrm{ZE}$ & NL & LM \\
\hline MH & $\mathrm{H}$ & ZE & ZE & LM \\
\hline MH & $\mathrm{H}$ & $\mathrm{ZE}$ & PL & LM \\
\hline $\mathrm{MH}$ & $\mathrm{H}$ & ZE & PM & LM \\
\hline
\end{tabular}




\begin{tabular}{|c|c|c|c|c|}
\hline $\mathrm{MH}$ & $\mathrm{H}$ & $\mathrm{ZE}$ & $\mathrm{PH}$ & LM \\
\hline $\mathrm{MH}$ & $\mathrm{H}$ & PL & $\mathrm{NH}$ & LM \\
\hline $\mathrm{MH}$ & $\mathrm{H}$ & PL & NM & LM \\
\hline $\mathrm{MH}$ & $\mathrm{H}$ & PL & NL & LM \\
\hline $\mathrm{MH}$ & $\mathrm{H}$ & PL & $\mathrm{ZE}$ & LM \\
\hline MH & $\mathrm{H}$ & PL & PL & LM \\
\hline $\mathrm{MH}$ & $\mathrm{H}$ & PL & PM & LM \\
\hline $\mathrm{MH}$ & $\mathrm{H}$ & PL & $\mathrm{PH}$ & LM \\
\hline $\mathrm{MH}$ & $\mathrm{H}$ & $\mathrm{PM}$ & $\mathrm{NH}$ & LM \\
\hline MH & $\mathrm{H}$ & PM & $\mathrm{NM}$ & M \\
\hline MH & $\mathrm{H}$ & PM & NL & LM \\
\hline $\mathrm{MH}$ & $\mathrm{H}$ & PM & $\mathrm{ZE}$ & LM \\
\hline $\mathrm{MH}$ & $\mathrm{H}$ & PM & PL & LM \\
\hline $\mathrm{MH}$ & $\mathrm{H}$ & PM & $\mathrm{PM}$ & LM \\
\hline $\mathrm{MH}$ & $\mathrm{H}$ & $\mathrm{PM}$ & $\mathrm{PH}$ & LM \\
\hline $\mathrm{MH}$ & $\mathrm{H}$ & $\mathrm{PH}$ & $\mathrm{NH}$ & LM \\
\hline $\mathrm{MH}$ & $\mathrm{H}$ & $\mathrm{PH}$ & $\mathrm{NM}$ & LM \\
\hline $\mathrm{MH}$ & $\mathrm{H}$ & $\mathrm{PH}$ & NL & LM \\
\hline $\mathrm{MH}$ & $\mathrm{H}$ & $\mathrm{PH}$ & $\mathrm{ZE}$ & LM \\
\hline MH & $\mathrm{H}$ & $\mathrm{PH}$ & PL & LM \\
\hline MH & $\mathrm{H}$ & $\mathrm{PH}$ & $\mathrm{PM}$ & LM \\
\hline MH & $\mathrm{H}$ & $\mathrm{PH}$ & $\mathrm{PH}$ & LM \\
\hline $\mathrm{H}$ & $\mathrm{L}$ & $\mathrm{NH}$ & $\mathrm{NH}$ & $\mathrm{H}$ \\
\hline $\mathrm{H}$ & $\mathrm{L}$ & $\mathrm{NH}$ & $\mathrm{NM}$ & $\mathrm{H}$ \\
\hline $\mathrm{H}$ & $\mathrm{L}$ & $\mathrm{NH}$ & NL & $\mathrm{H}$ \\
\hline $\mathrm{H}$ & $\mathrm{L}$ & $\mathrm{NH}$ & $\mathrm{ZE}$ & $\mathrm{H}$ \\
\hline $\mathrm{H}$ & $\mathrm{L}$ & $\mathrm{NH}$ & $\mathrm{PL}$ & $\mathrm{H}$ \\
\hline $\mathrm{H}$ & L & $\mathrm{NH}$ & $\mathrm{PM}$ & $\mathrm{H}$ \\
\hline
\end{tabular}




\begin{tabular}{|c|c|c|c|c|}
\hline $\mathrm{H}$ & $\mathrm{L}$ & $\mathrm{NH}$ & $\mathrm{PH}$ & $\mathrm{H}$ \\
\hline $\mathrm{H}$ & $\mathrm{L}$ & $\mathrm{NM}$ & $\mathrm{NH}$ & $\mathrm{H}$ \\
\hline $\mathrm{H}$ & $\mathrm{L}$ & $\mathrm{NM}$ & NM & $\mathrm{H}$ \\
\hline $\mathrm{H}$ & $\mathrm{L}$ & $\mathrm{NM}$ & NL & $\mathrm{H}$ \\
\hline $\mathrm{H}$ & $\mathrm{L}$ & $\mathrm{NM}$ & $\mathrm{ZE}$ & $\mathrm{H}$ \\
\hline $\mathrm{H}$ & $\mathrm{L}$ & $\mathrm{NM}$ & PL & $\mathrm{H}$ \\
\hline $\mathrm{H}$ & $\mathrm{L}$ & $\mathrm{NM}$ & $\mathrm{PM}$ & $\mathrm{MH}$ \\
\hline $\mathrm{H}$ & $\mathrm{L}$ & $\mathrm{NM}$ & $\mathrm{PH}$ & $\mathrm{H}$ \\
\hline $\mathrm{H}$ & $\mathrm{L}$ & NL & $\mathrm{NH}$ & $\mathrm{H}$ \\
\hline $\mathrm{H}$ & L & NL & NM & $\mathrm{H}$ \\
\hline $\mathrm{H}$ & $\mathrm{L}$ & $\mathrm{NL}$ & NL & $\mathrm{H}$ \\
\hline $\mathrm{H}$ & $\mathrm{L}$ & NL & ZE & $\mathrm{H}$ \\
\hline $\mathrm{H}$ & $\mathrm{L}$ & NL & PL & $\mathrm{H}$ \\
\hline $\mathrm{H}$ & $\mathrm{L}$ & $\mathrm{NL}$ & $\mathrm{PM}$ & $\mathrm{H}$ \\
\hline $\mathrm{H}$ & $\mathrm{L}$ & NL & $\mathrm{PH}$ & $\mathrm{H}$ \\
\hline $\mathrm{H}$ & $\mathrm{L}$ & ZE & $\mathrm{NH}$ & $\mathrm{H}$ \\
\hline $\mathrm{H}$ & $\mathrm{L}$ & $\mathrm{ZE}$ & NM & $\mathrm{H}$ \\
\hline $\mathrm{H}$ & $\mathrm{L}$ & $\mathrm{ZE}$ & NL & $\mathrm{H}$ \\
\hline $\mathrm{H}$ & $\mathrm{L}$ & $\mathrm{ZE}$ & $\mathrm{ZE}$ & $\mathrm{H}$ \\
\hline $\mathrm{H}$ & $\mathrm{L}$ & $\mathrm{ZE}$ & PL & $\mathrm{H}$ \\
\hline $\mathrm{H}$ & $\mathrm{L}$ & $\mathrm{ZE}$ & $\mathrm{PM}$ & $\mathrm{H}$ \\
\hline $\mathrm{H}$ & $\mathrm{L}$ & ZE & $\mathrm{PH}$ & $\mathrm{H}$ \\
\hline $\mathrm{H}$ & L & PL & $\mathrm{NH}$ & $\mathrm{H}$ \\
\hline $\mathrm{H}$ & $\mathrm{L}$ & $\mathrm{PL}$ & NM & $\mathrm{H}$ \\
\hline $\mathrm{H}$ & $\mathrm{L}$ & PL & NL & $\mathrm{H}$ \\
\hline $\mathrm{H}$ & $\mathrm{L}$ & PL & ZE & $\mathrm{H}$ \\
\hline $\mathrm{H}$ & $\mathrm{L}$ & $\mathrm{PL}$ & PL & $\mathrm{H}$ \\
\hline $\mathrm{H}$ & L & PL & $\mathrm{PM}$ & $\mathrm{H}$ \\
\hline
\end{tabular}




\begin{tabular}{|c|c|c|c|c|}
\hline $\mathrm{H}$ & $\mathrm{L}$ & $\mathrm{PL}$ & $\mathrm{PH}$ & $\mathrm{H}$ \\
\hline $\mathrm{H}$ & $\mathrm{L}$ & $\mathrm{PM}$ & $\mathrm{NH}$ & $\mathrm{H}$ \\
\hline $\mathrm{H}$ & $\mathrm{L}$ & $\mathrm{PM}$ & NM & $\mathrm{H}$ \\
\hline $\mathrm{H}$ & $\mathrm{L}$ & $\mathrm{PM}$ & NL & $\mathrm{H}$ \\
\hline $\mathrm{H}$ & $\mathrm{L}$ & $\mathrm{PM}$ & $\mathrm{ZE}$ & $\mathrm{H}$ \\
\hline $\mathrm{H}$ & $\mathrm{L}$ & $\mathrm{PM}$ & PL & $\mathrm{H}$ \\
\hline $\mathrm{H}$ & $\mathrm{L}$ & $\mathrm{PM}$ & $\mathrm{PM}$ & $\mathrm{H}$ \\
\hline $\mathrm{H}$ & $\mathrm{L}$ & PM & $\mathrm{PH}$ & $\mathrm{H}$ \\
\hline $\mathrm{H}$ & $\mathrm{L}$ & $\mathrm{PH}$ & $\mathrm{NH}$ & $\mathrm{H}$ \\
\hline $\mathrm{H}$ & L & $\mathrm{PH}$ & NM & $\mathrm{H}$ \\
\hline $\mathrm{H}$ & $\mathrm{L}$ & $\mathrm{PH}$ & NL & $\mathrm{H}$ \\
\hline $\mathrm{H}$ & $\mathrm{L}$ & $\mathrm{PH}$ & ZE & $\mathrm{H}$ \\
\hline $\mathrm{H}$ & $\mathrm{L}$ & $\mathrm{PH}$ & PL & $\mathrm{H}$ \\
\hline $\mathrm{H}$ & $\mathrm{L}$ & $\mathrm{PH}$ & $\mathrm{PM}$ & $\mathrm{H}$ \\
\hline $\mathrm{H}$ & $\mathrm{L}$ & $\mathrm{PH}$ & $\mathrm{PH}$ & $\mathrm{H}$ \\
\hline $\mathrm{H}$ & LM & $\mathrm{NH}$ & $\mathrm{NH}$ & $\mathrm{H}$ \\
\hline $\mathrm{H}$ & LM & $\mathrm{NH}$ & NM & $\mathrm{H}$ \\
\hline $\mathrm{H}$ & LM & $\mathrm{NH}$ & NL & $\mathrm{H}$ \\
\hline $\mathrm{H}$ & LM & $\mathrm{NH}$ & $\mathrm{ZE}$ & $\mathrm{H}$ \\
\hline $\mathrm{H}$ & LM & $\mathrm{NH}$ & PL & $\mathrm{H}$ \\
\hline $\mathrm{H}$ & LM & $\mathrm{NH}$ & $\mathrm{PM}$ & $\mathrm{MH}$ \\
\hline $\mathrm{H}$ & LM & $\mathrm{NH}$ & $\mathrm{PH}$ & $\mathrm{H}$ \\
\hline $\mathrm{H}$ & LM & $\mathrm{NM}$ & $\mathrm{NH}$ & $\mathrm{MH}$ \\
\hline $\mathrm{H}$ & LM & $\mathrm{NM}$ & NM & $\mathrm{H}$ \\
\hline $\mathrm{H}$ & LM & $\mathrm{NM}$ & NL & $\mathrm{MH}$ \\
\hline $\mathrm{H}$ & LM & $\mathrm{NM}$ & ZE & $\mathrm{MH}$ \\
\hline $\mathrm{H}$ & LM & $\mathrm{NM}$ & $\mathrm{PL}$ & $\mathrm{MH}$ \\
\hline $\mathrm{H}$ & LM & $\mathrm{NM}$ & $\mathrm{PM}$ & $\mathrm{M}$ \\
\hline
\end{tabular}




\begin{tabular}{|c|c|c|c|c|}
\hline $\mathrm{H}$ & LM & $\mathrm{NM}$ & $\mathrm{PH}$ & $\mathrm{MH}$ \\
\hline $\mathrm{H}$ & LM & NL & $\mathrm{NH}$ & $\mathrm{H}$ \\
\hline $\mathrm{H}$ & LM & NL & $\mathrm{NM}$ & $\mathrm{H}$ \\
\hline $\mathrm{H}$ & LM & NL & NL & $\mathrm{H}$ \\
\hline $\mathrm{H}$ & LM & NL & $\mathrm{ZE}$ & $\mathrm{H}$ \\
\hline $\mathrm{H}$ & LM & NL & PL & $\mathrm{H}$ \\
\hline $\mathrm{H}$ & LM & NL & PM & MH \\
\hline $\mathrm{H}$ & LM & NL & $\mathrm{PH}$ & $\mathrm{H}$ \\
\hline $\mathrm{H}$ & LM & $\mathrm{ZE}$ & $\mathrm{NH}$ & $\mathrm{H}$ \\
\hline $\mathrm{H}$ & LM & ZE & $\mathrm{NM}$ & $\mathrm{H}$ \\
\hline $\mathrm{H}$ & LM & ZE & NL & $\mathrm{H}$ \\
\hline $\mathrm{H}$ & LM & ZE & ZE & $\mathrm{H}$ \\
\hline $\mathrm{H}$ & LM & ZE & PL & $\mathrm{H}$ \\
\hline $\mathrm{H}$ & LM & $\mathrm{ZE}$ & PM & MH \\
\hline $\mathrm{H}$ & LM & ZE & $\mathrm{PH}$ & $\mathrm{H}$ \\
\hline $\mathrm{H}$ & LM & PL & $\mathrm{NH}$ & $\mathrm{H}$ \\
\hline $\mathrm{H}$ & LM & PL & NM & $\mathrm{H}$ \\
\hline $\mathrm{H}$ & LM & PL & NL & $\mathrm{H}$ \\
\hline $\mathrm{H}$ & LM & PL & ZE & $\mathrm{H}$ \\
\hline $\mathrm{H}$ & LM & PL & PL & $\mathrm{H}$ \\
\hline $\mathrm{H}$ & LM & PL & $\mathrm{PM}$ & $\mathrm{MH}$ \\
\hline $\mathrm{H}$ & LM & PL & $\mathrm{PH}$ & $\mathrm{H}$ \\
\hline $\mathrm{H}$ & LM & PM & $\mathrm{NH}$ & $\mathrm{H}$ \\
\hline $\mathrm{H}$ & LM & PM & NM & $\mathrm{H}$ \\
\hline $\mathrm{H}$ & LM & PM & NL & $\mathrm{H}$ \\
\hline $\mathrm{H}$ & LM & $\mathrm{PM}$ & $\mathrm{ZE}$ & $\mathrm{H}$ \\
\hline $\mathrm{H}$ & LM & PM & PL & $\mathrm{H}$ \\
\hline $\mathrm{H}$ & LM & PM & $\mathrm{PM}$ & $\mathrm{MH}$ \\
\hline
\end{tabular}




\begin{tabular}{|c|c|c|c|c|}
\hline $\mathrm{H}$ & LM & $\mathrm{PM}$ & $\mathrm{PH}$ & $\mathrm{H}$ \\
\hline $\mathrm{H}$ & LM & $\mathrm{PH}$ & $\mathrm{NH}$ & $\mathrm{H}$ \\
\hline $\mathrm{H}$ & LM & PH & NM & $\mathrm{H}$ \\
\hline $\mathrm{H}$ & LM & $\mathrm{PH}$ & NL & $\mathrm{H}$ \\
\hline $\mathrm{H}$ & LM & $\mathrm{PH}$ & $\mathrm{ZE}$ & $\mathrm{H}$ \\
\hline $\mathrm{H}$ & LM & $\mathrm{PH}$ & PL & $\mathrm{H}$ \\
\hline $\mathrm{H}$ & LM & $\mathrm{PH}$ & $\mathrm{PM}$ & $\mathrm{MH}$ \\
\hline $\mathrm{H}$ & LM & $\mathrm{PH}$ & $\mathrm{PH}$ & $\mathrm{H}$ \\
\hline $\mathrm{H}$ & M & $\mathrm{NH}$ & $\mathrm{NH}$ & $\mathrm{MH}$ \\
\hline $\mathrm{H}$ & $\mathrm{M}$ & $\mathrm{NH}$ & NM & $\mathrm{H}$ \\
\hline $\mathrm{H}$ & $\mathrm{M}$ & $\mathrm{NH}$ & NL & $\mathrm{MH}$ \\
\hline $\mathrm{H}$ & $\mathrm{M}$ & $\mathrm{NH}$ & ZE & $\mathrm{MH}$ \\
\hline $\mathrm{H}$ & $\mathrm{M}$ & $\mathrm{NH}$ & PL & $\mathrm{MH}$ \\
\hline $\mathrm{H}$ & $\mathrm{M}$ & $\mathrm{NH}$ & $\mathrm{PM}$ & $\mathrm{M}$ \\
\hline $\mathrm{H}$ & $\mathrm{M}$ & $\mathrm{NH}$ & $\mathrm{PH}$ & $\mathrm{MH}$ \\
\hline $\mathrm{H}$ & $\mathrm{M}$ & $\mathrm{NM}$ & $\mathrm{NH}$ & M \\
\hline $\mathrm{H}$ & $\mathrm{M}$ & $\mathrm{NM}$ & NM & $\mathrm{MH}$ \\
\hline $\mathrm{H}$ & $\mathrm{M}$ & $\mathrm{NM}$ & NL & $\mathrm{M}$ \\
\hline $\mathrm{H}$ & $\mathrm{M}$ & $\mathrm{NM}$ & $\mathrm{ZE}$ & $\mathrm{M}$ \\
\hline $\mathrm{H}$ & $\mathrm{M}$ & $\mathrm{NM}$ & PL & $\mathrm{M}$ \\
\hline $\mathrm{H}$ & $\mathrm{M}$ & $\mathrm{NM}$ & $\mathrm{PM}$ & LM \\
\hline $\mathrm{H}$ & $\mathrm{M}$ & $\mathrm{NM}$ & $\mathrm{PH}$ & $\mathrm{M}$ \\
\hline $\mathrm{H}$ & $\mathrm{M}$ & $\mathrm{NL}$ & $\mathrm{NH}$ & $\mathrm{MH}$ \\
\hline $\mathrm{H}$ & $\mathrm{M}$ & $\mathrm{NL}$ & NM & $\mathrm{H}$ \\
\hline $\mathrm{H}$ & $\mathrm{M}$ & $\mathrm{NL}$ & NL & $\mathrm{MH}$ \\
\hline $\mathrm{H}$ & $\mathrm{M}$ & NL & ZE & $\mathrm{MH}$ \\
\hline $\mathrm{H}$ & $\mathrm{M}$ & $\mathrm{NL}$ & $\mathrm{PL}$ & $\mathrm{MH}$ \\
\hline $\mathrm{H}$ & $\mathrm{M}$ & $\mathrm{NL}$ & $\mathrm{PM}$ & $\mathrm{M}$ \\
\hline
\end{tabular}




\begin{tabular}{|c|c|c|c|c|}
\hline $\mathrm{H}$ & $\mathrm{M}$ & $\mathrm{NL}$ & $\mathrm{PH}$ & $\mathrm{MH}$ \\
\hline $\mathrm{H}$ & M & ZE & $\mathrm{NH}$ & $\mathrm{MH}$ \\
\hline $\mathrm{H}$ & $\mathrm{M}$ & ZE & NM & $\mathrm{H}$ \\
\hline $\mathrm{H}$ & $\mathrm{M}$ & $\mathrm{ZE}$ & NL & $\mathrm{MH}$ \\
\hline $\mathrm{H}$ & $\mathrm{M}$ & $\mathrm{ZE}$ & $\mathrm{ZE}$ & $\mathrm{MH}$ \\
\hline $\mathrm{H}$ & $\mathrm{M}$ & ZE & PL & $\mathrm{MH}$ \\
\hline $\mathrm{H}$ & $\mathrm{M}$ & $\mathrm{ZE}$ & $\mathrm{PM}$ & $\mathrm{M}$ \\
\hline $\mathrm{H}$ & $\mathrm{M}$ & $\mathrm{ZE}$ & $\mathrm{PH}$ & $\mathrm{MH}$ \\
\hline $\mathrm{H}$ & $\mathrm{M}$ & PL & $\mathrm{NH}$ & $\mathrm{MH}$ \\
\hline $\mathrm{H}$ & $\mathrm{M}$ & PL & NM & $\mathrm{H}$ \\
\hline $\mathrm{H}$ & $\mathrm{M}$ & PL & NL & $\mathrm{MH}$ \\
\hline $\mathrm{H}$ & $\mathrm{M}$ & PL & ZE & $\mathrm{MH}$ \\
\hline $\mathrm{H}$ & $\mathrm{M}$ & PL & PL & $\mathrm{MH}$ \\
\hline $\mathrm{H}$ & $\mathrm{M}$ & PL & $\mathrm{PM}$ & $\mathrm{M}$ \\
\hline $\mathrm{H}$ & $\mathrm{M}$ & PL & $\mathrm{PH}$ & $\mathrm{MH}$ \\
\hline $\mathrm{H}$ & M & PM & $\mathrm{NH}$ & $\mathrm{MH}$ \\
\hline $\mathrm{H}$ & $\mathrm{M}$ & PM & NM & $\mathrm{H}$ \\
\hline $\mathrm{H}$ & $\mathrm{M}$ & PM & NL & $\mathrm{MH}$ \\
\hline $\mathrm{H}$ & $\mathrm{M}$ & $\mathrm{PM}$ & $\mathrm{ZE}$ & $\mathrm{MH}$ \\
\hline $\mathrm{H}$ & $\mathrm{M}$ & $\mathrm{PM}$ & PL & $\mathrm{MH}$ \\
\hline $\mathrm{H}$ & $\mathrm{M}$ & PM & $\mathrm{PM}$ & $\mathrm{M}$ \\
\hline $\mathrm{H}$ & $\mathrm{M}$ & PM & $\mathrm{PH}$ & $\mathrm{MH}$ \\
\hline $\mathrm{H}$ & M & PH & $\mathrm{NH}$ & $\mathrm{MH}$ \\
\hline $\mathrm{H}$ & $\mathrm{M}$ & $\mathrm{PH}$ & NM & $\mathrm{H}$ \\
\hline $\mathrm{H}$ & $\mathrm{M}$ & $\mathrm{PH}$ & NL & $\mathrm{MH}$ \\
\hline $\mathrm{H}$ & $\mathrm{M}$ & $\mathrm{PH}$ & ZE & $\mathrm{MH}$ \\
\hline $\mathrm{H}$ & $\mathrm{M}$ & $\mathrm{PH}$ & $\mathrm{PL}$ & $\mathrm{MH}$ \\
\hline $\mathrm{H}$ & $\mathrm{M}$ & $\mathrm{PH}$ & $\mathrm{PM}$ & $\mathrm{M}$ \\
\hline
\end{tabular}




\begin{tabular}{|c|c|c|c|c|}
\hline $\mathrm{H}$ & M & $\mathrm{PH}$ & $\mathrm{PH}$ & $\mathrm{MH}$ \\
\hline $\mathrm{H}$ & $\mathrm{MH}$ & $\mathrm{NH}$ & $\mathrm{NH}$ & M \\
\hline $\mathrm{H}$ & $\mathrm{MH}$ & $\mathrm{NH}$ & $\mathrm{NM}$ & MH \\
\hline $\mathrm{H}$ & $\mathrm{MH}$ & $\mathrm{NH}$ & NL & M \\
\hline $\mathrm{H}$ & $\mathrm{MH}$ & $\mathrm{NH}$ & $\mathrm{ZE}$ & $\mathrm{M}$ \\
\hline $\mathrm{H}$ & $\mathrm{MH}$ & $\mathrm{NH}$ & PL & $\mathrm{M}$ \\
\hline $\mathrm{H}$ & $\mathrm{MH}$ & $\mathrm{NH}$ & PM & LM \\
\hline $\mathrm{H}$ & $\mathrm{MH}$ & $\mathrm{NH}$ & $\mathrm{PH}$ & M \\
\hline $\mathrm{H}$ & $\mathrm{MH}$ & $\mathrm{NM}$ & $\mathrm{NH}$ & LM \\
\hline $\mathrm{H}$ & $\mathrm{MH}$ & $\mathrm{NM}$ & $\mathrm{NM}$ & LM \\
\hline $\mathrm{H}$ & $\mathrm{MH}$ & $\mathrm{NM}$ & NL & LM \\
\hline $\mathrm{H}$ & $\mathrm{MH}$ & $\mathrm{NM}$ & ZE & LM \\
\hline $\mathrm{H}$ & $\mathrm{MH}$ & $\mathrm{NM}$ & PL & LM \\
\hline $\mathrm{H}$ & $\mathrm{MH}$ & $\mathrm{NM}$ & PM & LM \\
\hline $\mathrm{H}$ & $\mathrm{MH}$ & $\mathrm{NM}$ & $\mathrm{PH}$ & LM \\
\hline $\mathrm{H}$ & $\mathrm{MH}$ & NL & $\mathrm{NH}$ & M \\
\hline $\mathrm{H}$ & $\mathrm{MH}$ & NL & NM & MH \\
\hline $\mathrm{H}$ & $\mathrm{MH}$ & NL & NL & M \\
\hline $\mathrm{H}$ & $\mathrm{MH}$ & NL & ZE & M \\
\hline $\mathrm{H}$ & $\mathrm{MH}$ & NL & PL & $\mathrm{M}$ \\
\hline $\mathrm{H}$ & $\mathrm{MH}$ & NL & $\mathrm{PM}$ & LM \\
\hline $\mathrm{H}$ & $\mathrm{MH}$ & NL & $\mathrm{PH}$ & M \\
\hline $\mathrm{H}$ & $\mathrm{MH}$ & ZE & $\mathrm{NH}$ & $\mathrm{M}$ \\
\hline $\mathrm{H}$ & $\mathrm{MH}$ & ZE & NM & $\mathrm{MH}$ \\
\hline $\mathrm{H}$ & $\mathrm{MH}$ & ZE & NL & M \\
\hline $\mathrm{H}$ & $\mathrm{MH}$ & $\mathrm{ZE}$ & $\mathrm{ZE}$ & $\mathrm{M}$ \\
\hline $\mathrm{H}$ & $\mathrm{MH}$ & $\mathrm{ZE}$ & PL & M \\
\hline $\mathrm{H}$ & $\mathrm{MH}$ & ZE & $\mathrm{PM}$ & LM \\
\hline
\end{tabular}




\begin{tabular}{|l|l|l|l|l|}
\hline H & MH & ZE & PH & M \\
\hline H & MH & PL & NH & M \\
\hline H & MH & PL & NM & MH \\
\hline H & MH & PL & NL & M \\
\hline H & MH & PL & ZE & M \\
\hline H & MH & PL & PL & M \\
\hline H & MH & PL & PM & LM \\
\hline H & MH & PL & PH & M \\
\hline H & MH & PM & NH & M \\
\hline H & MH & PM & NM & MH \\
\hline H & MH & PM & NL & M \\
\hline H & MH & PM & ZE & M \\
\hline H & MH & PM & PL & M \\
\hline H & MH & PM & PM & LM \\
\hline H & MH & PM & PH & M \\
\hline H & MH & PH & NH & M \\
\hline H & MH & PH & NM & MH \\
\hline H & MH & PH & NL & M \\
\hline H & MH & PH & ZE & M \\
\hline H & MH & PH & PL & M \\
\hline H & MH & PH & PM & LM \\
\hline H & MH & PH & PH & M \\
\hline H & H & NH & NH & LM \\
\hline H & H & NH & NM & M \\
\hline H & H & NH & NL & LM \\
\hline H & PM & LM \\
\hline H & LM \\
\hline
\end{tabular}




\begin{tabular}{|c|c|c|c|c|}
\hline $\mathrm{H}$ & $\mathrm{H}$ & $\mathrm{NH}$ & $\mathrm{PH}$ & LM \\
\hline $\mathrm{H}$ & $\mathrm{H}$ & $\mathrm{NM}$ & $\mathrm{NH}$ & LM \\
\hline $\mathrm{H}$ & $\mathrm{H}$ & $\mathrm{NM}$ & $\mathrm{NM}$ & LM \\
\hline $\mathrm{H}$ & $\mathrm{H}$ & $\mathrm{NM}$ & NL & LM \\
\hline $\mathrm{H}$ & $\mathrm{H}$ & $\mathrm{NM}$ & $\mathrm{ZE}$ & LM \\
\hline $\mathrm{H}$ & $\mathrm{H}$ & $\mathrm{NM}$ & PL & LM \\
\hline $\mathrm{H}$ & $\mathrm{H}$ & $\mathrm{NM}$ & PM & LM \\
\hline $\mathrm{H}$ & $\mathrm{H}$ & $\mathrm{NM}$ & $\mathrm{PH}$ & LM \\
\hline $\mathrm{H}$ & $\mathrm{H}$ & NL & $\mathrm{NH}$ & LM \\
\hline $\mathrm{H}$ & $\mathrm{H}$ & NL & $\mathrm{NM}$ & M \\
\hline $\mathrm{H}$ & $\mathrm{H}$ & NL & NL & LM \\
\hline $\mathrm{H}$ & $\mathrm{H}$ & NL & ZE & LM \\
\hline $\mathrm{H}$ & $\mathrm{H}$ & NL & PL & LM \\
\hline $\mathrm{H}$ & $\mathrm{H}$ & NL & PM & LM \\
\hline $\mathrm{H}$ & $\mathrm{H}$ & NL & $\mathrm{PH}$ & LM \\
\hline $\mathrm{H}$ & $\mathrm{H}$ & ZE & $\mathrm{NH}$ & LM \\
\hline $\mathrm{H}$ & $\mathrm{H}$ & ZE & NM & M \\
\hline $\mathrm{H}$ & $\mathrm{H}$ & $\mathrm{ZE}$ & NL & LM \\
\hline $\mathrm{H}$ & $\mathrm{H}$ & ZE & ZE & LM \\
\hline $\mathrm{H}$ & $\mathrm{H}$ & ZE & PL & LM \\
\hline $\mathrm{H}$ & $\mathrm{H}$ & ZE & $\mathrm{PM}$ & LM \\
\hline $\mathrm{MH}$ & $\mathrm{H}$ & ZE & $\mathrm{PH}$ & LM \\
\hline $\mathrm{H}$ & $\mathrm{H}$ & PL & $\mathrm{NH}$ & LM \\
\hline $\mathrm{H}$ & $\mathrm{H}$ & PL & NM & $\mathrm{M}$ \\
\hline $\mathrm{H}$ & $\mathrm{H}$ & PL & NL & LM \\
\hline $\mathrm{H}$ & $\mathrm{H}$ & PL & $\mathrm{ZE}$ & LM \\
\hline $\mathrm{H}$ & $\mathrm{H}$ & PL & PL & LM \\
\hline $\mathrm{H}$ & $\mathrm{H}$ & PL & $\mathrm{PM}$ & LM \\
\hline
\end{tabular}




\begin{tabular}{|c|c|c|c|c|}
\hline $\mathrm{H}$ & $\mathrm{H}$ & PL & $\mathrm{PH}$ & LM \\
\hline $\mathrm{H}$ & $\mathrm{H}$ & $\mathrm{PM}$ & $\mathrm{NH}$ & LM \\
\hline $\mathrm{H}$ & $\mathrm{H}$ & $\mathrm{PM}$ & NM & $\mathrm{M}$ \\
\hline $\mathrm{H}$ & $\mathrm{H}$ & PM & NL & LM \\
\hline $\mathrm{H}$ & $\mathrm{H}$ & PM & $\mathrm{ZE}$ & LM \\
\hline $\mathrm{H}$ & $\mathrm{H}$ & PM & PL & LM \\
\hline $\mathrm{H}$ & $\mathrm{H}$ & $\mathrm{PM}$ & PM & LM \\
\hline $\mathrm{H}$ & $\mathrm{H}$ & PM & $\mathrm{PH}$ & LM \\
\hline $\mathrm{H}$ & $\mathrm{H}$ & $\mathrm{PH}$ & $\mathrm{NH}$ & LM \\
\hline $\mathrm{H}$ & $\mathrm{H}$ & $\mathrm{PH}$ & NM & M \\
\hline $\mathrm{H}$ & $\mathrm{H}$ & $\mathrm{PH}$ & NL & LM \\
\hline $\mathrm{H}$ & $\mathrm{H}$ & $\mathrm{PH}$ & $\mathrm{ZE}$ & LM \\
\hline $\mathrm{H}$ & $\mathrm{H}$ & $\mathrm{PH}$ & PL & LM \\
\hline $\mathrm{H}$ & $\mathrm{H}$ & $\mathrm{PH}$ & PM & LM \\
\hline $\mathrm{H}$ & $\mathrm{H}$ & $\mathrm{PH}$ & $\mathrm{PH}$ & LM \\
\hline
\end{tabular}




\section{Appendix D - DC Regulation}

A traditional buck-boost converter, Figure D.1, must be discussed to explore the limitations of the design. The source voltage is represented by the voltage being produced by the module, both bipolar junction transistors (BJTs) and metal-oxide semiconductor field effect transistors (MOSFETs) can be used as switching devices [43]. For this model MOSFETs are used as they offer increased efficiency and are cost efficient.

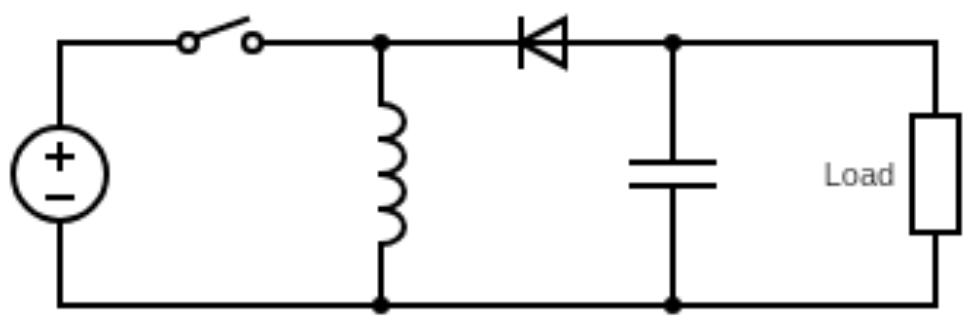

Figure D.1: Conventional design for buck-boost converter.

During the on state the input current flows into the inductor and transistor; as the energy increases, the inductor and capacitor provide energy to the load. In contrast, during the off state the switch is open thereby disconnecting the source from the rest of the system, during this time the energy stored in the inductor is dissipated to the load.

The conventional low cost and simple buck-boost design can effectively manage a wide-input voltage range which fluctuates either above and below the desired voltage. This model unfortunately suffers from stresses caused by high current and are impacted by conduction losses resulting in reduced efficiencies. A resolution to 
this is to use a four-switch buck boost converter as it benefits from higher efficiencies and power capabilities when compared to conventional designs [44].

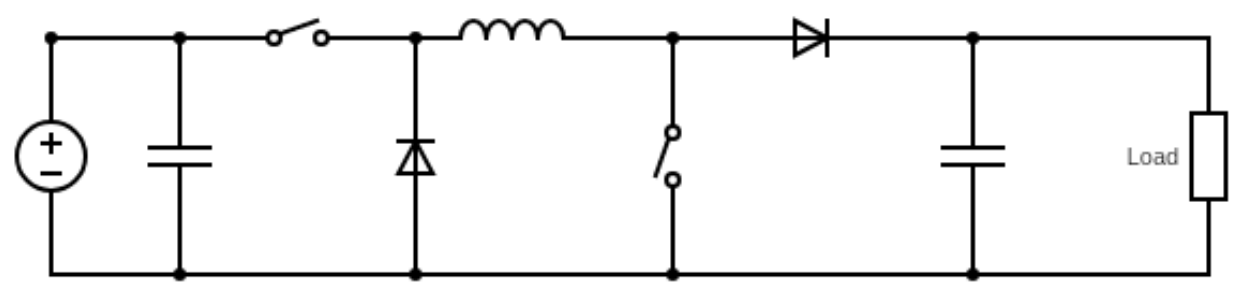

Figure D.2: Four-switch buck boost DC converter design.

The four-switch model, Figure D.2, in continuous conduction mode (CCM) is similar to the function of the conventional buck boost converter [44]. The conduction losses of the diode model and the four MOSFET model are dependent on the voltage differences of the switching mechanism. The voltage losses of the MOSFETs are often much smaller yielding a very low on-resistance. The reduced conduction losses using this method improves the efficiency of the system. As this model is a cascaded combination of a buck converter and a boost converter, the four-switch converter works as the equivalent circuits. The four-switch model performs synchronous rectification while reducing the conduction and switching losses thereby yielding the highest efficiency [45].

The rule base for the fuzzy logic controller was adapted from [7] to function in this specific application. The fuzzy rule base was implemented using the fuzzy logic toolbox within Matlab/Simulink 2019a. The input quantities of the FLC2 controller are the error and change of error determined by the feedback response in the DC regulation stage. The rule base for the proportional gain, $K_{p}$ and integral gain, $K_{i}$, are described in Figure D.3(a) and Figure D.3(b) respectively. 


\begin{tabular}{|c|c|c|c|c|c|c|c|c|c|c|c|}
\hline \multicolumn{4}{|c|}{ Change In Error } & \multicolumn{8}{|c|}{ Change In Error } \\
\hline Error & NB & NS & ZE & PS & PB & Error & NB & NS & ZE & PS & PB \\
\hline NB & NB & NS & NS & NS & ZE & $\mathrm{N}$ & NB & NS & NB & NS & ZE \\
\hline NS & NB & NS & NS & ZE & PS & $\mathrm{N}$ & NB & NB & NS & ZE & PS \\
\hline ZE & NB & NS & ZE & PS & PB & Z & NB & NS & ZE & PS & PB \\
\hline PS & NS & ZE & PS & PS & PB & $P$ & NS & ZE & PS & PB & PB \\
\hline PB & ZE & PS & PS & PS & PB & $P$ & ZE & PS & PB & PB & PB \\
\hline
\end{tabular}

Figure D.3: Fuzzy logic rules for determining the necessary change in (a) $K_{p}$ and (b) $K_{i}$ to account for dynamic load changes in islanded systems. 


\section{Appendix E}

As previously mentioned, the designs presented in this thesis were modelled and simulated using Matlab/Simulink 2019a. Simulink offers a number of libraries and toolboxes which can be interfaced within the Simulink environment using a block representation. The blocks can be determined by the designer such as the improved MPPT and optimization subsystems or can be incorporated within preexisting toolkits such as the fuzzy logic controller or four-switch buck boost converter. An example of the Simulink diagram used to simulate a singular MLPE device as designed in Chapter 3 is presented in Figure E.1.

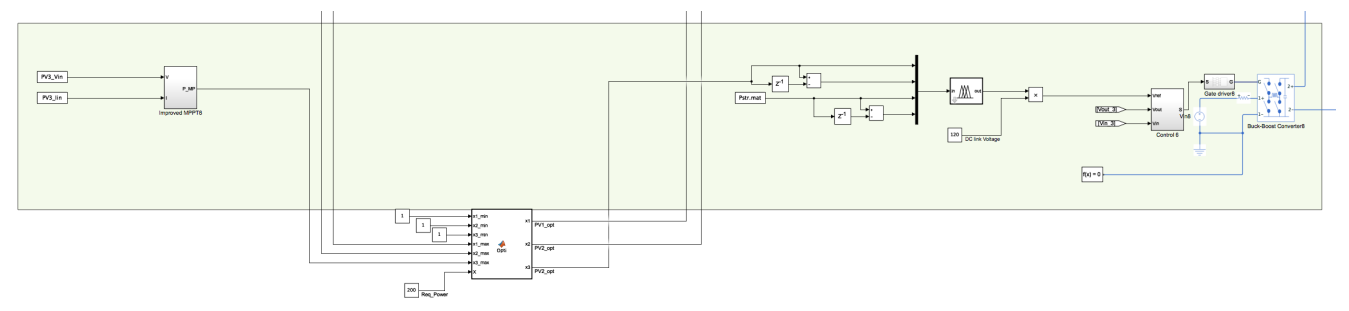

Figure E.1: Simulink diagram of one module-level power optimizer.

The system diagram presented in Figure E.2 depicts the subsystems within a string of three PV modules. Each MLPO consists of an individual improved MPPT, ramp rate reduction, and DC regulation stage while sharing one centralized mode selection system capable of MPP and curtailment operation. 


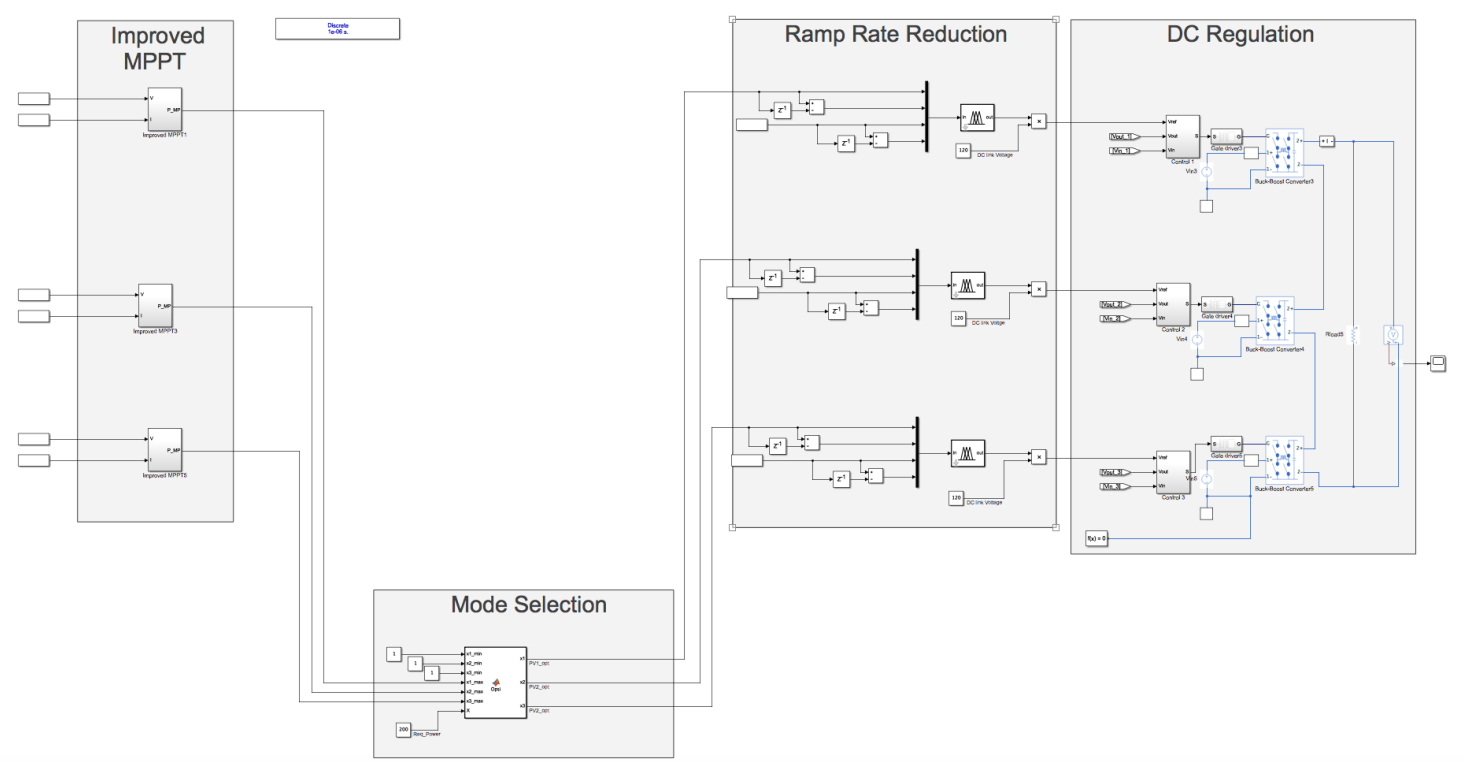

Figure E.2: Three PV string simulation diagram depicting the improved MPPT, mode selection, ramp rate reduction, and DC regulation stages.

Subsystems such as the Matlab function block, utilized in the mode selection stage, conveniently call a specific Matlab code - in this case 'Opti.m' - and performs the necessary function within the Simulink environment. The input characteristics are data files which contain the timeseries power determined by the improved MPPT stage for each module. The 'Opti.m' function, discussed in Appendix B, compares the MPP string power and the requested power to determine the mode of operation. The data file representing the optimal power of each module, whether that be the MPP or curatiled power quantity, is returned to the appropriate MLPO.

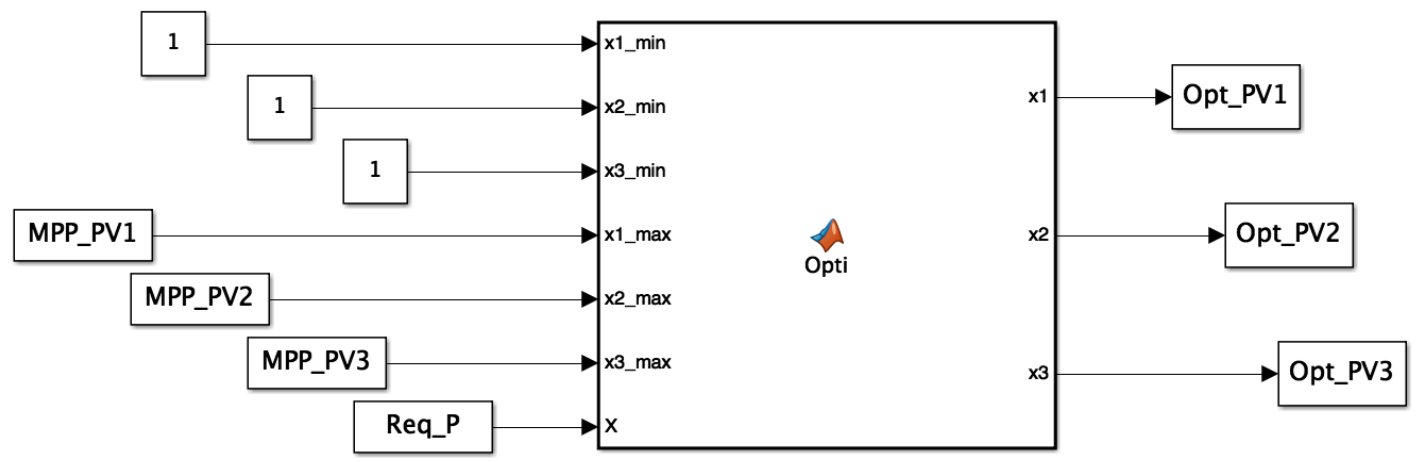

Figure E.3: Optimization engine schematic diagram presented in Simulink. 
The Fuzzy Logic and Power System toolkits introduce customizable blocks for well understood systems. Within the simulink environment, the fuzzy logic controller block is represented by a single input single output, Figure E.4. The four quantities representing the input variables are grouped together using the 'mux' block as the input to the fuzzy logic toolbox. The output is represented by the ratio $\left(\frac{P_{n}}{P_{s t r}}\right)^{\prime}$ which must be multiplied by the DC link voltage $(120 \mathrm{~V})$ to determine the reference voltage for each of the $n$ modules in the string.

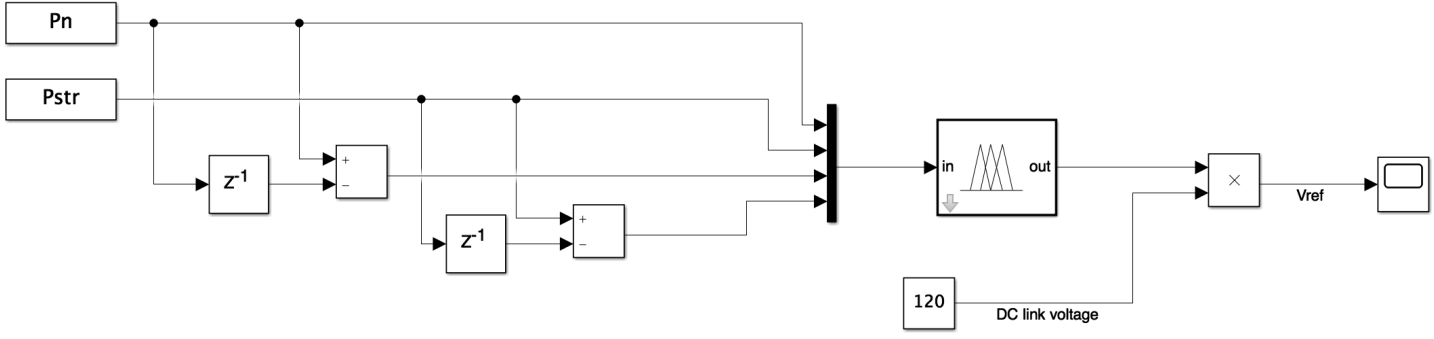

Figure E.4: Fuzzy logic controller (FLC1) in Simulink environment.

All the components associated with fuzzy logic design are represented within the fuzzy logic toolkit block, Figure E.5. The membership functions of the four inputs (represented on the left in yellow) and one output (shown on the right in blue) are customizable using the drop down menu at the bottom of the window. Note that the input quantities appear to be represented using gaussian membership functions however the true design is appropriately described in Figure E.6. 


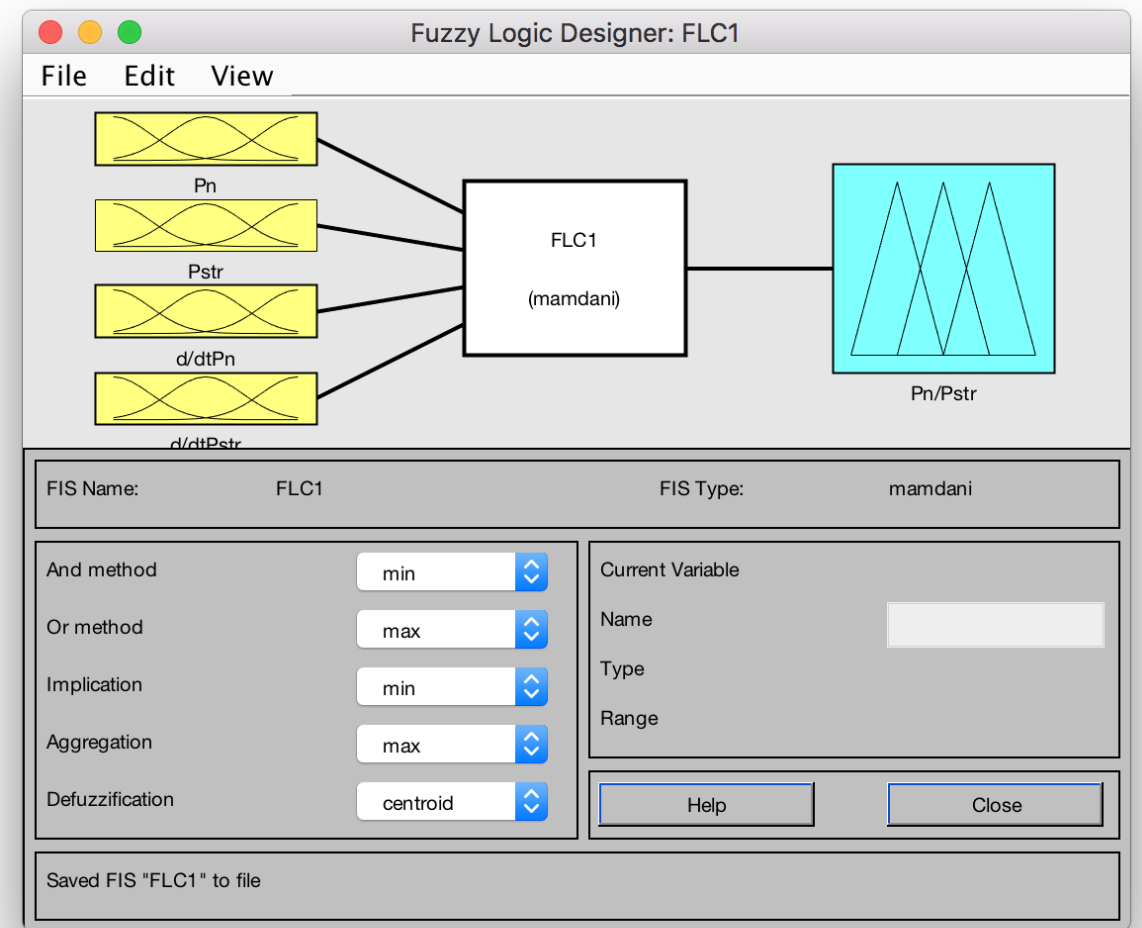

Figure E.5: Fuzzy logic toolbox depicting four inputs and one output for FLC1.

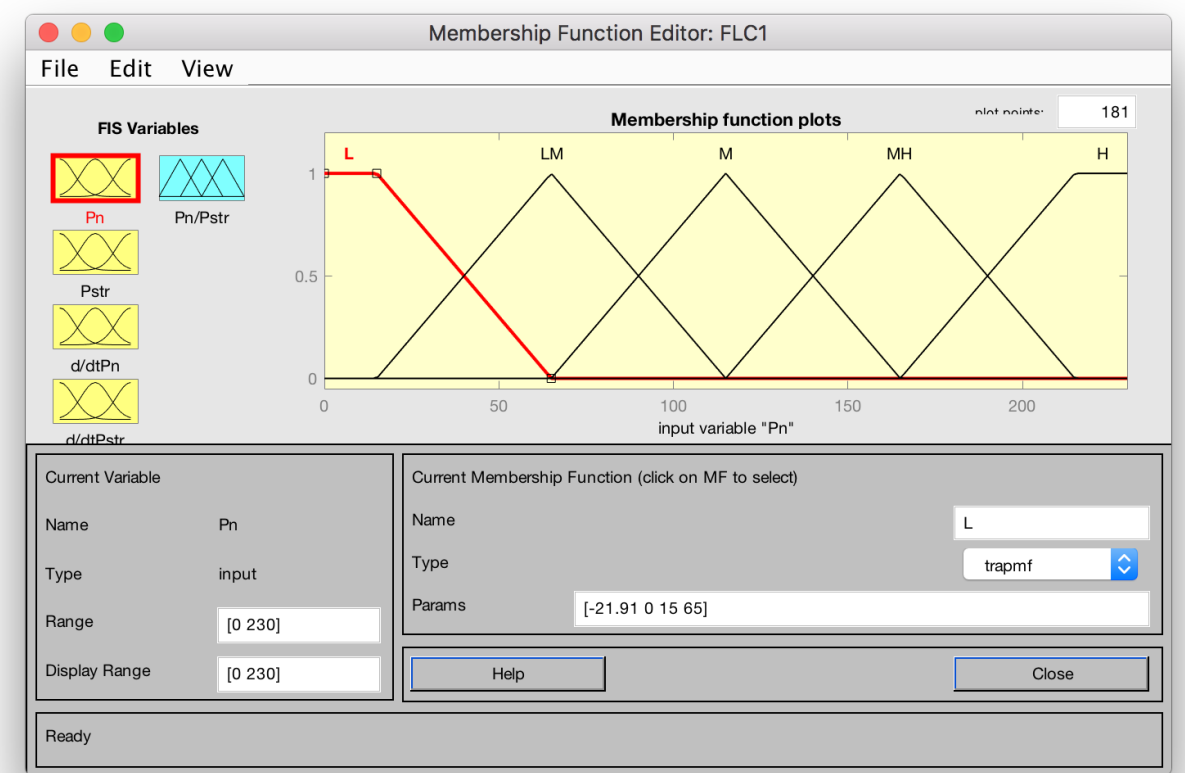

Figure E.6: An example of the membership function for the input power quantity $P_{n}$ for FLC1. 
The rule base can also be developed within this block, Figure E.7. The input quantities are located within the drop-down menu toward the bottom of the window. The output ratio, represented by a linguistic variable, is determined using the rule base generated by the designer to describe the output response of all combinations of input characteristics. The rule base was determined experimentally, further information regarding the design of the fuzzy logic controller FLC1 is located in Appendix C.

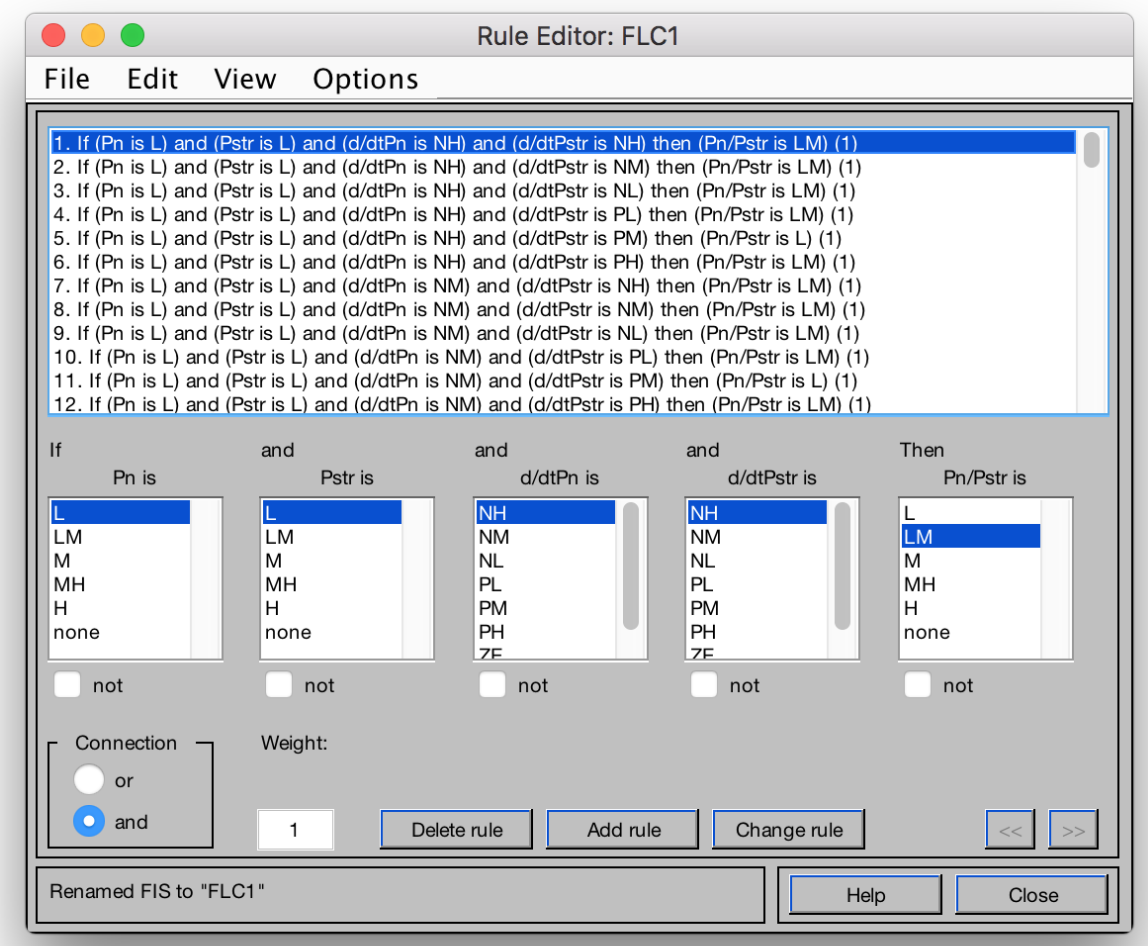

Figure E.7: A sample of the rule base used for the inference engine of FLC1.

The DC regulation stage, Figure E.8, is the final subsystem described in this thesis. The purpose of this stage is to ensure minimal error between the reference and output voltage. The controller stage consists of a conventional PI controller which is easily customized for the specifics of the design. This pre-existing Simulink control block uses the reference and output voltage as inputs to the PI controller and the input voltage, or the optimal voltage determined by the mode selector, as an input to the DC converter. 


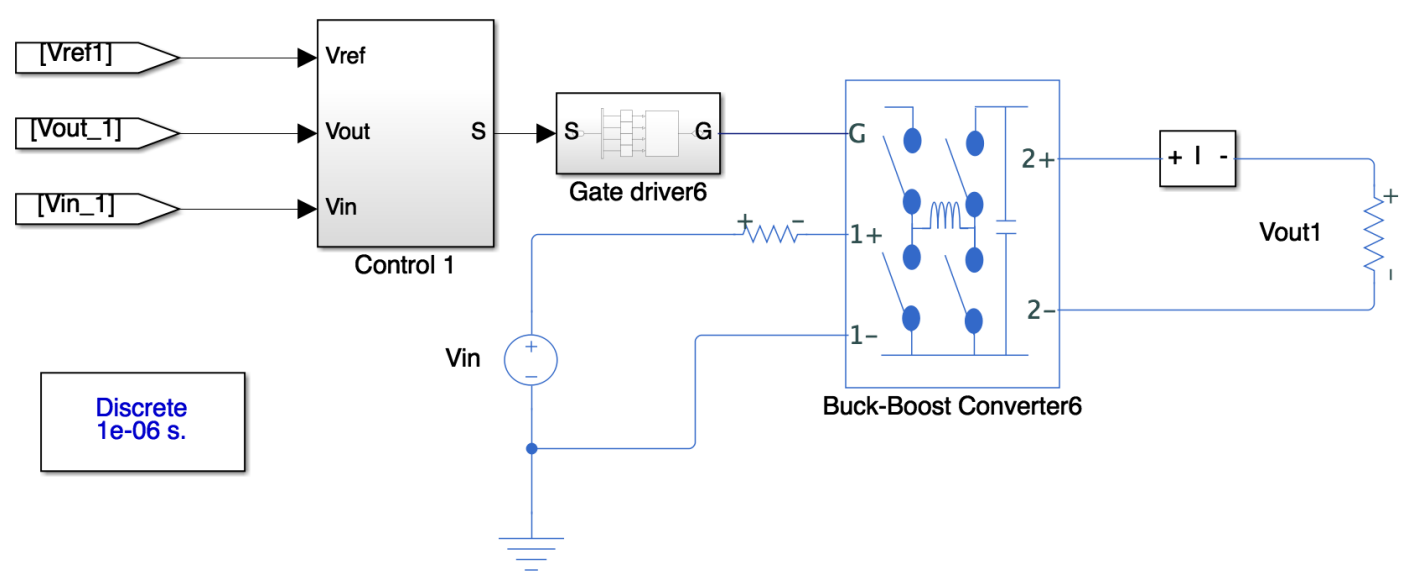

Figure E.8: Simulated four switch buck boost system.

A self-tuning gain controller, Figure E.9, adjusts the gain parameters to manage the load variability which occurs in grid islanded systems. The simulink model is incorporated within the control system of the DC regulation stage to determine an appropriate change in proportional, $K_{p}$, and integral, $K_{i}$ gain. The design of the fuzzy logic controller (FLC2) is similar to that described for FLC1 however each of the controllers have a two input, one output model. The input characteristics of the two fuzzy systems are the same; the inputs are the error determined by the reference and output voltages and the change in error. The rule base for each of these is discussed further in Appendix D.

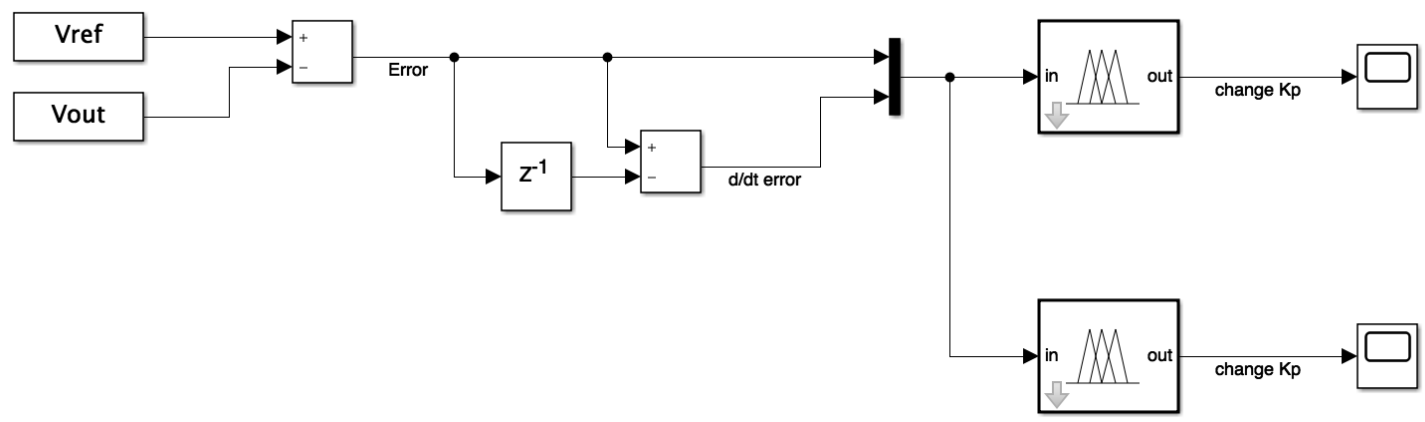

Figure E.9: The Simulink diagram of FLC2 to determine the necessary change in PI controller gains for islanded systems. 


\section{Bibliography}

[1] Bipartisan Policy Center. Annual Energy Outlook 2020. 2020.

[2] Dinesh Kumar Sharma and Ghanshyam Purohit. Maximum power angle (MPA) based maximum power point tracking (MPPT) technique for efficiency optimization of solar pv system. International Journal of Renewable Energy Research (IJRER), 4(3):810-815, 2014.

[3] Mohammed A. Elgendy, Bashar Zahawi, and David J. Atkinson. Assessment of the incremental conductance maximum power point tracking algorithm. IEEE Transactions on sustainable energy, 4(1):108-117, 2012.

[4] Xavier Serrano-Guerrero, José González-Romero, Xavier Cárdenas-Carangui, and Guillermo Escrivá-Escrivá. Improved variable step size P\&O MPPT algorithm for PV systems. In 2016 51st International Universities Power Engineering Conference (UPEC), pages 1-6. IEEE, 2016.

[5] Davis, Matthew and Ahiduzzaman, M.D. and Kumar, Amit. How will Canada's greenhouse gas emissions change by 2050? A disaggregated analysis of past and future greenhouse gas emissions using bottom-up energy modelling and Sankey diagrams. Applied energy, 220:754-786, 2018.

[6] Fu, Ran and Feldman, David J and Margolis, Robert M. US solar photovoltaic system cost benchmark: Q1 2018. Technical report, National Renewable Energy Lab.(NREL), Golden, CO (United States), 2018.

[7] Mutasim Nour, Omrane Bouketir, Eng Yong, et al. Self-tuning of pi speed 
controller gains using fuzzy logic controller. Modern Applied Science, 2(6): $55-65,2008$.

[8] Gueymard, Christian. Mathematically integrable parameterization of clear-sky beam and global irradiances and its use in daily irradiation applications. Solar Energy, 50(5):385-397, 1993.

[9] Marquez, Ricardo and Coimbra, Carlos F.M. Forecasting of global and direct solar irradiance using stochastic learning methods, ground experiments and the NWS database. Solar Energy, 85(5):746-756, 2011.

[10] Gordon Reikard, Sue Ellen Haupt, and Tara Jensen. Forecasting ground-level irradiance over short horizons: Time series, meteorological, and time-varying parameter models. Renewable Energy, 112:474-485, 2017.

[11] Shiva Moballegh and Jin Jiang. Modeling, prediction, and experimental validations of power peaks of PV arrays under partial shading conditions. IEEE Transactions on Sustainable Energy, 5(1):293-300, 2013.

[12] Keyong Hu, Shihua Cao, Lidong Wang, Wenjuan Li, and Mingqi Lv. A new ultra-short-term photovoltaic power prediction model based on ground-based cloud images. Journal of Cleaner Production, 200:731-745, 2018.

[13] Pascal Kuhn, Bijan Nouri, Stefan Wilbert, Christoph Prahl, Nora Kozonek, Thomas Schmidt, Zeyad Yasser, Lourdes Ramirez, Luis Zarzalejo, Angela Meyer, et al. Validation of an all-sky imager-based nowcasting system for industrial PV plants. Progress in Photovoltaics: Research and Applications, 26 (8):608-621, 2018.

[14] Ward T. Jewell and Timothy D. Unruh. Limits on cloud-induced fluctuation in photovoltaic generation. IEEE Transactions on Energy Conversion, 5(1):8-14, 1990.

[15] K. Mahmud, G.E. Town, and M.J. Hossain. Mitigating the impact of rapid 
changes in photovoltaic power generation on network voltage. In 2017 IEEE Power and Energy Conference at Illinois (PECI), pages 1-6. IEEE, 2017.

[16] Richard C. Easter and Peter V. Hobbs. The formation of sulfates and the enhancement of cloud condensation nuclei in clouds. Journal of the Atmospheric Sciences, 31(6):1586-1594, 1974.

[17] Georgi Hristov Yordanov, Ole-Morten Midtgård, Tor Oskar Saetre, Henrik Kofoed Nielsen, and Lars Einar Norum. Overirradiance (cloud enhancement) events at high latitudes. In 2012 IEEE 38th Photovoltaic Specialists Conference (PVSC) PART 2, pages 1-7. IEEE, 2012.

[18] Nicola Femia, Giovanni Petrone, Giovanni Spagnuolo, and Massimo Vitelli. Optimization of perturb and observe maximum power point tracking method. IEEE transactions on power electronics, 20(4):963-973, 2005.

[19] Samer Alsadi and Basim Alsayid. Maximum power point tracking simulation for photovoltaic systems using perturb and observe algorithm. 2012.

[20] Chee Wei Tan, Tim C Green, and Carlos A Hernandez-Aramburo. Analysis of perturb and observe maximum power point tracking algorithm for photovoltaic applications. In 2008 IEEE 2nd International Power and Energy Conference, pages 237-242. IEEE, 2008.

[21] Azadeh Safari and Saad Mekhilef. Simulation and hardware implementation of incremental conductance MPPT with direct control method using cuk converter. IEEE transactions on industrial electronics, 58(4):1154-1161, 2010.

[22] Zhou Xuesong, Song Daichun, Ma Youjie, and Cheng Deshu. The simulation and design for MPPT of PV system based on incremental conductance method. In 2010 WASE International Conference on Information Engineering, volume 2, pages 314-317. IEEE, 2010.

[23] Bangyin Liu, Shanxu Duan, Fei Liu, and Pengwei Xu. Analysis and improvement of maximum power point tracking algorithm based on incremental con- 
ductance method for photovoltaic array. In 2007 7th International Conference on Power Electronics and Drive Systems, pages 637-641. IEEE, 2007.

[24] Fawzan Salem and Mohamed A. Awadallah. Detection and assessment of partial shading in photovoltaic arrays. Journal of Electrical Systems and Information Technology, 3(1):23-32, 2016.

[25] Wang Ping, Ding Hui, Diao Changyu, and Qi Shengbiao. An improved MPPT algorithm based on traditional incremental conductance method. In 2011 th International Conference on Power Electronics Systems and Applications, pages 1-4. IEEE, 2011.

[26] I. De la Parra, J. Marcos, M. García, and Luis Marroyo. Dynamic ramp-rate control to smooth short-term power fluctuations in large photovoltaic plants using battery storage systems. In IECON 2016-42nd Annual Conference of the IEEE Industrial Electronics Society, pages 3052-3057. IEEE, 2016.

[27] Marjan Golob. Decomposed fuzzy proportional-integral-derivative controllers. Applied soft computing, 1(3):201-214, 2001.

[28] Mohammad B. Shadmand, Mostafa Mosa, Robert S. Balog, and Haitham Abu Rub. An improved MPPT technique for high gain DC-DC converter using model predictive control for photovoltaic applications. In 2014 IEEE Applied Power Electronics Conference and Exposition-APEC 2014, pages 2993-2999. IEEE, 2014.

[29] Xingshuo Li, Huiqing Wen, Lin Jiang, Weidong Xiao, Yang Du, and Chenhao Zhao. An improved mppt method for pv system with fast-converging speed and zero oscillation. IEEE Transactions on Industry Applications, 52(6):5051-5064, 2016.

[30] Kai Chen, Shulin Tian, Yuhua Cheng, and Libing Bai. An improved MPPT controller for photovoltaic system under partial shading condition. IEEE transactions on sustainable energy, 5(3):978-985, 2014. 
[31] Math HJ Bollen and Fainan Hassan. Integration of distributed generation in the power system, volume 80. John wiley \& sons, 2011.

[32] Reinaldo Tonkoski, Luiz A.C. Lopes, and Tarek H.M. El-Fouly. Coordinated active power curtailment of grid connected pv inverters for overvoltage prevention. IEEE Transactions on sustainable energy, 2(2):139-147, 2010.

[33] Shibani Ghosh, Saifur Rahman, and Manisa Pipattanasomporn. Distribution voltage regulation through active power curtailment with pv inverters and solar generation forecasts. IEEE Transactions on Sustainable Energy, 8(1):13-22, 2016.

[34] Wei Ma, Wei Wang, Xuezhi Wu, Ruonan Hu, Fen Tang, Weige Zhang, Xiaoyan Han, and Lijie Ding. Optimal allocation of hybrid energy storage systems for smoothing photovoltaic power fluctuations considering the active power curtailment of photovoltaic. IEEE Access, 7:74787-74799, 2019.

[35] J. Marcos, O. Storkël, L. Marroyo, M. Garcia, and E. Lorenzo. Storage requirements for pv power ramp-rate control. Solar Energy, 99:28-35, 2014.

[36] Apichai Saipet and Somboon Nuchprayoon. On controlling power ramping and output of grid-connected rooftop solar PV using battery energy storage system. In 2019 IEEE International Conference on Environment and Electrical Engineering and 2019 IEEE Industrial and Commercial Power Systems Europe (EEEIC/I\&CPS Europe), pages 1-5. IEEE, 2019.

[37] Shivashankar Sukumar, Marayati Marsadek, KR Agileswari, and Hazlie Mokhlis. Ramp-rate control smoothing methods to control output power fluctuations from solar photovoltaic (pv) sources - a review. Journal of energy storage, 20:218-229, 2018.

[38] V.S.C. Raviraj and Paresh C. Sen. Comparative study of proportional-integral, sliding mode, and fuzzy logic controllers for power converters. IEEE Transactions on Industry Applications, 33(2):518-524, 1997. 
[39] Saptarshi Das, Indranil Pan, and Shantanu Das. Performance comparison of optimal fractional order hybrid fuzzy PID controllers for handling oscillatory fractional order processes with dead time. ISA transactions, 52(4):550-566, 2013.

[40] Rihab Mahjoub Essefi, Pr. Mansour Souissi, and Pr. Hsan Hadj Abdallah. Maximum power point tracking control technique for photovoltaic systems using neural networks. In 2014 5th International Renewable Energy Congress (IREC), pages 1-6. IEEE, 2014.

[41] Ramazan Bayindir, Ilhami Colak, Orhan Kaplan, and Celal Can. MATLAB/GUI based simulation for photovoltaic systems. In 2011 International Conference on Power Engineering, Energy and Electrical Drives, pages 1-4. IEEE, 2011.

[42] Qianwei Zheng, Jiaming Li, Xiaomeng Ai, Jinyu Wen, and Jiakun Fang. Overivew of grid codes for photovoltaic integration. In 2017 IEEE Conference on Energy Internet and Energy System Integration (EI2), pages 1-6. IEEE, 2017.

[43] S.Y. Tseng, J.S. Kuo, S.W. Wang, and C.T. Hsieh. Buck-boost combined with active clamp flyback converter for PV power system. In $200^{\prime 7}$ IEEE Power Electronics Specialists Conference, pages 138-144. IEEE, 2007.

[44] Xiaoyong Ren, Xinbo Ruan, Hai Qian, Mingqiu Li, and Qianhong Chen. Threemode dual-frequency two-edge modulation scheme for four-switch buck-boost converter. IEEE Transactions on Power Electronics, 24(2):499-509, 2008.

[45] Marcos Orellana, Stephane Petibon, Bruno Estibals, and Corinne Alonso. Four switch buck-boost converter for photovoltaic DC-DC power applications. In IECON 2010-36th Annual Conference on IEEE Industrial Electronics Society, pages 469-474. IEEE, 2010. 